\title{
The quest for the origin and prevention of postoperative myalgia following succinylcholine : new insights in an old problem
}

Citation for published version (APA):

Schreiber, J-U. (2010). The quest for the origin and prevention of postoperative myalgia following succinylcholine : new insights in an old problem. [Doctoral Thesis, Maastricht University]. Datawyse / Universitaire Pers Maastricht. https://doi.org/10.26481/dis.20100702js

Document status and date:

Published: 01/01/2010

DOI:

$10.26481 /$ dis.20100702js

Document Version:

Publisher's PDF, also known as Version of record

Please check the document version of this publication:

- A submitted manuscript is the version of the article upon submission and before peer-review. There can be important differences between the submitted version and the official published version of record.

People interested in the research are advised to contact the author for the final version of the publication, or visit the DOI to the publisher's website.

- The final author version and the galley proof are versions of the publication after peer review.

- The final published version features the final layout of the paper including the volume, issue and page numbers.

Link to publication

\footnotetext{
General rights rights.

- You may freely distribute the URL identifying the publication in the public portal. please follow below link for the End User Agreement:

www.umlib.nl/taverne-license

Take down policy

If you believe that this document breaches copyright please contact us at:

repository@maastrichtuniversity.nl

providing details and we will investigate your claim.
}

Copyright and moral rights for the publications made accessible in the public portal are retained by the authors and/or other copyright owners and it is a condition of accessing publications that users recognise and abide by the legal requirements associated with these

- Users may download and print one copy of any publication from the public portal for the purpose of private study or research.

- You may not further distribute the material or use it for any profit-making activity or commercial gain

If the publication is distributed under the terms of Article $25 \mathrm{fa}$ of the Dutch Copyright Act, indicated by the "Taverne" license above, 
The quest for the origin and prevention of postoperative myalgia following succinylcholine.

New insights in an old problem 
(C) Copyright Jan-Uwe Schreiber, Maastricht 2010

ISBN 9789052789446

Productie: Datawyse | Universitaire Pers Maastricht 


\title{
The quest for the origin and prevention of postoperative myalgia following succinylcholine.
}

\section{New insights in an old problem}

\author{
PROEFSCHRIFT
}

\author{
ter verkrijging van de graad van doctor aan de \\ Universiteit Maastricht op gezag van de \\ Rector Magnificus, \\ Prof. mr. G.P.M.F. Mols \\ volgens het besluit van het College van Decanen, \\ in het openbaar te verdedigen \\ op vrijdag 2 juli 2010 om 12:00 uur
}

door

JAN-UWE SCHREIBER

geboren te Gütersloh, Duitsland op 30 december 1969

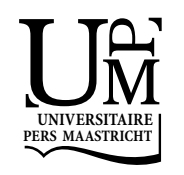


Promotores

Prof. dr. M. van Kleef

Prof. dr. M.A.E. Marcus

Prof. dr. T. Fuchs-Buder (Nancy, France)

\section{Beoordelingscommissie}

Prof. dr. B. Kremer (voorzitter)

Prof. dr. M. De Baets

Dr. C. Faber

Prof. dr. med. R. Larsen (Homburg/Saar, Germany)

Prof. dr. G.J. Scheffer (Nijmegen) 


\section{Contents}

$\begin{array}{lll}\text { Chapter } 1 & \text { Introduction } & 7\end{array}$

Chapter 2 Neuromuscular blocking agents and monitoring: 15 state of the art

Chapter 3 Pretreatment before succinylcholine for outpatient anesthesia

Chapter 4 Postoperative myalgia after succinylcholine:

No evidence for an inflammatory origin

Chapter 5 Women report more pain on injection of a precurarization dose of rocuronium: A randomised, prospective, placebocontrolled trial

Chapter 6 Prevention of succinylcholine-induced fasciculation and myalgia: A meta-analysis of randomized trials

Chapter 7 Does preoperatively administered parecoxib prevent succinylcholine-associated myalgia? A randomized, placebocontrolled trial

Chapter 8 Discussion

Chapter 9 Summary

Samenvatting (Summary in Dutch)

Curriculum vitae

List of publications

Acknowledgments 

Chapter 1

Introduction 
Since the introduction of curare into clinical practice by Griffith and Johnson [1] the use of neuromuscular blockers has become an essential part in clinical anaesthesia. Originally, these agents were used to improve surgical conditions in different settings due to muscle relaxation with less requirements for (mostly) inhalative anaesthetics. In anaesthesia, neuromuscular blocking agents might be useful because they may improve the conditions for endotracheal intubation and, thus, may reduce the incidence of intubation related morbidity [2].

In 1952, a few years after the introduction of curare, which was the first nondepolarizing neuromuscular agent in anaesthesia, succinylcholine was introduced [3].

Due to its unique pharmacological properties succinylcholine has become a widely used agent in the field of anaesthesia. Succinylcholine is a quaternary, depolarizing muscle relaxant that affects skeletal muscles. The substance has been first described in 1906 by Hunt and Taveau. However, the neuromuscular effects of the compound have been demonstrated for the first time by Bovet in 1949 [4].

Pharmacologically, the compound activates the nicotinergic acetylcholine receptors at the neuromuscular junction and, thus, initiates a muscular response. The paralysing effect occurs due to over stimulation of the receptor and has been described in detail elsewhere. The agent has an rapid on- and offset of action.[5] Over the years succinylcholine has become the drug of choice in clinical situations, where a rapid and complete relaxation of the patient following induction of anaesthesia is wanted; especially to facilitate optimal conditions for endotracheal intubation. Such situations may occur in emergency patients, who have an increased risk for the aspiration of gastric content. A dedicated technique to prevent patients from aspiration following an emergency induction is widely known as 'rapid sequence induction' (RSI) that can be described as follows: after applying pure oxygen to the patient over several minutes via face mask and optional administration of an analgesic an adequate dose of an hypnotic agent is injected followed by succinylcholine immediately after loss of eye lash reflex. No manual ventilation by mask should be performed between loss of consciousness and endotracheal intubation. Due to the rapid onset of succinylcholine the performing anaesthesiologist can expect optimal intubation conditions within 60 to 75 seconds after injecting the agent [6]. Furthermore, it is still a popular drug in ambulatory anaesthesia and day case procedures when a short duration of action is wanted [7]. 
Due to its depolarizing effect, succinylcholine has several undesirable effects. Some of them are possibly life threatening or may cause serious complications such as malignant hyperthermia, bradycardia, cardiac arrest, increase of intragastric or intraocular pressure [8]. Others may cause discomfort to the patient (and also to the treating anaesthesiologist). Two of the most frequent side effects associated with succinylcholine are fasciculations and postoperative myalgia. Clinically, fasciculations appear immediately after injection of the drug and might be best described as uncoordinated generalized muscular contractions of various intensity. Postoperative myalgia can be described as muscular stiffness and pain that is comparable to muscular soreness following unaccustomed muscular stress. Succinylcholine-associated pain and stiffness can last for up to one week. The incidence varies from 1.5 to $90 \%$ with different grades in pain perception [9]. In specific patient populations such as morbidly obese patients succinylcholine-associated myalgia has been associated to increase the postoperative morbidity [10].

Postoperative myalgia as a succinylcholine-related adverse effect has been described by Churchill-Davidson for the first time in 1952 even shortly after the clinical introduction of succinylcholine. Furthermore, he was the first who investigated the effects of a pretreatment with the non-depolarizing neuromuscular blocker gallamine prior to succinylcholine to avoid succinylcholineassociated myalgia and fasciculations [11].

In the following 50 years a huge number of studies on the effect of various compounds and strategies in the prevention of succinylcholine-associated myalgia were done. These studies investigated pharmacological strategies as well as physical methods such as stretch exercises. Pharmacological interventions included compounds with direct effects on the neuromuscular junction or central nervous effects such as small doses of different non-depolarizing neuromuscular blocking agents, magnesium, diazepam, lidocaine, dantrolene, and succinylcholine itself in a small precursor dose. Further trials tested calciumgluconate, vitamin C, chlorpromazine, and NSAID [9]. However, none of the tested interventions was found to be completely reliable in the prophylaxis of succinylcholine-associated myalgia and some trials ended with inconclusive results. One of the main problems in finding an optimal pretreatment in the prevention of succinylcholine-associated myalgia is the fact that the pathogenesis of this adverse effect is still unknown and it was suggested very early that this might be multifactorial. Firstly, Myalgia has been attributed to muscle damage produced by shearing forces with upcoming fasciculations during depolarization. Sec- 
ondly, fibre rupture may occur as well as microdamage of muscle cells. Succinylcholine-induced fasciculations may induce an increase of chemical markers such as serum creatine kinase, potassium and myoglobine $[12,13]$ and it has been hypothesized that the activation of prejunctional nicotinergic acetylcholine receptors due to succinylcholine and the following repetitive firing and antidromic discharge might be the reason for fasciculations. Therefore, several investigators tried to find a correlation between succinylcholine-induced fasciculations, increase in biochemical markers, and postoperative myalgia but none of the performed studies could find a clear relationship between these three issues [14-17].

\section{Methods used for the prevention of succinylcholine-associated myalgia}

Non-depolarizing neuromuscular blockers are supposed to inhibit the activation of prejunctional nicotinergic acetylcholine receptors. Most of the currently available non-depolarizing neuromuscular blockers have been tested on their effect in preventing succinylcholine-associated myalgia. A very popular technique called 'precurarization' has been used by several investigators. With this technique a small dose of a non-depolarizing neuromuscular blocker will be administered prior to succinylcholine at the beginning of induction. Most of the trials found that this technique may reduce the incidence of fasciculation and myalgia to some extend. However, these drugs may have side effects due to their paralyzing effect that may cause serious adverse events [18].

Lidocaine and phenytoine are sodium channel blockers with cell membrane stabilising properties that might reduce both, fasciculations and myalgia. Lidocaine has been firstly described as a pretreatment agent in 1967 by Usubiaga and co-workers [19]. It also inhibits the increase of serum potassium and the decrease of serum calcium which may occur following the administration of succinylcholine. Unfortunately, the preventive effect of sodium channel blockers was not observed by all investigators [13].

Benzodiazepines are sedatives that also may have muscle relaxing effects due to their central nervous mechanism of action. It has been hypothesized that these are located on the level of the spinal chord [20]. Furthermore, amnesic effects of benzodiazepines may have an influence on pain perception and, thus, can also decrease the perception of myalgia. However, data about the effect of benzodiazepines on myalgia have remained inconclusive. 
In 1987 Naguib and colleagues published one of the first studies on the preventive effect of aspirin on succinylcholine-associated myalgia with promising results [21]. Aspirin as well as other non-steroidal antiinflammatory drugs inhibit the prostaglandin synthesis. Prostaglandins are playing an important role in pain mediation and inflammation-related tissue damage. Therefore, the use of these compounds to prevent succinylcholine-associated myalgia was supposed to be a rationale. But these findings could not be confirmed in further studies by all investigators. Furthermore, aspirin and non-steroidal antiinflammatory drugs do have inhibiting effects onto haemostasis and, thus, may increase the risk of perioperative blood loss.

Dantrolene inhibits the intracellular calcium release in muscle cells and has become the agent of choice in the treatment of malignant hyperthermia. It has been suggested that a lack of serum calcium may play an important role in the development of myalgia. Thus, dantrolene should avoid an additional influx of calcium into the muscle cells. While oral dantrolene was tested successfully on the prevention of postoperative myalgia intravenous dantrolene failed in decreasing the incidence. Furthermore, dantrolene may cause postoperative side effects such as weakness, fatigue, and dizziness.

Succinylcholine itself has also been tested to prevent myalgia in various trials. A technique known as 'self-taming' uses a small dose of succinylcholine prior to the main dose. Other studies have tested the effect of high-dose succinylcholine during induction of anaesthesia.

A first approach to bundle the knowledge on the prevention of succinylcholine-associated fasciculations and myalgia was made with a meta-analysis on different pretreatments published by Pace in 1990 [22]. According to his results diazepam, lidocaine, and various non-depolarizing neuromuscular blocking agents such as atracurium, pancuronium, d-tubocurarine, and gallamine were effective in reducing the incidence of postoperative myalgia by about $30 \%$. In the 1990s new non-depolarizing neuromuscular blockers (rocuronium, mivacurium, cisatracurium) were introduced into clinical practice. Meanwhile, all of these drugs have been tested on their effect in preventing postoperative myalgia. Furthermore, more recent studies found that the concept of 'precurarization' and the avoidance of succinylcholine itself could not reduce the incidence of myalgia in ambulatory patients [23,24].

Even more than 50 years after the introduction of succinylcholine there is still a lack of knowledge about the pathogenesis of postoperative myalgia, an optimal pretreatment to avoid this undesirable adverse effect, and possible side effects of 
the various pretreatment strategies. Therefore, the aim of this thesis was to give some new insights in the problem of myalgia and to find answers on the following research questions:

Is succinylcholine a suitable drug for ambulatory anaesthesia in comparison to a modern non-depolarizing neuromuscular blocking agent (i.e. rocuronium) with respect to postoperative myalgia?

Does succinylcholine-associated myalgia have an inflammatory origin and can it be avoided through the preoperative use of a glucocorticoid? Is pain due to 'precurarization' with rocuronium an issue and are there gender related differences?

What is the optimal intervention to prevent succinylcholine-associated myalgia according to current standards in evidence-based medicine?

Is a pretreatment with a selective cyclooxygenase- 2 inhibitor effective in reducing the incidence of succinylcholine-associated myalgia?

In chapter II, this thesis provides a general overview about the 'state of the art' in using neuromuscular blocking agents and neuromuscular monitoring. In chapter III the first research question is discussed in a randomized controlled trial that was performed in ambulatory patients at the University Hospital of the Saarland, Homburg, Germany. Chapter IV contains a randomized controlled trial that investigates a possible inflammatory component of succinylcholine-associated myalgia with a laboratory and a clinical approach. The question of rocuronium-associated pain following a 'precurarization' dose of this compound is discussed in chapter V. To the aim of an evidence-based approach in finding an optimal pretreatment on succinylcholine-associated myalgia a meta-analysis of randomized controlled trials was performed in co-operation with the Division of Anaesthesia at Geneva University Hospitals and the Department of Anaesthesia and Critical Care at the University Hospital of NancyBrabois. The results can be found in chapter VI. Finally, the effect of the selective cyclooxygenase- 2 inhibitor parecoxib on postoperative myalgia was tested in a randomized controlled trial. The findings of this trial are discussed in chapter VII. 


\section{References}

1. Griffith, HR, Johnson, GE. The use of curare in general anaesthesia. Anesthesiology 1942; 3: 418-20.

2. Mencke T, Echternach M, Kleinschmidt S, Lux P, Barth V, Plinkert PK, Fuchs-Buder T. Laryngeal morbidity and quality of tracheal intubation: A randomized controlled trial. Anesthesiology 2003; 98:1049-56.

3. Mayrhofer, O. Self-Experiments with succinylcholine chloride; a new ultra-short-acting muscle relaxant. Br Med J 1952; 1(4772):1332-4.

4. Theslefe, S, Dardel OV, Holmberg G. Succinylcholine iodide - a new muscle relaxant. Br J Anaesth 1952; 24: 238-44.

5. Schreiber JU, Fuchs-Buder T. [Neuromuscular blockades. Agents, monitoring and antagonism]. Anaesthesist 2006; 55: 1225-35.

6. Mencke T, Knoll H, Schreiber JU, Echternach M, Klein S, Noeldge-Schomburg G, Silomon M. Rocuronium is not associated with more vocal cord injuries than succinylcholine after rapid-sequence induction: A randomized, prospective, controlled trial. Anesth Analg 2006; 102: 943-9.

7. Bettelli G. Which muscle relaxants should be used in day surgery and when. Curr Opin Anaesthesiol 2006; 19: 600-5.

8. Claudius C, Garvey LH, Viby-Mogensen J. The undesirable effects of neuromuscular blocking drugs. Anaesthesia 2009, Mar;64 Suppl 1:10-21.

9. Wong SF, Chung F. Succinylcholine-Associated postoperative myalgia. Anaesthesia 2000, Feb;55(2):144-52.

10. Tejirian T, Lewis CE, Conner J, Jensen C, Dutson E, Mehran A. Succinylcholine: A drug to avoid in bariatric surgery. Obes Surg 2009, Apr;19(4):534-6.

11. Churchill-Davidson HC. Suxamethonium (succinylcholine) chloride and muscle pains. $\mathrm{Br}$ Med J 1954; 1(4853):74-5.

12. Ventafridda V, Terno G, Sciancalepore G. [Behavior of serum creatine phosphokinase and potassium in relation to myalgia induced with succinylcholine]. Minerva Anestesiol 1970; 36: 200-5.

13. Laurence AS. Myalgia and biochemical changes following intermittent suxamethonium administration. Effects of alcuronium, lignocaine, midazolam and suxamethonium pretreatments on serum myoglobin, creatinine kinase and myalgia. Anaesthesia 1987; 42: 503-10.

14. Tammisto T, Airaksinen M. Suxamethonium-Induced myoglobinuria. Br J Anaesth 1965; 37: 464.

15. Eisenberg M, Balsley S, Katz RL. Effects of diazepam on succinylcholine-induced myalgia, potassium increase, creatine phosphokinase elevation, and relaxation. Anesth Analg 1979; 58: 314-7.

16. Laurence AS. Biochemical changes following suxamethonium. Serum myoglobin, potassium and creatinine kinase changes before commencement of surgery. Anaesthesia 1985; 40: 8549 . 
17. McLoughlin C, Elliott P, McCarthy G, Mirakhur RK. Muscle pains and biochemical changes following suxamethonium administration after six pretreatment regimens. Anaesthesia 1992; 47: 202-6.

18. Engbaek J, Viby-Mogensen J. Precurarization--A hazard to the patient? Acta Anaesthesiol Scand 1984; 28: 61-2.

19. Usubiaga JE, Wikinski JA, Usubiaga LE, Molina F. Intravenous lidocaine in the prevention of postoperative muscle pain caused by succinylcholine administration. Anesth Analg 1967; 46: 225-30.

20. Mingus ML, Herlich A, Eisenkraft JB. Attenuation of suxamethonium myalgias. Effect of midazolam and vecuronium. Anaesthesia 1990; 45: 834-7.

21. Naguib M, Farag H, Magbagbeola JA. Effect of pretreatment with lysine acetyl salicylate on suxamethonium-induced myalgia. Br J Anaesth 1987; 59: 606-10.

22. Pace NL. Prevention of succinylcholine myalgias: A meta-analysis. Anesth Analg 1990; 70: 477-83.

23. Joshi GP, Hailey A, Cross S, Thompson-Bell G, Whitten CC. Effects of pretreatment with cisatracurium, rocuronium, and d-tubocurarine on succinylcholine-induced fasciculations and myalgia: A comparison with placebo. J Clin Anesth 1999; 11: 641-5.

24. Mikat-Stevens M, Sukhani R, Pappas AL, Fluder E, Kleinman B, Stevens RA. Is succinylcholine after pretreatment with d-tubocurarine and lidocaine contraindicated for outpatient anesthesia? Anesth Analg 2000; 91: 312-6. 


\section{Chapter 2}

\section{Neuromuscular blocking agents and monitoring: state of the art}

Jan-Uwe Schreiber, Thomas Fuchs-Buder, Claude Meistelman This chapter has been published in parts in:

Anaesthesist 2006; 55: 1225-1236 (in German)

Anaesthesia 2009; 64 (Suppl. 1): 82-89 


\section{Requirements on neuromuscular blocking agents.}

The primary aims for the use of neuromuscular blocking agents during a general anaesthesia are twofold. Besides optimizing the surgical conditions during procedures where a relaxation of the skeletal muscles is required muscle relaxation may improve the intubation conditions for the anaesthesiologist and, thus, may reduce the incidence of postoperative laryngeal and pharyngeal trauma associated with endotracheal intubation [1]. The use of neuromuscular blocking agents requires a sufficient depth of anaesthesia and can not replace an insufficient administration of anaesthetics and analgesics. The ideal neuromuscular blocking agent should have a rapid onset with a reliable duration of action and recovery. Furthermore, it is desirable that the agent does have a profile that includes no drug-related adverse effects, a low anaphylactic potential, and no interaction with other compounds. None of the currently available neuromuscular blockers fulfils these requirements completely.

\section{Pharmacology}

The main effect side of all neuromuscular blocking agents is the acetylcholine receptors of the neuromuscular junction. These are situated in opposition to the acetylcholine storage vesicles of the presynaptic membrane. The acetylcholine receptor contains five subunits ( 2 alpha, beta, delta, and epsilon) and has the shape of a channel in form of a rosette. The channel works in accordance to the "all or nothing" principle and opens if acetylcholine or another depolarizing agent (succinylcholine) activates the two alpha-subunits. The opening is caused by an allosteric change of shape of the receptor which is now penetrable for sodium and potassium cations. If a sufficient count of receptors has been opened by acetylcholine a contraction of the skeletal muscle occurs after reaching the threshold. Subsequently, acetylcholine releases from the receptor and will be metabolized into acetate and choline. The channel closes for repolarisation (figure 1).

Thus, there are two different pharmacological options to avoid that threshold potential may be reached which results in a muscular contraction:

Pharmacological block of the alpha-subunits of the receptor (non-depolarizing block). The agent competes against acetylcholine for the subunits. The opening of the channel can be avoided if one of the alpha-subunits has been blocked against acetylcholine. Basically, non-depolarizing neuromuscular blocking 
agents can be antagonised with cholinesterase inhibitors or, in case of aminosteroid relaxants, also with the cyclodextrin sugammadex.

Pharmacological stimulation of the receptor with an agonist of the alphasubunits that imitates the effect of acetylcholine and avoids re-polarisation of the muscle cell due to its persistent presence at the neuromuscular junction (depolarizing block). This is the mechanism of action of succinylcholine. All other neuromuscular blocking agents that are currently in use are nondepolarizing neuromuscular blockers. In contrary to a non-depolarizing block it is not possible to reverse a depolarizing block with choline esterase inhibitors or sugammadex.

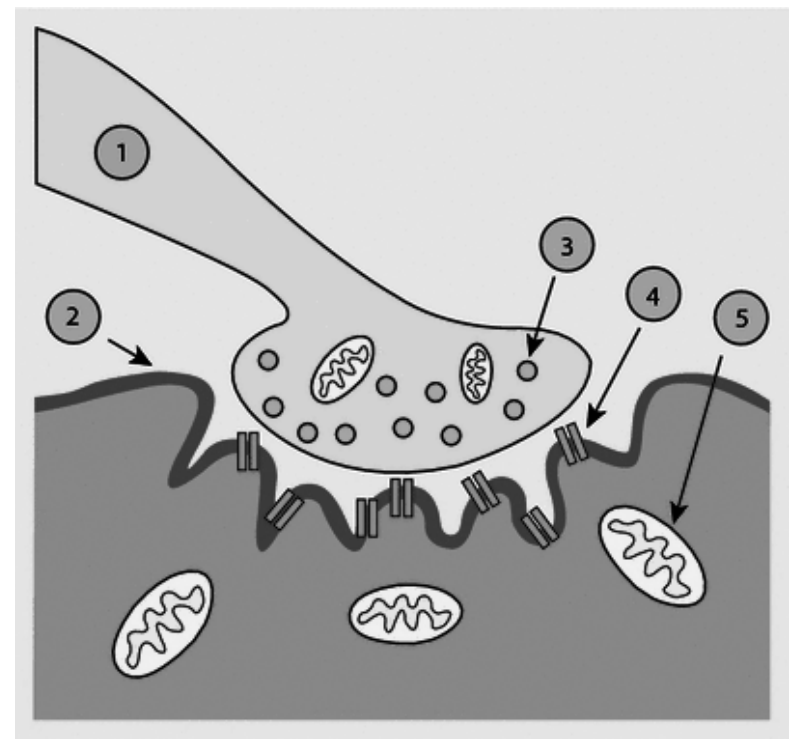

Figure 1. Schematic illustration of the neuromuscular junction ( $1=$ axon, $2=$ synapse, $3=$ vesicle containing acetylcholine, $4=$ acetylcholine receptor, $5=$ mitochondrium)

With the exception of mivacurium redistribution terminates the relaxing effect of the drugs at first order. Further metabolism occurs due to specific profile of the compound with involvement of organ dependent metabolism or not.

The pre-ganglia neurons of the autonomic nerve system are cholinergic and contain nicotinergic acetylcholine receptors (as well as the skeletal muscles). Furthermore, the post-ganglia neurons of the parasympathic system are cholinergic but these are muscarinergic receptors. Among others the clinical impact of hemodynamic side effects of the different neuromuscular blocking agents 
depends on the affinity of the single compounds on nicotinergic and muscarinergic acetylcholine receptors. The proportion of the blocking effect on ganglia compared to the neuromuscular blocking effect is known as the autonomic margin of safety. An increasing margin describes a lower probability of an autonomic block. Hemodynamic side effects from neuromuscular blocking agents might be also caused by a decreased nor-epinephrine re-uptake (i.e. pancuronium) or by histamine release.

\section{Definitions for the characterization of neuromuscular blocking agents}

The potency of the neuromuscular blocking effect of a single agent can be defined with the so called ED95. The ED95 represents the dose of a neuromuscular blocking agent in $\mathrm{mg} \mathrm{kg}^{-1}$ or $\mu \mathrm{gg} \mathrm{kg}^{-1}$ which causes a $95 \%$ blockade of the neuromuscular receptors. Commonly, a dose twice the ED95 has been accepted as an adequate dose for endotracheal intubation.

The onset time has been defined as the time between the administration of a neuromuscular blocking agent and its peak effect. The clinical duration (DUR25) describes the time in minutes between injection of the agent and the reversal of the then occurring block up to $25 \%$ of normal values. In this period the relaxation should be sufficient for most of the surgical procedures. The term has been also used in the description of the different agents regarding their classification in ultra short (DUR25 $<15 \mathrm{~min}$ ), short (DUR25 $<25 \mathrm{~min}$ ), medium (DUR25 20-50 min), and long (DUR25 > $50 \mathrm{~min}$ ) duration of action, respectively. Analogous, the DUR95 represents the time for a 95\% reversal of the block. The latter times depend directly from the initial dose that was administered.

The recovery index describes the time between a recovery of $25 \%$ and $75 \%$ from the neuromuscular block. In contrast to the DUR25 and DUR95 the recovery index is more likely to be a variable that is independent from the administered dose.

The Train-of-four-Ratio (TOF-Ratio) specifies the proportion of the fourth response compared to the first response. This technique of neuromuscular monitoring will be described in detail in the part "Neuromuscular monitoring" of this article. The TOF-Ratio provides information about the neuromuscular recovery and a possible residual curarization. In this context a TOF-Ratio $<0.6$ represents a profound and a TOF-Ratio between 0.7 and 0.9 a minimal residual 
block, respectively. Sufficient neuromuscular recovery has been reached with a TOF-Ratio of 0.9 (ideally 1.0).

Profound residual curarization $(T O F<0.6)$ Although this grade of residual paralysis can not be detected through clinical signs or with a simple neuromuscular monitoring device there might be a significant impact on ventilatory parameters such as forced vital capacity, pharyngeal function, integrity of the upper airway, and hypoxic ventilatory response. Tidal volume and breathing frequency can be expected within normal ranges.

Minimal residual curarization (TOF-Ratio 0.7 - 0.9) At this grade of neuromuscular recovery forced vital capacity, expiratory flow, and hypoxic ventilatory response have reached the ranges as equal as prior to the neuromuscular blockade. However, there is still a dysfunction of the upper airway with a decreased inspiratory airflow, difficulty in swallowing, decrease volume of the upper airway, and dysfunction of the airway dilating musculus genioglossus. Thus, an increased risk for pulmonary aspiration in the extubated patient should be taken into account. Therefore, a TOF-Ratio $<0.9$ does not represent a sufficient recovery of the integrity of the upper airway and the respiratory function.

Margin of safety of neuromuscular transmission. This term describes the percentage of acetylcholine receptors that has to be covered by a neuromuscular blocking agent to detect first clinical signs of muscular weakness. Commonly, this percentage is around $70-75 \%$. Thus, several clinical consequences appear for onset, repetitive administration, and neuromuscular recovery. Typically, a twofold ED95 is administered for endotracheal intubation. This dose makes sure that the margin of safety of neuromuscular transmission will be bridged rapidly and reliably. In case of an intraoperative necessity for a repetition normally $25 \%$ of the initial intubation dose of a neuromuscular blocking agent is adequate to restore a complete neuromuscular block because the major percentage of receptors is still covered by the blocking agent at this time. This effect also explains the comparably long effect of the short-acting mivacurium whether this compound is used for the enhancement of a pancuronium-induced block. The effect-side profile of pancuronium dominates the neuromuscular block at the majority of receptors.

Furthermore, there are clinical consequences in neuromuscular recovery. Situations with $25-30 \%$ of not-covered receptors can not be detected reliably with common qualitative stimulation patterns (Train of four or Double-burst stimulation) or with clinical signs. At this time no margin of safety exists and 
small changes in the relation between acetylcholine and the blocking agent at the neuromuscular junction may lead to a significant blockade again. In this context it was found that small doses of magnesium - which are normally without any neuromuscular effect - may cause a clinically relevant recurarization. Magnesium inhibits the pre-synaptic acetylcholine release and, thus, may interact with the proportions of acetylcholine and the compound. Similar effects can be observed with aminoglycosid antibiotics and calcium channel inhibitors [2]. Consequently, this effect might be harmful for extubated patients in the early postoperative period (figure 2).

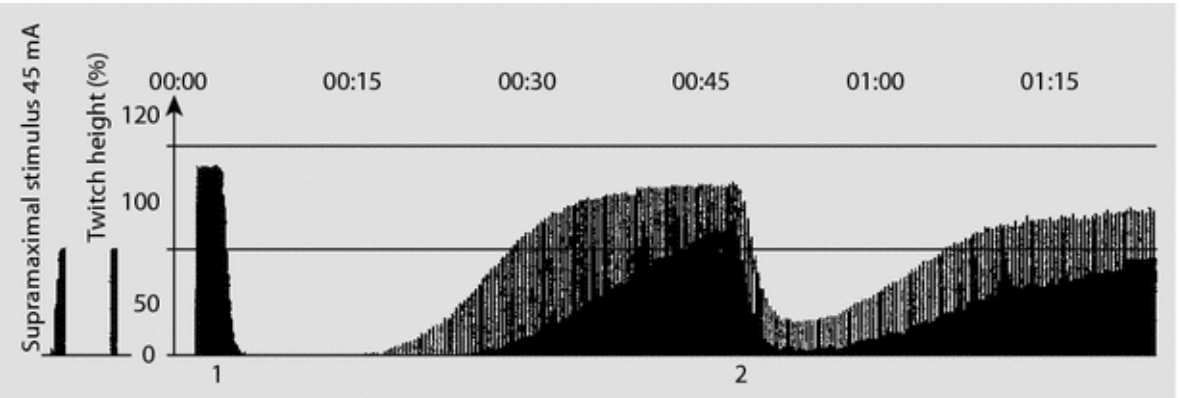

Figure 2. Neuromuscular recovery following vecuronium injection (1) and recurarization after injection of magnesium (2).

\section{Depolarizing agents - succinylcholine}

Mechanism and indication. Succinylcholine is the only depolarizing neuromuscular blocking agent that is currently used by clinicians. Moreover, it is the oldest neuromuscular blocking agent that is currently available; succinylcholine was introduced into clinical practice in 1952. Due to its pharmacological properties with a rapid onset and a short duration of action this agent is still unique. The ED95 has been described with $0.3 \mathrm{mg} \mathrm{kg}^{-1}$ [3]; to facilitate endotracheal intubation a three- to fivefold ED95 $\left(1-1.5 \mathrm{mg} \mathrm{kg}^{-1}\right)$ is commonly used. Optimal intubation conditions can be achieved within $45-60 \mathrm{~s}$ in $90 \%$ of all patients following this dosage. The duration of action is 9 to 12 minutes until a complete recovery has been accomplished. Spontaneous breathing of the patient returns gradually after 5 minutes. A repetitive administration within a short period may cause a prolonged duration of action due to a so called phase-2block (or dual block). It has been suggested that the cause might be an additional blockade of pre-synaptic acetylcholine receptors. Contrary to a depolariz- 
ing block the phase-2-block is suitable for antagonising with cholinesterase inhibitors.

Due to its pharmacological profile succinylcholine has been the agent of choice in short during procedures for a long time and it is still the most commonly used neuromuscular blocker for the 'rapid sequence induction'.

Side effects. Succinylcholine has been commonly associated with huge variety of side effects. In 1996 the German Society for Anesthesia and Critical Care published an advise that succinylcholine should be avoided in children undergoing elective surgery [4]. In 2002 adult patients were also included in this recommendation [5]. Succinylcholine is one of the drugs that may trigger a malignant hyperthermia and has to be avoided in patients with a known disposition. Due to activation of nicotinergic and muscarinergic acetylcholine receptors the agent may cause severe cardiac arrhythmias especially in children that may also include bradycardia and cardiac arrest. Therefore, it has been recommended to administer a small dose of a vagolytic agent in children prior to succinylcholine. Furthermore, an increasing intraocular and intragastric pressure as well as postoperative myalgia can be observed following succinylcholine.

Rhabdomyolysis and hyperkalemia must be seen as severe and lifethreatening complications. These may occur more frequently in immobilized patients, patients with major burns, denervation, and several days after major trauma. It has been suggested that these adverse effects are caused by peri- and extrajunctional acetylcholine receptors which has been newly constituted in those patients. These new receptors are being consistent with embryonal acetylcholine receptors and are different from the adult form due to one subunit. Furthermore, the newly constituted receptors do provide a prolonged channel opening and, consequently a potassium efflux from the myocyte that is increased twofold. Thus, an up-regulation on the sensitivity to succinylcholine might appear within 3 to 5 days in patients who suffer from the mentioned conditions. Therefore, succinylcholine should be absolutely avoided in those patients.

Degradation of succinylcholine occurs through plasmatic cholinesterase. In case of a genetic variation the effect of succinylcholine can be prolonged for hours. Activity of this cholinesterase might be also reduced in patients with hepatic diseases, cytotoxic therapy, during pregnancy, and undergoing cardiopulmonary bypass. 


\section{Non-depolarizing agents}

Non-depolarizing neuromuscular blockers are commonly quartery ammonium molecules. The compounds can be grouped into aminosteroids (i.e. rocuronium, pancuronium, vecuronium) and benzylisoquinolines (i.e. atracurium, cisatracurium, mivacurium) [6]. Alcuronium, doxacurium, and pipecuronium are not frequently used or no longer available and, thus, will not be part of this review.

\section{Pancuronium}

Pancuronium was introduced into clinical practice in 1967. Therefore, it is one of the oldest non-depolarizing agents available. The agent represents the group of neuromuscular blockers with a long duration of action. The single ED95 has been described as $0.06-0.07 \mathrm{mg} \mathrm{kg}^{-1}$ bodyweight. If a dose of $0.15 \mathrm{mg} \mathrm{kg}^{-1}$ was used for intubation a DUR25 of $100 \mathrm{~min}$ and a DUR95 of $150 \mathrm{~min}$ should be expected. The onset time with this dose will be around 3 minutes. Pancuronium is degraded mainly through hepatic metabolism and renal elimination. Biliary metabolism is of minor importance. The agent does not cause any histamine liberation. Impairments of the mentioned organs systems may cause a delay in metabolism and a prolonged effect. Pancuronium interacts with the norepinephrine re-uptake which consequently may result in tachycardia and increasing blood pressure. Pancuronium was also accused to increase the risk of postoperative pulmonary complications following surgery of long duration [7]. This might be related to an insufficient neuromuscular recovery following repetitive administrations of pancuronium [8].

Due to its lack of controllability even after repetitive administration pancuronium does not have a place in "fast-track surgery". The agent might be an alternative for long-during procedures that require a sufficient neuromuscular block. Patients should be scheduled for a postoperative ventilator therapy then.

\section{Vecuronium}

Vecuronium was introduced in the 1980s. It is an aminosteroid with an intermediate duration of action. Contrary to other neuromuscular blocking agents this agent is basically available as a powder for the preparation of a solution 
with saline and does not require being stored at $8-10^{\circ} \mathrm{C}$. Therefore, vecuronium is a suitable agent for disaster and emergency services. The ED95 of vecuronium is $0.05 \mathrm{mg} \mathrm{kg}$. The DUR25 has been described with $30 \mathrm{~min}$ and the DUR95 with 50 min, respectively. Following a twofold ED95 the onset time will be around $2.5 \mathrm{~min}$ and the recovery index $13 \mathrm{~min}$, respectively [6]. Even higher doses of vecuronium do not cause histamine liberation or sympathic activation. Thus, Vecuronium offers a good hemodynamic stability. Degradation of vecuronium occurs mainly due to hepatic metabolism; a minor part is eliminated by the kidneys. Vecuronium is metabolized into three different metabolites. One of them, 3-OH-vecuronium, has neuromuscular blocking properties with a potency of $80 \%$ of vecuronium. Without any impairment in organ function 3-OH-vecuronium does not reach clinically relevant concentrations. In case of an impaired renal or hepatic function the duration of a neuromuscular block might be prolonged.

Due to a lack of hemodynamic effects vecuronium still does have its place into clinical practice if hemodynamic stability is wanted during anaesthesia.

\section{Rocuronium}

The chemical structure of rocuronium that was introduced into clinical practice in 1994 is comparable with vecuronium. The ED95 of rocuronium has been described as $0.3 \mathrm{mg} \mathrm{kg}^{-1}$. The potency of the neuromuscular blocking effect is fivefold less in comparison to vecuronium; even the distribution volume of rocuronium is smaller [6]. These pharmacological properties allow a faster onset. The higher dose leads to an increased concentration of rocuronium molecules at the neuromuscular gap. The onset time following an intubation dose (i.e. $0.6 \mathrm{mg} \mathrm{kg}^{-1}$ ) varies in dependence of the evaluation technique between 60 and 150 seconds. However, even using a two- to threefold ED95 may produce acceptable or excellent intubation conditions after 60 seconds in up to $90 \%$ of the patients [9].

Reducing the intubation dose to $0.4 \mathrm{mg} \mathrm{kg}^{-1}$ leads to an increased onset time (i.e. $3 \mathrm{~min}$ ) and to a decreased clinical duration (i.e. $20 \mathrm{~min}$ ), respectively. Therefore, rocuronium might be an agent with a relatively short duration of action in case of a dose reduction [10].

Following an intubation dose of rocuronium both the DUR25 and the DUR95 are comparable to vecuronium. Its primary metabolism is hepatic and biliary; even a small part undergoes renal elimination. No active metabolites are 
produced during degradation. An increase of heart frequency and blood pressure might be observed following higher dosages of rocuronium. These effects like to be vagolytic due to a lack of increased histamine plasma concentrations. The fastest onset in comparison to all other non-depolarizing neuromuscular blockers is the most outstanding property of rocuronium. Furthermore, rocuronium offers hemodynamic stability and a lack of histamine liberation. Due to its specific pharmacological properties rocuronium can be taken as an alternative agent for the 'rapid sequence induction' in case of contraindications against succinylcholine. When using a reduced dosage rocuronium offers a comparatively short duration of action.

\section{Atracurium}

Atracurium is a non-depolarizing neuromuscular blocker that belongs to the group of benzylisoquinolines. As vecuronium atracurium was introduced into clinical practice in the early 1980s. It is also a neuromuscular blocker with an intermediate duration of action with an ED95 of $0.25 \mathrm{mg} \mathrm{kg}^{-1}$. If the intubation dose was used an onset time of 3 to 4 minutes should be taken into account. Then, the clinical duration is around 35 minutes; the recovery index is between 12 and 15 minutes. Mainly, atracurium is degraded organ independently by Hoffmann elimination and ester hydrolysis via unspecific esterases [6]. The Hoffmann reaction is a chemical reaction that occurs spontaneously under physiological conditions. One of the products from degradation is laudanosine which was potentially neurotoxic in animal studies. However, induction of seizures in animals required doses that can not be matched if common clinical doses of atracurium are used. In addition, laudanosine induces vasodilatation. Laudanosine is eliminated via the kidney. Therefore, laudanosine potentially may cumulate in case of renal insufficiency.

Through direct interaction with mast cells atracurium can induce histamine liberation. This may lead to a decrease in blood pressure, tachycardia, and generalized erythema. These adverse effects occur in particular following rapid injection and increased dosage. 


\section{Cisatracurium}

Cisatracurium is one of the ten stereo isomers of atracurium. It was introduced into clinical practice as $1 \mathrm{R}$-cis, 1 'Rcisatracurium in 1996. The agent is four to five times more potent in its neuromuscular blocking effects than atracurium. Therefore, the ED95 is $0.05 \mathrm{mg} \mathrm{kg}^{-1}$. The onset time after an intubation dose has been described as long as 3 to 5 minutes, the DUR25 as 45 minutes, and the recovery index as 15 minutes, respectively [6].

Degradation of cisatracurium occurs solely through Hoffmann reaction. In comparison to atracurium less laudanosine arises after degradation. Also histamine liberation is significantly reduced which means that there are no histamine associated symptoms even after rapid injection or high doses of cisatracurium. The hemodynamic stability has be been improved when compared to atracurium.

The main advantage of atracurium and cisatracurium is the more or less organ independently degradation that results in a low risk of accumulation. Both agents are suitable for continuous infusion. Basically, the problem of direct induced histamine liberation following atracurium does not appear after cisatracurium. A drawback might be the onset time that is quite longer than those of rocuronium. Therefore, cisatracurium and atracurium are no suitable drugs for use during a 'rapid sequence induction'.

\section{Mivacurium}

Mivacurium is the most recent agent from the group of benzylisoquinolines. It has received its approval for clinical use in 1996 from the German authorities. The compound is a mixture of three different isomers, predominantly of the cis-trans and the trans-trans isomer (around 96\%) which are responsible for relaxing properties. The molecule is degraded and inactivated by plasmatic cholinesterase. It has been already mentioned that the primary termination of the neuromuscular effects does not depend on redistribution but on metabolization which is contrary to other non-depolarizing neuromuscular blocking agents. The metabolites are neither toxic nor does they have muscle relaxing effects. In case of a genetic variation that results in an atypical plasmatic cholinesterase a prolongation of the duration of action up to 15 to 30 minutes may occur in patients with an heterozygous form. If the homozygous form is present (incidence 1 over 3000) the clinical effects of mivacurium may last for hours. In 
patients with terminal renal failure or impaired liver function the concentration of plasmatic cholinesterase might be decreased which may result in a prolongation of action.

Mivacurium has been classified as a muscle relaxant with a short duration of action. The estimated ED95 is $0.08 \mathrm{mg} \mathrm{kg}^{-1}$. A dose of at least $0.2 \mathrm{mg} \mathrm{kg}^{-1}$ $\left(2.5^{*}\right.$ ED95) should be used to reach good or excellent intubation conditions in most of the patients after 2 to 3 minutes [6]. Several authors have recommended the usage of higher doses $\left(3^{*}\right.$ ED 95$)$ for induction. The DUR25 following an induction dose (2.5*ED95) is between 20 to 25 minutes. The recovery index was estimated with 5 to 10 minutes independently from the technique of administration (bolus or continuous). Regarding these characteristics mivacurium should be an appropriate drug for continuous infusion with a dose of $4-6 \mu \mathrm{g} \mathrm{kg}^{-1} \mathrm{~min}^{-1}$ to maintain a sufficient block. However, infusion requirements may vary widely $\left(4-20 \mu \mathrm{g} \mathrm{kg}^{-1} \mathrm{~min}^{-1}\right)$. Thus, continuous neuromuscular monitoring is recommended for an optimal maintenance.

Similar to atracurium rapid injection of higher doses of mivacurium may induce a relevant histamine liberation that results in tachycardia, hypotension, and erythema.

Mivacurium has become a successor of succinylcholine in elective patients who are scheduled for surgical procedures of short duration. The agent offers an excellent controllability. Therefore, mivacurium is the ideal agent for continuous infusion. The main disadvantages of the compound are the prolonged onset time and potential histamine liberation.

\section{Neuromuscular monitoring}

In a recent survey covering 12 anaesthesia departments in the UK Grayling and Sweeney revealed that around $10 \%$ of anaesthetists applied routinely neuromuscular monitoring and more than $60 \%$ never used such a monitor. Moreover, these authors stated that there was an "apparent overall confusion among clinicians as to be the best method to confirm recovery from neuromuscular blockade". In addition, they found limited knowledge regarding the minimum train-of-four ratio which should be observed prior to extubation and insufficient reliance upon the use of quantitative monitors [11]. Similar results are reported in Germany, where a recently published nation wide survey showed that in around $18 \%$ of the anaesthesia departments only neuromuscular monitoring was routinely applied [12]. 
In view of these disappointing results current standards need to be reassessed in the light of recent improvements in neuromuscular monitoring. In the first part of the following article we will present an update of the basic considerations on neuromuscular monitoring. The second part will focus on current developments and ongoing discussions in that area.

\section{Basic considerations}

\section{Nerve stimulation}

Using nerve stimulation as an indicator for a neuromuscular block has been described in 1941 by Harvey and Masland for the first time [13]. In 1958 Christie and Churchill-Davidson presented the first device for the estimation of a neuromuscular blockade in a clinical setting [14]. The basic principles of neuromuscular monitoring have not been changed since the clinical introduction of neuromuscular monitoring devices. Stimulating a peripheral motor nerve with an electric impulse results in a muscular response following the all-or-nothing principle. The force and intensity of the response depends upon the count of activated muscular fibres. In case of a sufficient stimulating intensity all fibers of the innervated muscle should contract and a response at a maximum level should result. At this level, an additional increase of stimulating intensity will not lead to an increase of the muscular response. For clinical application of neuromuscular monitoring it is widely recommended to use an electrical stimulus that is $15-20 \%$ above the level of maximum muscular response, i.e. a supramaximal stimulus [15]. This is to ensure that factors, such as variability in skin impedance, do not have a significant influence on the muscular response and, therefore, on the quality of measurement.

\section{Stimulating electrodes}

Even the preparation and the placement of the stimulating electrodes may have an influence on neuromuscular monitoring. Before placing the electrodes the skin should be cleaned with an alcoholic solution and rubbed afterwards. The electrodes should be placed correctly at the site to ensure that the current stimulates the target nerve in an appropriate way. It is less important whether $\mathrm{Ag} / \mathrm{AgCl} \mathrm{ECG}$ electrodes or special neuromuscular monitoring electrodes are intended for use. When using ECG electrodes the distance between the two electrodes should be less than $6 \mathrm{~cm}$. Moreover, it is recommended to place the 
negative electrode at the distal site [16]. To avoid interrogation of the measurement, through hypothermia-related increase of skin impedance, skin temperature should be maintained at $32^{\circ} \mathrm{C}$.

\section{Sites of nerve stimulation}

Choosing the site of neuromuscular monitoring depends on several factors. Firstly, the site should allow easy access. Secondly, interrogation through other nerve-muscle units should be avoided, and, thirdly, it is recommended to choose a nerve-muscle-unit that allows a quantitative monitoring. The most common used nerve-muscle-unit for neuromuscular monitoring is the N. ulnaris with the M. adductor pollicis as the responding muscle. The distal stimulating electrodes should be placed at the Sulcus ulnaris, while the second electrode can be situated 3-5 cm proximal of this site. In case of quantitative accelerographic monitoring the probe can be placed at the tip of the thumb. For optimal results in quantitative monitoring the four other fingers should be fixed. It might be also helpful to use an arm cast as well as a special thumb adapter.

A couple of surgical procedures do not allow free access to the arms of a patient, e.g. during ENT surgery or if the patient is situated in a prone position. For the last setting the use of N. tibialis posterior/M. flexor hallucis brevis nerve-muscle-unit might be an alternative. The electrodes have to be placed next to the medial malleolus. For accelerographic quantitative measurement the probe of the device can be fixed at the plantar tip of the big toe. It has been shown that quantitative measurement of neuromuscular recovery at this site does not differ significantly from measurements at the N. ulnaris/M. adductor pollicis [17]. However, the estimation of the neuromuscular response might be interfered by flexion of the foot sole through additional stimulation of the plantar muscles.

Another option for neuromuscular stimulation is the N. facialis. The indicating muscles are then either the M. orbicularis occuli or the M. corrugator supercilii [18]. Moreover, the required current intensity at the N. facialis seems to be less compared to the other sites of stimulation. When using the M. corrugator supercilii or the M. orbicularis oculi as indicators for neuromuscular response it is important to remind that even the mimic muscles may interfere with the measurement. The accelerographic probe tip should take place either just above the medial part (M. corrugator supercilii) or at the lateral part below the eyebrow (M. orbicularis oculi). 
Muscle groups differ in onset, offset and peak effect of neuromuscular blocking agents. Therefore, monitoring of one nerve-muscle-unit can only provide limited information about other major muscle groups It is important to choose the monitored nerve-muscle-unit dependently from the goal of observation. It would be appropriate to use the N. facials/M. corrugator supercilii for monitoring optimal intubation conditions or paralysis of the diaphragm and the abdominal wall muscles following neuromuscular blocking agents whereas the N.ulnaris/M. adductor pollicis would be the better choice if information about the pharyngeal recovery is wanted [18].

\section{Stimulation patterns}

Clinically used stimulation patterns are the single twitch stimulation, the Trainof-four stimulation (TOF), the tetanic stimulation, the Post-tetanic count stimulation (PTC), and the Double-burst stimulation (DBS) (table 1). Independently from the type, the characteristics of pulse wave form and duration are the same in all stimulation patterns. A monophasic impulse with a rectangular wave form and a duration of $0.2 \mathrm{~ms}$ is recommended and implemented in almost all nerve stimulators.

\section{Single twitch}

It consists of application of supramaximal stimuli on the target nerve with a frequency between $0.1 \mathrm{~Hz}$ and $1.0 \mathrm{~Hz}$. Choosing a frequency $>0.15 \mathrm{~Hz}$ may result in a decrease of muscular response due to fading. In a clinical setting single twitch stimulation has only limited relevance. Without using suitable monitoring equipment (e.g. a mechanomyograph or an electromyograph) the technique does not provide reliable information neither about the neuromuscular recovery nor the onset of a neuromuscular block. However, in neuromuscular research single twitch stimulation may play an important role when investigating the onset of neuromuscular blocking agents. 
Table 1. Recommendations for the use of the single stimualation patterns for the estimation of a neuromuscular block in different clinical situations*

\begin{tabular}{lllll}
\hline $\begin{array}{l}\text { Stimulation } \\
\text { pattern }\end{array}$ & Onset block & $\begin{array}{l}\text { Deep block } \\
(\mathrm{TOF}=0)\end{array}$ & $\begin{array}{l}\text { Moderate block } \\
(\mathrm{TOF}>0)\end{array}$ & Recovery \\
\hline TOF & Adequate & Not adequate & Adequate & $\begin{array}{l}\text { Intermediate }(\mathrm{a}) \\
\text { Adequate }(\mathrm{b})\end{array}$ \\
DBS & Intermediate & Not adequate & Not adequate & $\begin{array}{l}\text { Intermediate } \\
\text { PTC }\end{array}$ \\
$\begin{array}{l}\text { Intermediate } \\
\text { Tetanus }\end{array}$ & Not adequate & Not adequate & Not adequate & Not adequate \\
$(50 / 100 \mathrm{~Hz})$ & & & Intermediate \\
\hline
\end{tabular}

* Modified from Fuchs-Buder T. Neuromuskuläres Monitoring in Klinik und Forschung. Heidelberg. Springer 2008: 44. TOF=Train of four; DBS=Double burst stimulation; PTC=Post tetanic count; $(a)=$ tactile estimation; $(b)=$ quantitative estimation

\section{Train of four (TOF)}

Train-of-four stimulation was introduced into clinical practice in the early 1970s by Ali and colleagues [19]. Compared to single twitch stimulation, TOF allows a more reliable tactile assessment of a neuromuscular block. The stimulation pattern contains four twitches of $2 \mathrm{~Hz}$ over a period of $2 \mathrm{sec}$. A stimulation free interval of at least $10 \mathrm{sec}$ should be allowed between two TOF stimulations to avoid a fading associated bias in measurement. Train of four count describes the number of noticeable responses following a TOF stimulation pattern. Without a neuromuscular block all four responses are present with equal intensity. Loss of the fourth response a represents a $75-80 \%$ neuromuscular block. The disappearance of response three, two, and one can be associated with a block of $85 \%, 90 \%$, and $98-100 \%$, respectively [20]. A sufficient neuromuscular block for surgical procedures can be assumed until the reappearance of the fourth twitch response.

Train of four ratio describes the relation of the amplitude between the fourth and the first twitch response. This relation that results from dividing the amplitudes of the fourth to the first twitch and can be taken as a parameter for neuromuscular recovery following non-depolarizing neuromuscular blockade. For exact estimation of the TOF ratio a device that supports mechanmygraphic, acceleromyographic, or electromyographic recordings is necessary. Tactile estimation allows detecting a fading during TOF stimulation only if TOF ratio is below 0.4 [21]. An objectively measured TOF ratio of 0.7 represents adequate 
recovery of the diaphragm. However, to ensure sufficient return of the function of the pharyngeal muscles, a TOF ratio of 1.0 is mandatory.

\section{Tetanic stimulus}

Tetanic stimulation is a high-frequency $(50-200 \mathrm{~Hz})$ stimulation pattern that applies for $5 \mathrm{sec}$. Due to the high frequency an estimation of single twitches is not possible. The muscular response will be perceived as a single, forceful contraction. In case of an incomplete neuromuscular recovery following nondepolarizing neuromuscular blockers a fading effect can be observed while stimulating. Baurain and colleagues found a visual fading effect of $100 \mathrm{~Hz}, 5$ sec tetanic stimulation up to a comparable TOF ratio of 0.85 [22]. However, recent studies on this topic have shown that the sensitivity of using a tetanic stimulation in detecting residual curarisation is about $70 \%$ but with a low specifity of only $50 \%$ [21].

\section{Post-tetanic count (PTC)}

Post-tetanic count allows the tactile or visual evaluation of a deep nondepolarizing neuromuscular block that does not respond on a train-of-four stimulation [23]. During a PTC stimulation a $50 \mathrm{~Hz}$ tetanic stimulation applies for 5 sec. $1 \mathrm{~Hz}$ supramaximal single stimuli follow after a break of $3 \mathrm{sec}$. The PTC results in the number of responses following the $1 \mathrm{~Hz}$ stimulation and should be ideally at 0 if a deep neuromuscular block is desired. If, however, 5 7 responses are detectable, return of TOF is imminent.

\section{Double-burst stimulation (DBS)}

DBS was introduced for clinical use in 1989 by Engbaek and colleagues [24]. The technique allows a better tactile evaluation of minor neuromuscular blocks than tactile evaluation of the Train of four ratio. During DBS two bursts of 50 $\mathrm{Hz}$ with an interval of $750 \mathrm{~ms}$ apply. A burst consists of two or three impulses. The bursts are combined as a series of 3 and 3 impulses or 3 and 2 impulses, respectively. In clinical practice DBS 3,2 is currently used. A fading of the second impulse series compared to the first correlates with an incomplete neuromuscular recovery with a comparable TOF ratio $<0.6$. Therefore, the method is more sensitive in tactile evaluation of a residual blockade in comparison with a tactile evaluation of the fading during a train-of-four stimulation [25] 


\section{Equipment}

Monitoring equipment for the surveillance of neuromuscular block can be divided into two groups. Nerve stimulators that allow a quantitative monitoring of the blockade and devices that do not, respectively. The last group of devices is most common in hospitals of several countries. However, the use of nerve stimulators without an option for quantitative measurement does not allow the detection minor levels of neuromuscular block (i.e. a TOF ratio between 0.7 and 1.0) reliably. Therefore, the use of an objective monitoring is generally recommended [26]. The most widely used methods are acceleromyography, electromyography, and mechanomyography. Kinemyography that was recently introduced by GE Healthcare is a procedure that works based on the measurement of the thumb movement. Currently, there are only few data about comparability with other types of measurement available.

\section{Acceleromygraphy}

Accleromyography is one of the most popular quantitative monitoring techniques in daily clinical use because it is comparably cheap, handy, and easy to install. After placing the stimulating electrodes at the target nerve a piezoelectric element has to be placed over a muscle. Acceleromyography measures the isotonic acceleration of the end-organ (e.g. the thumb) when moved by the stimulated muscle. Basis for the method is Newton's second law (force $=$ mass*acceleration). If mass is constant, muscle contraction can be calculated if acceleration is measured. The movement of the end-organ generates voltage in the piezo-electric element that correlates proportional with the acceleration of the muscle. The generated voltage is used for calculation by the connected device.

Acceleromyography has been shown as a well correlating procedure in comparison to the techniques such as mechanomyography but intraoperative measurements with acceleromyography can be influenced by artifacts, patients' movement, and unstable twitch responses. Therefore, the fixation of fingers and forearm is recommended when using the thumb as end-organ. Moreover, the use of devices that produce a small elastic preload at the thumb, and therefore may decrease the variability of measurements, is recommended [15]. 


\section{Mechanomyography}

Mechanomyography measures the isometric contraction of a muscle following nerve stimulation. A force transducer is placed at the end-organ that converts the muscle force into an electric signal. Most commonly the N. ulnaris and the M. adductor pollicis are used for stimulation with this technique. For stabilization of the signal a preload of $200 \mathrm{~g}$ must be applied. Moreover, the limb of the end-organ has to be immobilized.

Due to the stringent precautions, time consuming preparation, and the large scale design of the monitoring equipment mechanomyography is not used in daily clinical practice. However, when investigating new neuromuscular blocking agents the technique still remains as the "gold standard".

\section{Electromyography}

Electromyography is the oldest technique for the estimation of a neuromuscular blockade. Based on the fact that the force of muscular contraction is proportional to the compound action potential of the muscle, the device records the electric activity of the stimulated muscle (i.e. the compound action potential) following the stimulation of the corresponding nerve. The device records the amplitude of the signal as a sum of the compound action potential. The recorded results show a good correlation with mechanomyography but can not be used interchangeably. Electromyography can be used not only at the limbs but also at other muscular sites of interest (e.g. the diaphragm or the larynx). However, a careful skin preparation and maintaining the skin temperature at a constant level may improve quality of signal. The equipment is not as bulky as for mechanomyography recordings but not even handy. Therefore, electromyography has been primary used for scientific matters in the last time.

\section{Current developments}

\section{Neuromuscular Monitoring \& PORC}

There is a large consensus in the literature that neuromuscular monitoring in general and objective neuromuscular monitoring in particular may reduce the incidence of postoperative residual curarization (PORC). However, the results of a meta-analysis published 2007 by Naguib, Kopman, and Ensor were more 
than surprising [27]. These authors conclude that they "could not demonstrate that the use of an intraoperative neuromuscular function monitor decreased the incidence of PORC“. However, serious remarks on both the design and the methodology of their meta-analysis soon arise. Indeed, it has been criticized that no distinction between objective and non-objective monitoring methods were made in this meta-analysis. The chosen methodology to select articles - included comparative and not comparative studies - and therefore was questionable [28].

Moreover, in the meantime Claudius and colleagues published a systematic review about the role that plays acceleromyography in research and clinical practice [29]. This complete overview over the place of AMG found also good evidence that acceleromyography improves the detection of postoperative residual paralysis and it confirmed that recovery of the AMG TOF-ratio to unity indicates with a high predictive value recovery of pulmonary and upper airway function from residual neuromuscular blockade.

Baillard and colleagues have chosen another approach to point out the impact of neuromuscular monitoring on the incidence of residual paralysis [30]. An initial survey in their department revealed an incidence of residual paralysis of about $62 \%$; at that time quantitative monitoring was applied in just $2 \%$ and reversal in $6 \%$ of patients undergoing general anaesthesia. This gives rise to the suspicion of a link between the high incidence of residual paralysis and the poor application of monitoring and reversal. Consequently, theses authors made quantitative neuromuscular monitoring available in all OR and also implemented guidelines for monitoring and reversal of neuromuscular block. In the following 10 years the incidence of residual paralysis in their PACU decreased successively from initially $62 \%$ to $3 \%$ ! In the same period the proportion of patients being intraoperatively monitored with AMG increased from $2 \%$ to $60 \%$; and in $42 \%$ of patients neuromuscular block was now reversed at the end of the case compared to initially only $6 \%$ ! Moreover, these data also revealed that the absences of neuromuscular monitoring as well as the absence of pharmacological reversal were independent risk factors for postoperative residual paralysis.

Thus, these recent reports further confirmed that neuromuscular monitoring and the large use of reversal agents are key elements for any successful strategy to prevent postoperative residual paralysis. 


\section{Performance of Acceleromyography}

Convincing evidence indicates that even low levels of residual paralysis corresponding to a mechanomyographically (MMG) measured TOF-ratio between 0.7 and 0.9 may be potentially harmful. Especially impaired laryngeal function and pharyngeal function with an increasing risk of an upper airway obstruction and/or pulmonary inhalation may contribute to residual paralysis-associated morbidity and mortality [31]. In the view of these recent findings the question arises whether in clinical practice acceleromyography (AMG) may detect low levels of residual paralysis, reliably. Moreover, AMG is increasingly used for research purpose, too. Thus, it must be clarified whether AMG-derived values and MMG-derived values can be used interchangeably. Consequently, the performance of AMG was in the focus of current research activity over the last years.

\section{Acceleromyography for use in clinical practice}

In clinical practice different ways to assess neuromuscular recovery with AMG can be seen: punctually at the end of surgery or continuously - with or without initial calibration. In addition, normalization of AMG values, i.e. dividing the value of TOF recovery by the control value determined before the injection of the neuromuscular blocking agent, has also be proposed. Unfortunately, the impact of these different AMG set up to detect low but potentially harmful levels of residual paralysis has not yet been systematically evaluated. Whilst the baseline train-of- four (TOF) ratio measured with MMG is usually close to 1.0, the average baseline TOF ratio assessed with AMG is most often significantly higher than 1.0. A similar situation is found during recovery. AMG TOFrecovery is most often significantly higher than 1.0 contrary to MMG TOFrecovery which normally is situated near 1.0. Therefore AMG and MMG cannot be used interchangeably and the TOF ratio assessed by MMG should be regarded as a real TOF ratio. By consequence it may be essential to correct raw AMG TOF-parameters to avoid overestimation of neuromuscular recovery and thus, to miss low levels of residual paralysis.

Capron and co-workers first asked the question how to detect under routine clinical conditions with acceleromyography low levels of residual paralysis reliably [32]. These authors measured MMG TOF-recovery of the m. adductor policies and compared it with the corresponding AMG TOF-recovery of the contralateral arm. This set-up allowed assessing concomitantly AMG and 
MMG recovery in the same patient. In their study AMG was applied either calibrated or uncalibrated and the uncalibrated AMG recovery values were expressed with or without normalization. The results of that study confirmed that independently of the set-up AMG overestimates neuromuscular recovery compared to MMG and thus, despite an AMG recovery of 0.9 laryngeal function and pharyngeal function may still be significantly impaired. The negative predictive value (NPV) in that context indicates the percent of patients without residual paralysis, i.e. with a MMG TOF-ratio $\geq 0.9$, at a given level of AMG TOF-recovery. As indicated in table 2 recovery of the TOF ratio to unity and initial calibration or normalization of the final TOF values are mandatory to detect low levels of residual paralysis reliably with AMG. Without initial calibration, however, even an AMG TOF-recovery to unity is insufficient to exclude low levels of residual paralysis (table 2).

Table 2. Negative Predictive Values of Different Acceleromyographic (AMG) TOF Ratios; adapted from reference [21].

\begin{tabular}{llll}
\hline \multirow{2}{*}{ AMG TOF ratio } & \multicolumn{2}{l}{ Negative Predictive Value } \\
\cline { 2 - 4 } & Calibrated data & $\begin{array}{l}\text { Uncalibrated data, not } \\
\text { normalized }\end{array}$ & $\begin{array}{l}\text { Uncalibrated but } \\
\text { normalized data }\end{array}$ \\
\hline 0.9 & $37(20-56) \%$ & $40(23-59) \%$ & $89(70-98) \%$ \\
0.95 & $70(51-85) \%$ & $60(41-77) \%$ & $92(75-99) \%$ \\
1.0 & $97(83-100) \%$ & $77(58-90) \%$ & $96(80-100) \%$ \\
\hline
\end{tabular}

Presuming that AMG is often used as an isolated test at the end of surgery Samet et al compared the performance of DBS, $100 \mathrm{~Hz}$ tetanus and a single, and thus uncalibrated, AMG TOF to detect residual neuromuscular blockade at the end of surgery [11]. The NPV of these tests were between 29\% (DBS) and $47 \%$ (single AMG TOF) with the tetanus in between (38\%) and thus are not appropriate to detect low levels of residual paralysis reliably. These results further support that AMG monitoring should be continuously applied from the induction of anaesthesia until the end of surgery rather than only punctually. By consequence appropriate monitoring devices should be available at any anaesthesia workplace. Moreover, recovery to unity and calibration or normalization is mandatory to detect low levels of residual paralysis with AMG. 


\section{Calibration in clinical practice}

There exist two different calibration programs for the current AMG devices, depending on the respective model (i.e. TOF-Watch ${ }^{\oplus}$, TOF Watch $S^{\oplus}$ or TOF Watch $S X^{\oplus}$ ). The first one applies only several single twitches and then sets the T1 response to $100 \%$. This calibration modus sets the current automatically at $50 \mathrm{~Hz}$. Calibration with this program needs approximatively $10 \mathrm{~s}$. The second program not only calibrates the $\mathrm{T} 1$ response but also determined the supramaximal current. It is available only in TOF-Watch $S^{\bullet}$ and TOF-Watch SX monitors and needs about $30 \mathrm{~s}$ to be correctly applied. Both calibration programs are user friendly and can easily be applied during induction of anaesthesia.

\section{Normalization in clinical practice}

As suggested by the data from Capron et al normalization of the final TOF ratio's may be an other option to correct raw AMG recovery parameters to improve the detection of residual paralysis [32]. Kopman and colleagues as well as Suzuki and colleagues have both confirmed the potential interest of normalization to improve the performance of AMG [33,34]. However, baseline control TOF determined before the administration of the neuromuscular blocking agent is also a prerequisite for normalization. In addition, the automatically calculated TOF-value given by most monitor devices loses of its usefulness as today manual calculation is still required to normalize TOF-parameters. Thus, actually normalization is not appropriate for routine application under clinical conditions. Nevertheless, is should be feasible for the manufacture to integrate in a future software-update of the TOF-Watch series a program allowing automatic calculation of normalized TOF ratio's by taking into account the baseline control TOF.

However, it must be emphasized that both, calibration and normalization, require a reference value before the administration of the neuromuscular blocking agent. This reference value is specific for the respective nerve/muscle unit. Therefore an intraoperative switch of the monitoring site, s.a. from the corrugator supercili during onset to the adductor policis during recovery, as sometimes proposed when simple qualitative monitoring devices are applied, cannot be recommended when AMG is used. 


\section{Acceleromyography for scientific use}

Since many years mechanomyography is considered as the "gold standard" for precise quantification of neuromuscular block. This method should still be considered as the standard when new neuromuscular monitoring techniques or new compounds are under evaluation. However, acceleromyography is now increasingly used for research purpose, too. Nevertheless, despite good concordance between acceleromyography and mechanomyography as indicated by the Bland and Altman analysis (figure 3), TOF-values from both monitors cannot be directly compared. Indeed, the difference in TOF between AMG and MMG showed a bias of $-6.6 \%$ and the limits of agreement were -22.3 and 9.1 . These values are still too wide to allow both monitors to be used interchangeably.

Not all commercially available acceleromyographs are suitable for research. For instance, in two of the three acceleromyographs commercialized by Schering Plough (TOF-Watch ${ }^{\odot}$ and TOF Watch ${ }^{\oplus}$ S) a special algorithm is used to calculate the TOF ratio. If the value of T2 is higher than the value of T1, the TOF ratio will not be calculated as T4/T1 but as T4/T2 and if this value is also above 1.0, the TOF Watch ${ }^{\circ}(S)$ will only display a TOF ratio of 1.0. Although this method of calculating the TOF ratio has yet not been evaluated systematically, it is probably of little real importance when used in the clinical context. However, such devices are not appropriate when used for research studies. In contrast, the actual TOF Watch ${ }^{\oplus} \mathrm{XX}$ device, does not have this special algorithm built-in and can therefore be used in the research setting.

Originally, unrestricted movement of the thumb was considered a prerequisite for the use of this measurement method, but there is increasing evidence that a small elastic preload in the range of $75-150 \mathrm{~g}$ on the thumb may decrease the variability. An appropriate preload device from the manufacturer is commercially available. Finally, because AMG is prone to errors as a result of artefacts, unstable twitch responses and movements (including those caused by the surgeon or other personnel in the operating room) more often than MMG and EMG, it is advised to fix the fingers and the forearm when the $\mathrm{m}$. adductor policies is used for AMG monitoring.

Details about the used of AMG for research purpose are summarized in the last update of the guidelines for good clinical research practice in pharmacodynamic studies of neuromuscular blocking agents [15]. 


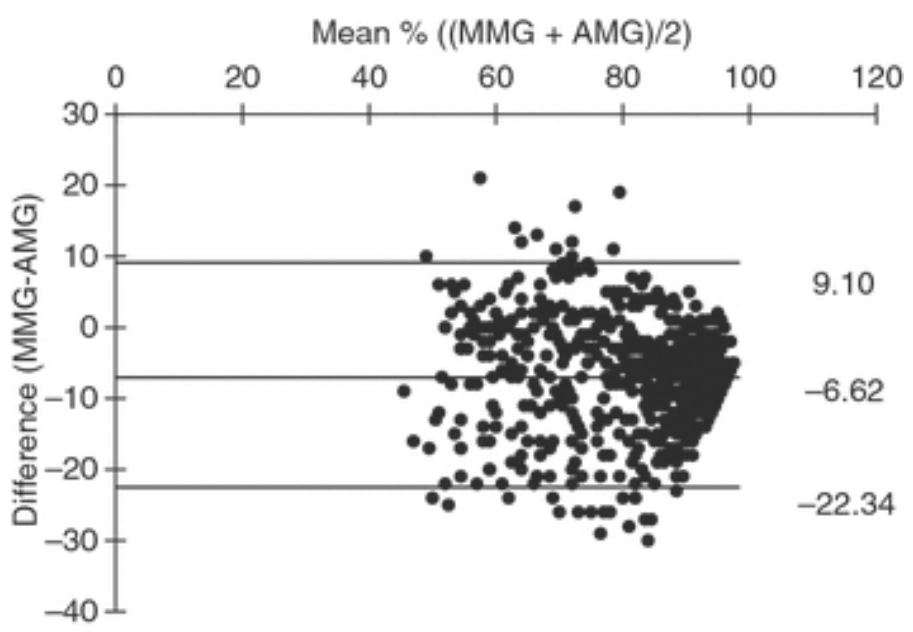

Figure 3. (AMG) and (MMG) with 95\% limits of agreement, adapted from reference [33].

\section{Neuromuscular monitoring \& PONV}

Several randomized and controlled clinical trials confirmed that the stimulation of the acupuncture point P6 effectively reduce the incidence of postoperative nausea and vomiting (PONV). In 2004 a systematic review including 26 trials with more than 3000 patients further confirmed this [35- 37]. The efficacy of the P6 stimulation to reduce PONV was independently of the technique chosen for its stimulation, i.e. with a classical acupuncture needle or with electropressure respectively acupressure. However, despite its proven efficacy this approach to prevent PONV never gained widespread popularity in clinical routine. It is likely that it may be difficult to assume continuous stimulation intraoperatively. However, according to a recent publication by Arnberger and colleagues things could change. Indeed, these authors reported that intraoperative P6 acupuncture point stimulation with a conventional nerve stimulator significantly reduces the incidence of PONV over $24 \mathrm{~h}$ and the efficacy of this nonpharmacological approach to PONV was similar to that of commonly used antiemetic drugs in the prevention of PONV [38]. To perform this study, the authors used a TOF-Watch S AMG monitor for the P6 stimulation, this acupuncture point being located proximal to the wrist crease between the tendons of the palmaris longus and the flexor carpi radialis muscles of the forearm and thus close to the course of the n. medianus. One might speculate whether stimulation of the P6 could allow both, assessment of neuromuscular blockade 
and prevention of PONV. Unfortunately until today only one single study evaluated the $n$. medianus as a stimulation site for neuromuscular monitoring and more comparative information about the stimulation characteristics of the P6 but also about the evaluation of the muscular response is needed [39].

Thus, before changing current practice and abandon the $\mathrm{n}$. ulnaris as reference site for neuromuscular monitoring stimulation it has to be proven that the n. medianus is also appropriate for neuromuscular monitoring [40]! 


\section{References}

1. Mencke T, Echternach M, Kleinschmidt $S$ et al. Laryngeal morbidity and quality of tracheal intubation: a randomized controlled trial. Anesthesiology 2003; 98: 1049-56.

2. Fuchs-Buder T, Tassonyi E. Magnesium sulphate enhances residual neuromuscular block induced by vecuronium. Br J Anaesth 1996; 76: 565-6.

3. Kopman AF, Klewicka MM, Neuman GG. An alternate method for estimating the doseresponse relationships of neuromuscular blocking drugs. Anesth Analg 2000; 91: 1191-7.

4. Dt. Gesellschaft für Anästhesiologie und Intensivmedizin. Stellungnahme der DGAI zu Einsatz von Succinylcholin bei Kindern. Anaesth Intensivmed 1995; 36: 31-32.

5. Dt. Gesellschaft für Anästhesiologie und Intensivmedizin.Verwendung von Succinylcholin, Aktualisierte Stellungnahme der DGAI. Anaesth Intensivmed 2002; 43: 831.

6. Sparr HJ, Beaufort TM, Fuchs-Buder T. Newer neuromuscular blocking agents: How do they compare to estabilshed agents? Drugs 2001; 61: 919-942.

7. Pedersen T, Viby-Mogensen J, Ringsted C. Anaesthetic practice and postoperative pulmonary complications. Acta Anaesthesiol Scand 1992; 36: 812-818.

8. Berg H, Roed J, Viby-Mogensen J, Mortensen CR et al. Residual neuromuscular block is a risk factor for postoperative pulmonary complications. A prospective, randomised, and blinded study of postoperative pulmonary complications after atracurium, vecuronium, and pancuronium. Acta Anaesthesiol Scand 1997; 41: 1095-1103.

9. Larsen PB, Hansen EG, Jacobsen LS et al. Intubation conditions after rocuronium or succinylcholine for rapid sequence induction with alfentanil and propofol in the emergency patient. Eur J Anaesthesiol 2005; 22: 748-753.

10. Schlaich N, Mertzlufft F, Slotész S, Fuchs-Buder T. Remifentail and propofol without muscle relaxants or with different doses of rocuronium for tracheal intubation in outpatient anaesthesia. Acta Anaesthesiol Scand 2000; 44: 720-726

11. Grayling M, Sweeny BP. Recovery from neuromuscular blockade: a survey of practice. Anaesthesia 2007; 62: 806-9.

12. Fuchs-Buder T, Fink H, Hofmockel R, Geldner G, Ulm K, Blobner M Application of neuromuscular monitoring in Germany. Anaesthesist 2008; 57: 908-14.

13. Harvey AM, Masland RL. Actions of curarizing preparations in the human. Journal of Pharmacology and Experimental Therapeutics 1941; 73: 304-11.

14. Christie TH, Churchill-Davidson HC. The St. Thomas's Hospital nerve stimulator in the diagnosis of prolonged apnoea. Lancet 1958; 1: 776.

15. Fuchs-Buder T, Claudius C, Skovgaard LT, Eriksson LI, Mirakhur RK, Viby-Mogensen J. Good clinical research practice in pharmacodynamic studies of neuromuscular blocking agents II: the Stockholm revision. Acta Anaesthesiological Scandinavica 2007; 51: 789-808.

16. Brull SJ, Silverman DG. Pulse width, stimulus intensity, electrode placement, and polarity during assessment of neuromuscular block. Anesthesiology 1995; 83: 702-9.

17. Saitoh Y, Fujii Y, Takahashi K, Makita K, Tanaka H, Amaha K. Recovery of post-tetanic count and train-of-four responses at the great toe and thumb. Anaesthesia 1998; 53: 244-8. 
18. Plaud B, Debaene B, Donati F. The corrugator supercilii, not the orbicularis oculi, reflects rocuronium neuromuscular blockade at the laryngeal adductor muscles. Anesthesiology 2001; 95: 96-101.

19. Ali HH, Utting JE, Gray C. Stimulus frequency in the detection of neuromuscular block in humans. Br J Anaesth 1970; 42: 967-78.

20 Lee CM. Train-of-4 quantitation of competitive neuromuscular block. Anesth Analg 1975; 54: 649-53.

21. Samet A, Capron F, Alla F, Meistelman C, Fuchs-Buder T. Single acceleromyographic trainof-four, 100-Hertz tetanus or double-burst stimulation: which test performs better to detect residual paralysis? Anesthesiology 2005; 102: 51-6.

22. Baurain MJ, Hennart DA, Gottschalx A, et al. Visual evaluation of residual curarisation in anesthesized patients using a one hundred-hertz, five-second tetanic stimulation at the adductor pollicis muscle. Anesth Analg 1998; 87: 185-9.

23. Viby-Mogensen J, Howardy-Hansen P, Chraemmer-Jørgensen B, Ording H, Engbaek J, Nielsen A. Posttetanic count (PTC): a new method of evaluating an intense non-depolarizing neuromuscular blockade. Anesthesiology 1981; 55: 458-61.

24. Engbaek J, Ostergaard D, Viby-Mogensen J. Double burst stimulation (DBS): a new pattern of nerve stimulation to identify residual neuromuscular block. Br J Anaesth 1989; 62: 274-8.

25. Drenk NE, Ueda N, Olsen NV, et al. Manual evaluation of residual curarization using double burst stimulation: a comparison with train of four. Anesthesiology 1989; 70: 578-81.

26. Hemmerling TM, Le N. Brief review: neuromuscular monitoring: an update for the clinician. Can J Anaesth 2007; 54: 58-72.

27. Naguib M, Kopmann AF, Ensor JE. Neuromuscular monitoring and postoperative residual curarization: a meta-analysis. Br J Anaesth 2007; 93: 302-16.

28. Viby-Mogensen J, Claudius C, Eriksson LI. Neuromuscular monitoring and postoperative residual curarization. Br J Anaesth 2007; 99: 297.

29. Claudius C, Viby-Mogensen J. Acceleromyography for use in scientific and clinical practice: a systematic review of the evidence. Anesthesiology 2008; 108: 1117-40.

30. Baillard C, Clec'h J, Catineau J, et al. Postoperative neuromuscular block: a survey of management. Br J Anaesth 2005; 95: 622-6.

31. Sundman E, Witt H, Olsson R, Ekberg O, Kuylenstierna R, Eriksson LI. The incidence and mechanisms of pharyngeal and upper esophageal dysfunction in partially paralyzed humans: pharyngeal videoradiography and simultaneous manometry after atracurium. Anesthesiology 2000; 92: 977-84.

32. Capron F, Alla F, Hottier C, Meistelman C, Fuchs-Buder T. Can acceleromyography detect low levels of residual paralysis? A probability approach to detect a mechanomyographic trainof-four ratio of 0.9. Anesthesiology 2004; 100: 1119-24.

33. Kopman AF. Normalization of the acceleromyographic train-of-four. Acta Anaesthesiol Scand 2005; 49: 1575-6.

34. Suzuki T, Fukano N, Kitajima O, Saeki S, Ogawa S. Normalization of acceleromyographic train-of-four ratio by baseline value for detecting residual neuromuscular block. Br J Anaesth 2006; 96: 44-7. 
35. Dundee JW, Ghaly RG, Bill KM, Chestnutt WN, Fitzpatrick KT, Lynas AG. Effect of stimulation of the P6 antiemetic point on postoperative nausea and vomiting. Br J Anaesth 1989; 63: 612-8.

36. Chernyak GV, Sessler DI. Perioperative acupuncture and related techniques. Anesthesiology 2005; 102: 1031-49.

37. Lee A, Done M. Stimulation of the wrist acupuncture point - for preventing postoperative nausea and vomiting. Cochrane Database Syst Rev 2004; 3/CD003281.

38. Arnberger M, Stadelmann K, Alischer P, et al. Monitoring of the neuromuscular blockade at the P6 acupuncture point reduces the incidence of postoperative nausea and vomiting. Anesthesiology 2007; 107: 903-8.

39. Lam HS, Cass NM, Ng KC. Electromyographic monitoring of neuromuscular block. Br J Anaesth 1981; 53: 1351-6.

40. Fuchs-Buder T, Meistelman C. From Chinese traditional medicine to neuromuscular monitoring. Ann Fr Anesth Reanim 2008; 27: 461-2. 



\section{Chapter 3}

\section{Pretreatment before succinylcholine for outpatient anesthesia}

Thomas Mencke, Jan-Uwe Schreiber, Christine Becker, Marion Bolte, Thomas Fuchs-Buder. Anesthesia \& Analgesia 2002; 94: 573-76 


\begin{abstract}
This study aims to evaluate whether precurarization reduces the incidence or the severity of myalgia after succinylcholine in outpatient anesthesia. To this end, 120 patients undergoing ambulatory knee arthroscopy were randomized as follows: Group A: pretreatment with rocuronium 0.06 mg kg${ }^{-1}, 4$ min later succinylcholine $1.5 \mathrm{mg} \mathrm{kg}^{-1}$; Group B: pretreatment with saline, 4 min later succinylcholine $1.5 \mathrm{mg} \mathrm{kg}^{-1}$; Group $\mathrm{C}$ (control): pretreatment with saline, 4 min later rocuronium $0.6 \mathrm{mg} \mathrm{kg}^{-1}$. Three min after pretreatment, the patients were asked for signs of muscle weakness. After induction of anesthesia the following parameters were assessed: incidence and severity of fasciculations and myalgia and cardiac side effects. Postoperative care and pain management were standardized. The incidence and severity of postoperative myalgias did not differ significantly between the three treatment groups; the overall incidence in the groups A, B and C was 25,30 and $17.5 \%$, respectively. Pretreatment with rocuronium (group A) led to signs of muscle weakness compared with the other two groups (B and C): 36 patients (90\%) vs 9 patients $(22.5 \%)$ and 6 patients $(15 \%)$, respectively; $\mathrm{p}<0.001$.
\end{abstract}

\title{
Implications
}

This study demonstrated that pretreatment of succinylcholine with rocuronium failed to decrease the incidence or the severity of postoperative myalgia. However, in most patients, pretreatment was associated with muscle weakness before loss of consciousness. Thus, there is no convincing evidence supporting routine pretreatment with succinylcholine. 


\section{Introduction}

Succinylcholine is a popular muscle relaxant for ambulatory anesthesia [1]. Unfortunately, postoperative myalgia (POM) may frequently occur after the use of succinylcholine [2-7] and this myalgia may be particularly troublesome in outpatients $[3,5,6]$. Although pretreatment with succinylcholine with nondepolarizing myorelaxants seems to be effective in decreasing muscle fasciculation, its effectiveness in reducing POM is controversial $[5,6]$. Moreover, pretreatment may produce muscle weakness preceding loss of consciousness [8]. Interestingly, increasing evidence suggests that POM is multifactorial in its origin, with succinylcholine being only one contributing factor $[3,5,9,10]$. Therefore, it is of clinical relevance in the context of ambulatory anesthesia to quantify the specific contribution of succinylcholine on POM, thus allowing clinicians to decide whether strategies to prevent succinylcholine-induced myalgia pretreatment are worth their side effects. To this end, this study was designed to compare the incidence and severity of POM after succinylcholine-with and without pretreatment-with those observed in a control group not receiving succinylcholine but using a nondepolarizing myorelaxant. Moreover, the side effects of pretreatment were also systematically assessed.

\section{Methods}

After obtaining approval from the Institutional Ethics Committee and written informed consent, we studied 120 adult, ASA physical status I or II patients, undergoing ambulatory knee arthroscopy under general anesthesia. Pregnant patients, patients with neuromuscular disease or medications known to interact with neuromuscular function were excluded.

Patients were randomly assigned to one of three groups ( $n=40$ for each) by random number: Group A: rocuronium $0.06 \mathrm{mg} \mathrm{kg}^{-1}$ and 4 min later succinylcholine $1.5 \mathrm{mg} \mathrm{kg}^{-1}$; Group B: saline 4 min before succinylcholine $1.5 \mathrm{mg} \mathrm{kg}^{-1}$; and Group C (control): saline 4 min before rocuronium $0.6 \mathrm{mg} \mathrm{kg}^{-1}$. Pretreatment was administered in a double-blinded manner, and syringes were adjusted to a 3 -mL volume. One hour before arrival in the operating room, patients were premedicated with midazolam $7.5 \mathrm{mg}$ orally. The induction regimen was standardized for all groups as follows. At time 0 , injection of fentanyl $1-2 \mu \mathrm{g} \mathrm{kg}^{-1}$ and the pretreatment regimen according to the patient's group; 4 min later, anesthesia was induced with thiopentone $4-7 \mathrm{mg} \mathrm{kg}^{-1} \mathrm{IV}$ and succinylcholine 
$1.5 \mathrm{mg} \mathrm{kg}^{-1}$ (Group A and B) or rocuronium $0.6 \mathrm{mg} \mathrm{kg}^{-1}$ (Group C); $60 \mathrm{~s}$ later, the patient's trachea was intubated. Afterward, patients received a diclofenac suppository $100 \mathrm{mg}$. Anesthesia was maintained with remifentanil $0.25 \mu \mathrm{g} \cdot \mathrm{kg}^{-1}$ - $\min ^{-1}$ and desflurane $2 \%-3 \%$ in $\mathrm{O}_{2} /$ air; 15 min before the end of surgery, patients received $1.0 \mathrm{~g}$ metamizol as a short infusion and a bolus of piritramid $3.0 \mathrm{mg}$ IV. For the first postoperative hour, patients received piritramid $3.0 \mathrm{mg}$ IV, if requested.

An investigator blinded to the patient's group assignment assessed the following variables:

Fasciculation: recorded according to a 4-point rating scale (6): $0=$ absent (no fasciculation), $1=$ mild (fine fasciculation of the eyes, face, neck, or fingers but without limb movement), 2 = moderate (fasciculation involving limbs and/or trunk), 3 = severe (fasciculation with movement of one or more limbs and/or movements requiring forceful retention).

Muscle weakness: patients were asked 3 min after injection of the pretreatment whether they had one or more of the following symptoms: diplopia, heavy eyelids, misarticulation (i.e., "voice disorder"), difficulty in swallowing, or dyspnea. The severity of muscle weakness was defined as the number of these symptoms $(0-5)$ mentioned by the patients.

The incidence of bradycardia (decrease of heart rate of at least $20 \%$ or heart rate $<60 / \mathrm{min}$ ) and irregular rhythm were assessed after the intubating dose of the myorelaxant.

Severity and intensity of POM: an investigator unaware whether patients fasciculated asked them specific questions $1 \mathrm{~h}$ and $24 \mathrm{~h}$ after surgery [11]; see Appendix.

Comparisons among groups were performed by using Fisher's exact test, or the Kruskal-Wallis analysis of variance test, followed by the Duncan's post test (versus Control group) or Dunn's post test (pairwise comparison) as appropriate. Demographic data were analyzed by using the Mann-Whitney $U$-test. Results were presented as mean (SD or percentage) or as median (25th and 75th percentiles). Results were considered statistically significant at $P<0.05$. Samplesize estimation was based on the results of a meta-analysis [4]. 


\section{Results}

Patient characteristics and surgical duration did not differ among groups (Table 1). Six patients in Group A, 3 in Group B, and 4 in Group C received a bolus of $3 \mathrm{mg}$ of piritramid IV in the postanesthesia care unit (not significant).

The incidence and the severity of myalgias did not differ among groups (Table 2).

The incidence and severity of muscle fasciculation were significantly reduced by pretreatment with succinylcholine with rocuronium instead of saline (2.5\% versus $80 \%$ Group A versus B; $P<0.001)$. Fasciculations were not observed when succinylcholine was avoided (Group C). In the 120 patients studied, there was no correlation between the fasciculation score and POM.

Table 1. Patient Characteristics and Incidence of Patients Requesting Analgesics (Piritramide 3.0 $\mathrm{mg}$ ) in the Postanesthesia Recovery Room (PACU)

\begin{tabular}{llll}
\hline & $\begin{array}{l}\text { Group A } \\
\text { Pretreatment with } \\
\text { rocuronium } \\
\mathrm{n}=40\end{array}$ & $\begin{array}{l}\text { Group B } \\
\text { Pretreatment with } \\
\text { saline } \\
\mathrm{n}=40\end{array}$ & $\begin{array}{l}\text { Group C } \\
\text { Rocuronium } \\
0.6 \mathrm{mg} / \mathrm{kg}\end{array}$ \\
$\mathrm{n}=40$
\end{tabular}

Values are mean $\pm S D$; Values are numbers (patients requiring piritramide).

Pretreatment with rocuronium (Group A) was associated with a significantly more frequent incidence of signs of muscle weakness compared with both groups pretreated with saline, i.e., Group B and C ( $90 \%$ versus $22.5 \%$ versus $15 \%$, respectively; $P<0.001)$. In Group A, the severity of muscle weakness was also significantly increased (Table 3).

After succinylcholine administration, bradycardia requiring atropine IV occurred in six patients (three in each group, A and B). 
Table 2. Incidence, Severity, and Localization of Myalgia

\begin{tabular}{|c|c|c|c|}
\hline Pretreatment & Group A $(n=40)$ & Group B $(n=40)$ & Group C $(n=40)$ \\
\hline Muscle & Rocuronium & Saline $0.9 \%$, & Saline $0.9 \%$ \\
\hline \multirow{2}{*}{ Relaxant } & $0.06 \mathrm{mg} / \mathrm{kg}$ & Succinylcholine & Rocuronium \\
\hline & $\begin{array}{l}\text { Succinylcholine } 1.5 \\
\mathrm{mg} / \mathrm{kg}\end{array}$ & $1.5 \mathrm{mg} / \mathrm{kg}$ & $0.6 \mathrm{mg} / \mathrm{kg}$ \\
\hline \multicolumn{4}{|c|}{ Myalgia in PACU } \\
\hline Incidence & $4(10)$ & $2(5)$ & $2(5)$ \\
\hline Severity & $0(0-1)$ & $0(0-1)$ & $0(0-1)$ \\
\hline \multicolumn{4}{|c|}{ Myalgia at $24 \mathrm{~h}$} \\
\hline Incidence & $7(17.5)$ & $11(27.5)$ & $7(17.5)$ \\
\hline Severity & $0(0-2)$ & $0(0-3)$ & $0(0-3)$ \\
\hline \multicolumn{4}{|c|}{ Overall myalgia } \\
\hline Incidence & $10(25)$ & $12(30)$ & $7(17.5)$ \\
\hline \multicolumn{4}{|l|}{ Localization } \\
\hline Neck & 5 & 6 & 4 \\
\hline Shoulder & 2 & 6 & 5 \\
\hline Throat & 4 & 3 & 3 \\
\hline Other & 4 & 6 & 4 \\
\hline
\end{tabular}

Incidence of myalgia = number (percentage) of patients; Severity of myalgia = median (range) according to a 4-point rating scale (11): $0=$ none, 1=slight, $2=$ moderate, $3=$ severe.; PACU = Postanesthesia Care Unit

Table 3. Incidence, Symptoms, and Severity of Muscle Weakness After Pretreatment

\begin{tabular}{|c|c|c|c|}
\hline Pretreatment & Group A $(n=40)$ & Group B $(n=40)$ & Group C $(n=40)$ Saline \\
\hline Muscle & Rocuronium & Saline $0.9 \%$, & $0.9 \%$ \\
\hline \multirow[t]{2}{*}{ Relaxant } & $0.06 \mathrm{mg} / \mathrm{kg}$ & Succinylcholine & Rocuronium \\
\hline & $\begin{array}{l}\text { Succinylcholine } 1.5 \\
\mathrm{mg} / \mathrm{kg}\end{array}$ & $1.5 \mathrm{mg} / \mathrm{kg}$ & $0.6 \mathrm{mg} / \mathrm{kg}$ \\
\hline Incidence & $36(90)^{*}$ & $9(22.5)$ & $6(15)$ \\
\hline \multicolumn{4}{|l|}{ Symptoms } \\
\hline Heavy eyelids & $31^{*}$ & 7 & 6 \\
\hline Diplopia & $18^{*}$ & 3 & 2 \\
\hline Voice disorder & $6^{*}$ & 0 & 0 \\
\hline Dyspnea & 3 & 1 & 0 \\
\hline Swallowing difficulty & $8^{*}$ & 1 & 0 \\
\hline \multicolumn{4}{|l|}{ Severity } \\
\hline Once & $13^{*}$ & 6 & 4 \\
\hline Twice & $16^{*}$ & 3 & 2 \\
\hline Three or more & $7^{*}$ & 0 & 0 \\
\hline
\end{tabular}

Values are numbers (percentage). Severity $=$ number of paralytic symptoms $(0-5)$ presented ${ }^{*} \mathrm{P}<0.001$ compared with Group B or C. 


\section{Discussion}

Increasing evidence suggests that eliminating succinylcholine may not eliminate POM in outpatients. Pretreatment with different nondepolarizing myorelaxants did not affect the incidence of succinylcholine-induced myalgia [6]. Substituting vecuronium for succinylcholine failed to decrease the incidence of POM after outpatient laparoscopy and similar findings were reported for atracurium $[3,5,10]$. To assess the specific contribution of succinylcholine on POM in outpatients, we standardized the perioperative management, and the type of surgery was uniform (all patients underwent ambulatory knee arthroscopy). Thus, anesthesia- and surgery-related factors contributing to POM were controlled; demographic data were also comparable among groups (Table 1). In this clinical setting, the incidence and the severity of POM did not differ whether 2xED95 rocuronium or succinylcholine-with or without pretreatment-was used to facilitate intubation (Table 2). These observations further support the claim that there may be a baseline incidence of POM in outpatients that is unrelated to the choice of muscle relaxant $[3,5,9,10]$. Pretreatment of succinylcholine, however, led to muscle weakness in most patients (Table 3). Whereas Martin et al. [8] reported a similarly frequent rate of muscle weakness after pretreatment, some other studies observed those symptoms only rarely [6,9]. This discrepancy may be explained by the manner in which side effects were assessed. Similarly to Martin et al., we asked all patients systematically for the occurrence of weakness symptoms. Most studies reporting an infrequent incidence assessed weakness by observation. However, diplopia or heavy eyelids may be difficult to quantify by observation, thus leading to an underestimation of their incidence. Surprisingly, some patients being pretreated with saline (Groups B and C) also complained of signs of muscle weakness. This may be related to the prior administration of fentanyl because drowsiness and dizziness were reported after opioids, and some patients may have interpreted these symptoms as weakness [12].

A significant limitation of this study is that POM was assessed only up to 24 h. However, it has been reported that $92 \%$ of patients who complained of POM reported it within 24 hours after surgery. Another study reported no difference in the incidence 24 versus 48 hours after surgery [13,14]. Therefore, we expect that our methodology would have identified most cases of severe POM.

In conclusion, in the present study, pretreatment with rocuronium failed to decrease the incidence or severity of POM. Pretreatment, however, was regularly associated with muscle weakness before loss of consciousness. In light of these 
results, there is no convincing evidence supporting routine pretreatment with succinylcholine for outpatients. 


\section{References}

1. Tang J, Joshi GP, White PF. Comparison of rocuronium and mivacurium to succinylcholine during outpatient laparoscopic surgery. Anesth Analg 1996; 82: 994-8.

2. Churchill-Davidson HC. Suxamethonium (succinylcholine) chloride and muscle pains. BMJ 1954; 1: 74-5.

3. Zahl K, Apfelbaum JL. Muscle pain after outpatient laparoscopy despite the substitution of vecuronium for succinylcholine. Anesthesiology 1989; 70: 408-11.

4. Pace N. Prevention of succinylcholine myalgias: a meta-analysis. Anesth Analg 1990; 70: 477-83.

5. Smith I, Ding Y, White PF. Muscle pain after outpatient laparoscopy: influence of propofol versus thiopental and enflurane. Anesth Analg 1993; 76: 1181-4.

6. Joshi GP, Hailey A, Cross S, et al. Effects of pretreatment with cisatracurium, rocuronium, and d-tubocurarine on succinylcholine-induced fasciculations and myalgia: a comparison with placebo. J Clin Anesth 1999; 11: 641-5.

7. Wong SF, Chung F. Succinylcholine-associated postoperative myalgia. Anaesthesia 2000; 55: $144-52$.

8. Martin R, Carrier J, Pirlet M, et al. Rocuronium is the best non-depolarizing relaxant to prevent succinylcholine fasciculations and myalgia. Can J Anaesth 1998; 45: 521-5.

9. Mikat-Stevens M, Sukhani R, Pappas AL, et al. Is succinylcholine after preteatment with dtubocurarine and lidocaine contraindicated for outpatient anesthesia? Anesth Analg 2000; 91: 312-6.

10. Trepanier CA, Brosseau L, Lacertel L. Myalgia in outpatient surgery: a comparison of atracurium and succinylcholine. Can Anaesth Soc J 1988; 35: 225-9.

11. White DC. Observations on prevention of muscle pain after suxamethonium. Br J Anaesth 1962; 34: 332-5.

12. Smith LA, Carroll D, Edwards JE, et al. Single-dose of ketorolac and pethidine in acute postoperative pain: systematic review with meta-analysis. Br J Anaesth 2000; 84: 48-58.

13. Erkola O. Effects of precurarisation on suxamethonium-induced postoperative myalgia during the first trimester of pregnancy. Acta Anaesthesiol Scand 1990; 34: 63-7.

14. Maddineni R, Mirakhur RK, Copper AR. Myalgia and biochemical changes following suxamethonium after induction of anaesthesia with thiopentone or propofol. Anaesthesia 1993; 48: 626-8. 


\section{Appendix: Assessment of postoperative myalgia}

Do you have any pains and aches or stiffness in your muscles other than the knee wherein the arthroscopy was performed?

If the answer was no, myalgia was graded $0=$ none (no pain); if the answer was yes, the location (i.e., neck, shoulder, arm, throat, abdomen, buttocks), the severity of pain, and the necessity for pain medication were recorded:

A: If the pain was confined to one location, myalgia was graded $1=$ slight (pain confirmed to one site but causing no disability).

B: If the pain was affecting more than one location, myalgia was graded $2=$ moderate or $3=$ severe.

Does the muscle pain restrict your normal activity? Restriction of normal activity was assessed as follows: Can you get out of bed? Are you able to turn your head? Can you cough without distress or pain?

A: If the answer was yes, myalgia was graded $2=$ moderate (pain affecting more than one site but causing no disability).

B: If one of these questions was answered with no, myalgia was graded $3=$ severe (pain affecting more than one site and causing disability). 


\section{Chapter 4}

\section{Postoperative myalgia after succinylcholine}

No evidence for an inflammatory origin

Jan-Uwe Schreiber, Thomas Mencke, Andreas Biedler, Oliver Fürst, Stefan Kleinschmidt, Heiko Buchinger, Thomas Fuchs-Buder

Anesthesia \& Analgesia 2003; 96:1640-44 


\begin{abstract}
A common side effect associated with succinylcholine is postoperative myalgia. The pathogenesis of this myalgia is still unclear; inflammation as a cause has been suggested but without convincing evidence. The present study was designed to investigate whether an inflammatory reaction contributes to this myalgia. The incidence and severity of succinylcholine-associated myalgia was determined in 64 patients pretreated with saline or dexamethasone prior succinylcholine $(n=32$ for each). Incidence and severity of myalgia did not differ significantly between the two groups: 15 patients in the dexamethasone group complained of myalgia, compared to 18 patients in the saline group, and severe myalgia was reported by 5 patients and 3 patients, respectively (n.s.). At 48 hours postoperatively 12 patients in both groups still suffered from myalgia; n.s. In addition, interleukin-6 (IL-6) as an early marker of inflammation was assessed in a subgroup of 10 patients pretreated with saline. We found an increase of IL- 6 for only three patients but only one patient reported myalgia; no relationship between myalgia and the increase of IL- 6 was found. In conclusion, there is no evidence for an inflammatory origin of succinylcholine-associated myalgia.
\end{abstract}

\title{
Implications
}

Administration of dexamethasone before succinylcholine was not effective in decreasing the incidence or the severity of succinylcholine-induced postoperative myalgia. Furthermore, there was no significant relationship between postoperative myalgia and time course of interleukin-6 concentrations, a marker of inflammation. Pretreatment with dexamethasone is not justified to prevent postoperative myalgia after succinylcholine. 


\section{Introduction}

A common side effect associated with succinylcholine is postoperative myalgia (POM) [1]. The pathogenesis of this myalgia is still unclear but pretreatment with non-depolarizing neuromuscular blockers apparently fails to decrease the incidence or intensity of POM [2-5]. Interestingly, POM is clinically similar to a well known phenomenon following physical exertion, that is, delayed onset muscular soreness [6]. A recent study in sports medicine found an increase of inflammatory variables such as interleukin-6 (IL-6) in direct correlation to the incidence and severity of muscle soreness after unaccustomed muscular stress [7]. Inflammation as a cause for succinylcholine-associated myalgia has been also suggested by several authors but without convincing evidence [8-12].

The present study was designed to investigate whether an inflammatory reaction contributes to POM. The incidence and severity of POM in patients pretreated with saline or dexamethasone prior to succinylcholine was determined. Dexamethasone is a glucocorticoid with a powerful anti-inflammatory potency. In addition, in a subgroup receiving succinylcholine pretreated with saline, interleukin- 6 concentrations as a marker of inflammation were determined.

\section{Material and Methods}

After obtaining approval from the institutional ethics committee and informed consent, we included 64 adult patients (ASA physical status I-II) undergoing elective ENT-surgery. Exclusion criteria were: Inflammatory disease, obesity (body mass index $>30$ ), diabetes, and intake of steroids and non-steroidal antiflammatory drugs (NSAID). During the premedication visit, a postoperative pain questionaire and the system of numeric analogue scale (NAS) for verbal pain and stiffness rating were discussed with the included probands [2]; Appendix A. To simplify data analysis the 11 muscle groups were divided in three regions (head/neck/shoulder, trunk, and limbs), myalgias were graded as none, mild (NAS 1-3), moderate (NAS 4-6), or severe (NAS 7-10). The highest rating of pain in this three regions determined the severity of myalgia.

All patients received midazolam $7.5 \mathrm{mg}$ orally for premedication. Before induction of anesthesia, two groups were randomized receiving either dexamethasone $8 \mathrm{mg}$ iv (DEX group) or saline iv (SAL group). 3 minutes later, a continuous infusion of remifentanil $0.25 \mu \mathrm{g} \mathrm{kg}^{-1} \mathrm{~min}^{-1}$ followed by thiopental 
$5-7 \mathrm{mg} \mathrm{kg}^{-1}$ iv, and succinylcholine $1.5 \mathrm{mg} \mathrm{kg}^{-1}$ iv, 60 s later, tracheal intubation was performed. Fasciculations were evaluated as follows [5]: None $=$ absent, Mild = fine fasciculations of the eyes, face, neck, or fingers but without limb movement, Moderate $=$ fasciculations involving limbs and/or trunk, Severe $=$ fasciculations with movement of one or more limbs and/or movements requiring forceful retention. Anesthesia was maintained with remifentanil $0.15-0.25$ $\mu \mathrm{g} \mathrm{kg}{ }^{-1} \mathrm{~min}^{-1}$ and 0.5 minimal alveolar concentration isoflurane. Twenty minutes before the expected end of surgery, all patients received piritramide $3 \mathrm{mg}$ $\mathrm{IV}$, which is a synthetic opioid with pharmacodynamic properties similar to morphine $[13,14]$. After surgery piritramide $0.05 \mathrm{mg} \mathrm{kg}^{-1}$ iv was given by request for the first 24 hours, and thereafter also diclofenac.

All patients were visited postoperatively for four times (6h, 24h, 48h, 72h) on the ward by an investigator blinded to the group assignment. Besides the number of patients with POM and severity of POM, the cumulative incidence (total number of episodes of myalgia during the first $72 \mathrm{~h}$ ) was determined. Duration of anesthesia and doses of additional taken analgetic drugs because of muscular pain were documented.

From ten patients of the SAL group, who underwent an additional randomization, blood samples for the assay of interleukin- 6 were taken. Samples were obtained before induction, twenty minutes after induction, at the end of anesthesia, 6 and 24 hours after the end of anesthesia. Blood samples were drawn in EDTA-tubes and kept on melting ice until seperation of plasma by centrifugation. After centrifugation plasma was aspirated in 1-mL aliqouts and stored at $-70^{\circ} \mathrm{C}$ for later analysis. IL- 6 concentrations were determined with a commercially available enzyme-linked immunosorbent assay (ELISA)-Kit (Biosource Europe SA, Nivelles, Belgium. Detection limit: $2 \mathrm{pg} \mathrm{ml}^{-1}$ ).

All data were presented as mean $( \pm S D)$. For statistical analysis Fisher's exact test or Chi-Square-Test and t-test for unpaired groups were used. Demographic data were compared with Mann-Whitney-U-test. Numbers-needed-totreat (NNT) were calculated [15]. A positive NNT indicated how many patients had to be exposed to the intervention (i.e. pretreatment with dexamethasone) in order to prevent one particular event (i.e. POM) in one patient. According to pre-set criteria a NNT between 1 and 5 was considered as clinically relevant. A P Value of $<0.05$ was considered significant. The estimation of the sample size was based on the results of the study of Naguib and co-workers [8]. For an $80 \%$ power to detect a 55\% difference in the incidence of myalgia 
between the groups with an $\alpha=0.05,62$ patients were needed. We enrolled 64 patients, i.e. 32 patients in each group, if not all patients completed the study.

\section{Results}

Groups were comparable in age, weight, height, and sex distribution. Also duration of anesthesia did not differ significantly (Table 1). Analgesic requirements were comparable between the two groups.

Table 1. Demographic data

\begin{tabular}{llll}
\hline & DEX $(\mathrm{n}=32)$ & SAL $(\mathrm{n}=32)$ & $P$ \\
\hline Age $(\mathrm{y})$ & $38.2( \pm 13.9)$ & $37.8( \pm 12.1)$ & NS \\
Gender $(\mathrm{M} / \mathrm{F})$ & $23 / 9$ & $21 / 11$ & NS \\
Height $(\mathrm{cm})$ & $174.4( \pm 9.5)$ & $175.8( \pm 9.1)$ & NS \\
Weight $(\mathrm{kg})$ & $77.3( \pm 12.3)$ & $76.9( \pm 13.3)$ & NS \\
Duration of Anesthesia $(\min )$ & $93.3( \pm 30.3)$ & $97.9( \pm 40.9)$ & NS \\
\hline
\end{tabular}

Incidence and severity of myalgia did not differ significantly between the two groups: At the assessment of myalgia, i.e. 6, 24, 48, and 72 hours postoperatively, 15 patients in the DEX group complained 25 times of myalgia, compared to 18 patients with 31 episodes of myalgia in the SAL group (not significant). Severe myalgia was reported by 5 patients in the DEX group versus 3 patients in the SAL group and the study groups did not differ in the localization of myalgia (Table 2). At 48 hours after surgery 12 patients in both groups still suffered from myalgia; (not significant). To treat POM with dexamethasone, a NNT of 11 (confidence interval, 6.7 - -3) was calculated. We found an increase of IL- 6 more than the lower limit of detection for only three patients but only one patient reported myalgia. No relationship between POM and the increase of IL-6 was found (Table 3). 
Table 2. Incidence, severity, and localisation of postoperative myalgia.

\begin{tabular}{llll}
\hline & DEX $(\mathrm{n}=32)$ & SAL $(\mathrm{n}=32)$ & $P$ \\
\hline Myalgia at 6 h & & & \\
Incidence & 1 & 4 & NS \\
Severity\# & 6 & $4.3(3-5)$ & NS
\end{tabular}

Myalgia at $24 \mathrm{~h}$

Incidence

Severity\#

Myalgia at $48 \mathrm{~h}$

Incidence

Severity\#
11

$5.4(2-10)$

12

$3.7(1-6)$

NS

NS

NS

$4.7(2-8)$

$4.1(1-8)$

NS

Myalgia at $72 \mathrm{~h}$

Incidence

Severity\#

1

3

4

3,5 (1-9)

NS

NS

Overall Incidence

Patients w. myalgia $\$$

$15(47 \%)$

18 (56\%)

NS

Cumul. incidence+

$25(20 \%)$

$31(24 \%)$

NS

Localisation*

Neck/Shoulder

10

15

8

Trunk

12

4

2

NS

NS

NS

$\$$ Number of patients who had at least one episode of myalgia during follow-up. + Count of episodes with myalgia during follow-up. \# Median (range) of highest ranking of severity according to NAS. *Multiple notifications were allowed. 
Table 3. List of SAL subgroup with additional IL-6 quantification.

\begin{tabular}{lllll}
\hline Patient-No. & Gender & Myalgia & Fasciculations+ & IL-6 Conc. \\
\hline 1 & M & None & Moderate & n.d. \\
2 & M & Moderate & Severe & n.d. \\
3 & M & Mild & Severe & n.d. \\
4 & M & None & Mild & n.d. \\
5 & M & None & Moderate & n.d. \\
6 & M & None & Mild & 72 \\
7 & M & None & Moderate & 32 \\
8 & M & None & Moderate & n.d. \\
9 & F & Moderate & Mild & n.d. \\
10 & F & Moderate & Mild & 87 \\
\hline
\end{tabular}

*post-induction concentration maximum in pg ml-1 / "n.d." = not detectable, IL-6 concentration all times less than $2 \mathrm{pg} \mathrm{ml-1}$

+ Grading of fasciculations (5): None = absent, Mild = fine fasciculations of the eyes, face, neck, or fingers but without limb movement, Moderate $=$ fasciculations involving limbs and/or trunk, Severe $=$ fasciculations with movement of one or more limbs and/or movements requiring forceful retention.

\section{Discussion}

POM occurs frequently after succinylcholine and is particularly troublesome in outpatients $[1,2]$. This study was designed to investigate whether inflammatory processes cause POM. Naguib et al. were first to shown that the preoperative administration of cyclo-oxygenase inhibitors, i.e. salicylates could reduce the incidence of POM [8]. Then McLaughlin et al. postulated an activation of phospholipase A2 and the synthesis of prostaglandins, both pro-inflammatory, after succinylcholine [9]. Finally, Kahraman et al. reported a significant decrease of prostaglandine E2-like activity and a reduced incidence of POM in patients pretreated with diclofenac [11]. Despite the fact that ketorolac acts in a similar way as salicylates, pretreatment with the more potent ketorolac could not decrease the incidence and severity of POM [12]. The authors speculated that the relatively short duration of action of ketorolac, which is only 6 to 8 hours, might explain this discrepancy.

To differentiate succinylcholine-induced myalgia from other causes of postoperative myalgia, perioperative management was standardized and the type of surgery was uniform (all patients underwent elective ear-nose-throat surgery). Moreover, demographic data and duration of anesthesia were also comparable 
between the groups (Table 1). Thus, anesthesia- and surgery-related factors contributing to POM were controlled. In this clinical setting, the incidence and severity of myalgia did not differ whether patients were pretreated with dexamethasone or saline before succinylcholine. Based on the results of the present study, there are several explanations why the inflammatory reaction is not the cause of succinycholine-induced myalgia: first, dexamethasone was chosen for pretreatment because it has the highest antiinflammatory activity of all adrenocortical steroids and thus a much stronger potency than NSAID to reduce both the synthesis of prostaglandins and inflammatory stimulation [16]; as an effective dose for its antiinflammatory action dexamethasone $8 \mathrm{mg}$ iv has been proposed [17]. Moreover, its effective half-life of approximately 48-60 hours should cover the entire postoperative period effectively with a single dose. Thus, if an inflammatory process contributes to succinylcholine-induced myalgia, dexamethasone $8 \mathrm{mg}$ iv, should abolish it and thus reduce the intensity of POM. That hypothesis is not supported by our study (Table 2). Whether an earlier administration of dexamethasone would improve its efficacy in reducing succinylcholine-induced myalgia remains speculative. Second, interleukin-6 is a pro-inflammatory cytokine and plays a key role in human acute phase protein synthesis. It contributes to the early stages of the acute inflammatory response. The kinetics of clearance is biphasic and consists of a rapid inital elimination corresponding to a half-life of about 3 minutes and of a second lower decrease corresponding to a half life of about 55 minutes [18]. Potential cytokine sources in injured skeletal muscels include infiltrating neutrophils and monocytesmacrophages, activated fibroblasts, and stimulated endothelial cells [19]. It is upregulated by other interleukins, interferons and tumor necrosis factor $\alpha$ and reaches its maximum 6 hours after physical exercise [7]. Under physiological conditions, cytokines are undetectable or are only found in small concentrations in the blood [20]. In the present study, any inflammatory origin of succinylcholine-induced myalgia should have led to an increase in the plasma concentration of IL-6 because the influence of general anesthesia for minor surgery on IL-6 production seemed to be only minimal [20] and opioids for postoperative pain management such as piritramide apparently did not modify the cytokine response [21]. Moreover, similar to recent findings in sports medicine reporting a significant correlation between muscle soreness after muscular exertion and the plasma concentration of IL-6 $[7,19]$, this increase should be related to the severity of succinylcholine-induced myalgia. We measured the time course of IL-6 in the plasma of 10 patients from the SAL group. However, an increase in IL-6 
could only be detected in three patients, but only one of them reported myalgia; no correlation was observed between severity of POM and increase of IL-6 (Table 3).

We conclude that pretreatment with dexamethasone $8 \mathrm{mg}$ iv did not reduce succinylcholine-induced myalgia; no evidence for an inflammatory origin of POM was found. 


\section{References}

1. Pace NL. Prevention of succinylcholine myalgias: a meta-analysis. Anesth Analg 1990; 70: 477-83.

2. Mikat-Stevens M, Sukhani R, Pappas AL et al. Is succinylcholine after pretreatment with dtubocurarine and lidocaine contraindicated for outpatient anesthesia? Anesth Analg 2000; 91: 312-6.

3. Mencke T, Schreiber JU, Becker C et al. Pretreatment before succinylcholine for outpatient anesthesia? Anesth Analg 2002; 94: 573-6.

4. Mencke T, Becker C, Schreiber JU, Fuchs-Buder T. A longer pretreatment interval does not improve cisatracurium precurarization. Can J Anesth 2002; 49: 640-1.

5. Joshi GP, Hailey A, Cross S. et al. Effects of pretreatment with cisatracurium, rocuronium, and d-tubocurarine on succinylcholine-induced fasciculation and myalgia: a comparison with placebo. J Clin Anesth 1999; 11: 641-5.

6. Newnam PT, Loudon JM. Muscle pain following administration of suxamethonium: the aetiological role of muscular fitness. Br J Anaesth 1966: 38; 533-6.

7. MacIntyre DL, Sorichter S, Mair J et al. Markers of inflammation and myofibrillar proteins following eccentric exercise in humans. Eur J Appl Physiol 2001; 84: 180-6.

8. Naguib M, Farag H, Magbagbeola JAO. Effect of pretreatment with lysine acetyl salicylate on suxamethonium- induced myalgia. Br J Anaesth 1987; 59: 606-10.

9. McLoughlin C, Nesbitt GA, Howe JP. Suxamethonium induced myalgia and the effect of pre-operative administration of oral aspirin. Anaesthesia 1988; 43: 565-7.

10. McLoughlin C, Elliott P, McCarthy G, Mirakhur RK. Muscle pains and biochemical changes following suxamethonium administration after six pretreatment regimens. Anaesthesia 1992: 47: 202-6.

11. Kahraman S, Ercan S, Aypar U, Erdem K. Effect of preoperative i.m. administration of diclofenac on suxamethonium-induced myalgia. Br J Anaesth 1993; 71: 238-41.

12. Leeson-Payne CG, Nicoll JM, Hobbs GJ. Use of keterolac in the prevention of suxamethonium myalgia. Br J Anaesth 1994; 73: 788-90.

13. Kumar N, Rowbotham DJ. Piritramide. Br J Anaesth 1999; 82: 3-5.

14. Wiesner G, Gruber M, Wild K et al. Protein binding of piritramide: influence of various protein concentrations and the postoperative acute phase response. Eur J Clin Pharmacol 1999; 54: 843-5.

15. Laupacis A, Sackett DL, Roberts RS. An assessment of clinically useful measures of the consequences of treatment. N Engl J Med 1988; 318: 1728-33.

16. Horton JK, Williams AS, Smith-Phillips Z et al. Intracellular measurement of prostaglandin E2: effect of anti-inflammatory drugs on cyclooxygenase activity and prostanoid expresssion. Anal Biochem 1999; 271: 18-28.

17. Schimmer B, Parker K. Adrenocorticotropic hormone, adrenocortical steroids and their synthetic analogs, inhibitors of synthesis and actions of adrenocortical hormones. In: Hardmann EA, ed. Goodman \& Gilman's The Pharmacological Basis of Therapeutics. New York: McGraw-Hill, 1996: 1459-1485. 
18. Heinrich PC, Castell JV, Andus T. Interleukin-6 and the acute phase response. Biochem J 1990; 265: 621-36.

19. Cannon JG, St. Pierre BA. Cytokines in exertion-induced skeletal muscle injury. Mol Cell Biochem 1998; 179: 159-67.

20. Helmy SA, Al-Attiyah RJ. The effect of halothane and isoflurane on plasma cytokine levels. Anaesthesia 2000; 55: 904-10.

21. Taylor NM, Lacoumenta S, Hall GM. Fentanyl and the interleukin-6 response to surgery. Anaesthesia 1997; 52:112-5. 


\section{Appendix A; Postoperative Questionaire for myalgia study.}

Patient ID:

Date of surgery:

Type of surgery:

Follow-up: $\quad 6 \mathrm{~h} \quad 24 \mathrm{~h} \quad 48 \mathrm{~h} \quad 72 \mathrm{~h}$

1. Do you have any stiffness or soreness in your body besides headache and pain at the surgical side? yes

no

2. Have you been up? yes

no

3. Is there pain and stiffness in the muscles? yes

4. In which sites do you have the muscle pain/stiffness? Jaw

Throat

Neck__ Shoulders___ Arm___ Chest___ Abdomen___ Back__ But-

5. When did you first noticed the pain?

6. Rate the muscle stiffness/pain on score ( 0 being no pain an 10 worst pain ever) only on the sites to be painful by the patient. Jaw__ Throat_ Neck__ Shoulders___ Arm__ Chest___ Abdomen__ Back__ Buttocks__ Thighs___ Calves___ Generalized

7. What makes the muscle stiffness/pain worst? Movement___ Rest

8. Describe the muscle pain/stiffness in your (patient's) own words.

9. Do you think the muscle pain is restricting your activity? yes no

10. Is the muscle pain preventing you from getting out of bed? yes no

11. How would you rate this limitation of activity on a scale of $0-10$ ( 0 being no limitation of activity, 10 being muscle pain limiting the patient to bed all the time except for essential activity i.e., going to the bathroom.)

12. Have you ordered any extra pain medication because of the muscle pain? yes no

13. Are you taking your prescribed pain medication to help your surgical pain or your muscle pain 


\section{Chapter 5}

\section{Women report more pain on injection of a precurarization dose of rocuronium}

A randomised, prospective, placebo-controlled trial

Thomas Mencke, Jan-Uwe Schreiber, Heike Knoll, Christian Stracke, Stefan Kleinschmidt, Hauke Rensing, Malte Silomon.

Acta Anaesthesiologica Scandinavica 2004; 48:1245-48 


\begin{abstract}
Background. The purpose of this study was to investigate whether gender influences the perception of pain on injection of rocuronium.

Methods. In this prospective, placebo-controlled trial 120 patients were randomised in 4 groups to receive rocuronium $0.03 \mathrm{mg} \mathrm{kg}^{-1}$ (40 female and 40 male patients) or saline ( 20 female and 20 male patients). The incidence and severity of the injection pain after administration of the study drug was compared between female and male patients by using a numerical rating scale (0-10). Signs of local irritation, i.e. erythema and thrombophlebitis were assessed up to 48 hours after surgery.

Results. In 26 (32.5\%) of the 80 patients receiving rocuronium, pain on injection was observed. This occurred significantly more frequent in female compared with male patients: 18 (45\%) vs. 8 $(20 \%)$, respectively $(P=0.032)$. The severity was more pronounced in women than in men $(P=0.020)$. The incidence of the rocuronium-associated pain was significantly increased compared with the Saline groups $(P<0.001)$. After surgery no patient complained of any residual pain and no local signs were observed in any patient during the study period.

Conclusions. Women experienced more pain on injection of rocuronium than men, moreover this is an additional evidence for gender-related differences in pain perception. When rocuronium is used as a precurarization agent, an analgesic pretreatment (e.g. opioids) should be considered especially for female patients.
\end{abstract}

Keywords

Neuromuscular blocking drugs, rocuronium; injection, pain, pain perception; gender, sex 


\section{Introduction}

Gender differences have been identified in the perception of pain intensity and in the pharmacodynamics of anaesthetic drugs and neuromuscular blocking agents [1-4]. A previous study showed that the sensitivity of women to rocuronium was significantly higher compared with men, requiring $30 \%$ less of the drug to achieve the same degree of neuromuscular block [5]. Pain on injection is one of the main disadvantages of this drug during induction of anaesthesia [6-10]. When administered in subparalyzing doses, 50-100\% of patients reported a severe, burning pain [6,8-10]. Women have a lower pain threshold and a lower tolerance than men to most types of nociceptive stimuli $[1,11]$. However, the impact of gender on pain perception after injection of a precurarization dose of rocuronium has not been investigated to date.

Therefore, the purpose of this study was to investigate whether gender influences the perception of pain on injection of rocuronium $0.03 \mathrm{mg} \mathrm{kg}^{-1}$ (i.e. $10 \%$ of $\left.\mathrm{ED}_{95}\right)$. Thus, the incidence and severity of the injection pain between female and male patients was compared. Furthermore, we investigated the influence of the concentration of the solution of rocuronium on pain perception. Local irritations (i.e. erythema and thrombophlebitis) in the region of injection were assessed up to 48 hours after injection.

\section{Methods}

After obtaining approval from the Institutional Review Committee and written informed consent, we studied 120 patients, aged 18-70 years. The unpremedicated patients of ASA classification I or II underwent general anaesthesia for elective ear-nose-throat-surgery. Patients with analgesics, as were those with chronic pain and known allergy to the trial drug were excluded. Moreover, patients with obesity and pregnant patients were not included.

One hundred and twenty patients, i.e. 60 women and 60 men were randomised via random number draws in four groups as follows: rocuronium 0.03 $\mathrm{mg} \mathrm{kg}^{-1}$ (40 female and 40 male patients) or saline (20 female and 20 male patients). During the premedication visit, the system of numerical rating scale (NRS, $0=$ no pain, $10=$ worst pain imaginable) was explained to the patients.

On arrival in the operating room routine non-invasive monitoring was placed and the patients received two 20-gauge intravenous (IV) cannulas, one at each dorsum of the hand. Pretreatment was administered in a double-blind 
fashion and syringes were prepared by an investigator who did not participate in the evaluation of injection pain. The calculated rocuronium doses were adjusted to a volume of $5 \mathrm{ml}$ by saline, resulting in different concentrations of rocuronium in the study solution. Induction regimen was standardized as follows: At time 0 , the study drug (rocuronium or saline) according to the patient's group assignment was injected over $5 \mathrm{~s}$. Thereafter this cannula was flushed with $20 \mathrm{ml}$ saline and maintained closed; no further drugs or fluids were injected in this cannula until its removal at the post-anesthesia care unit (PACU). Three minutes after administration of the study drug, anaesthesia was induced with alfentanil 10-20 $\mu \mathrm{g} \mathrm{kg}^{-1}$, thiopentone 4-7 $\mathrm{mg} \mathrm{kg}^{-1}$ and succinylcholine $1.5 \mathrm{mg} \mathrm{kg}^{-1}$. Anaesthesia was maintained with remifentanil $0.25 \mu \mathrm{g} \mathrm{kg}^{-1} \mathrm{~min}^{-1}$ and desflurane $2-3 \%$ (end-tidal) in oxygen/air. At the end of surgery the patients were moved to the PACU.

Pain on injection of rocuronium was assessed as follows: Immediately after the end of the administration of the study drug, the patients were asked the following question: „Do you have any pain in the arm where the drug was injected?" If the answer was yes, the patients were asked to estimate the pain according to the system of the numerical rating scale (NRS, 0-10). Local signs were assessed on the arm immediately after the injection of rocuronium as well as 24 hours and 48 hours after recovery from anaesthesia as follows: Erythema = redness; Thrombosis = Hardness of the vein; Phlebitis = Tenderness on palpation of the vein; Thrombophlebitis = Tender and hard vein (12). Grading of the injection pain and the evaluation of local signs were performed by the same anaesthesiologist who was unaware of the patient's group assignment.

Statistical analysis: Statistical analysis was performed using the SigmaStat for Windows Version 2.0 statistical software (1995, Jandel corporation, USA). Demographic data were analyzed using Mann-Whitney U-test, and results are presented as median (range). Comparisons between groups were performed using the $\chi^{2}$ test, Fisher's exact test, or Kruskal-Wallis ANOVA test. Results were considered statistically significant when $P<0.05$. To evaluate a possible role of the concentration of the solution of rocuronium on the severity of pain on injection, a correlation analysis (Pearson product moment correlation test) of these two variables was performed.

The required number of patients for the Rocuronium groups (female and male groups) was calculated in expectation of $40 \%$ injection pain in the Male group and a $35 \%$ increase of the absolute risk in the Female group. For an $80 \%$ power and an $\alpha=0.05,72$ patients were needed. To compensate for 
possible drop-outs, we enrolled 80 patients, i.e. 40 women and 40 men to receive rocuronium. These patients were compared with 40 patients (20 female and 20 male) of the Saline groups (Placebo).

Obesity = defined as weight of $20 \%$ or more than the normal weight.

Normal weight $(\mathrm{kg})=$ height in $\mathrm{cm}-100$.

\section{Results}

Data from all 120 patients enrolled in this study could be analyzed without dropouts (Fig. 1). Patient characteristics and doses of rocuronium are shown in Table 1.

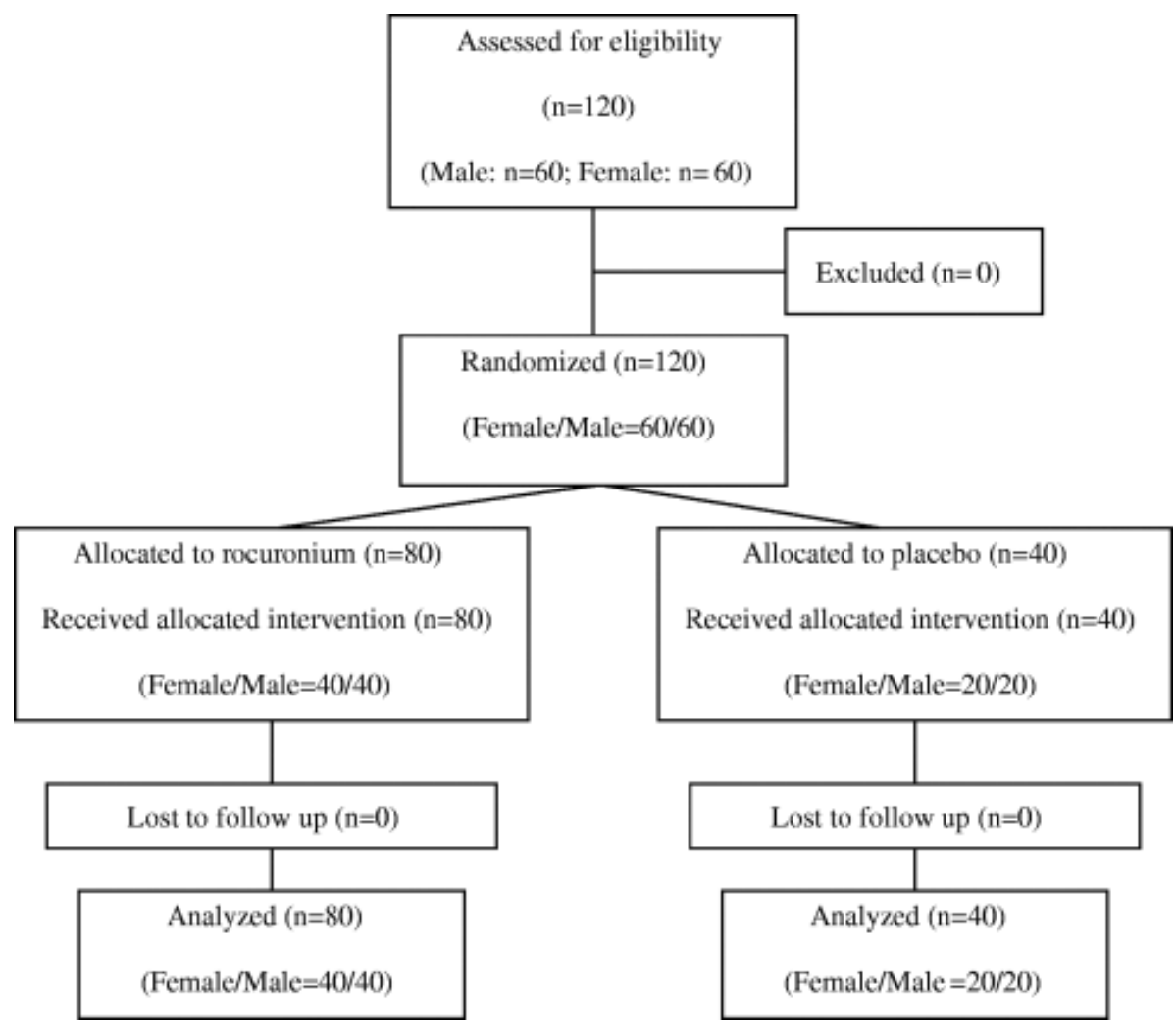

Figure 1. Flow diagram of patient distribution 
Table 1. Values are median (range). BMI = body mass index. Doses = total doses of rocuronium. Patient charateristics and doses of rocuronium.

\begin{tabular}{llll}
\hline \multicolumn{3}{l}{$\begin{array}{l}\text { Rocuronium groups } \\
\mathrm{n}=80\end{array}$} & $\begin{array}{l}\text { Male } \\
\mathrm{n}=40\end{array}$ \\
\cline { 2 - 4 } & $\begin{array}{l}\text { Female } \\
\mathrm{n}=40\end{array}$ & $36(18-68)$ & 0.112 \\
\hline Age (years) & $38(19-69)$ & $79(60-114)$ & $<0.001$ \\
Weight $(\mathrm{kg})$ & $61(46-98)$ & $176(164-192)$ & $<0.001$ \\
Height $(\mathrm{cm})$ & $165(154-182)$ & $25(19-32)$ & 0.054 \\
BMI $\left.(\mathrm{kg} \mathrm{m})^{-2}\right)$ & $23(18-31)$ & $2.3(1.8-3.4)$ & $<0.001$ \\
Doses $(\mathrm{mg})$ & $1.8(1.4-2.9)$ & &
\end{tabular}

One patient (2.5\%) of the saline groups (female group) described pain on injection of rocuronium, this was significantly decreased compared with the rocuronium groups: one $(2.5 \%)$ vs. $26(32.5 \%)$, respectively; $\mathrm{p}<0.001$. The incidence and severity of pain on injection were significantly higher in female compared with male patients, $\mathrm{p}<0.05$ (Table 2). After surgery no patient complained of any residual pain, and no erythema or thrombophlebitis were observed. There was no significant correlation between the concentration of rocuronium and pain scores (Fig 2).

Table 2. Incidence, severity, and localisation of postoperative myalgia.

\begin{tabular}{|c|c|c|c|}
\hline \multicolumn{4}{|c|}{ The incidence and severity of pain on injection. } \\
\hline & \multirow{2}{*}{\multicolumn{3}{|c|}{$\begin{array}{l}\text { Rocuronium groups } \\
\mathrm{n}=80\end{array}$}} \\
\hline & & & \\
\hline & Female & Male & $p$ \\
\hline & $\mathrm{n}=40$ & $\mathrm{n}=40$ & \\
\hline Incidence & $18(45)$ & $8(20)$ & 0.032 \\
\hline Severity & $3.0( \pm 2.9)$ & $0.5( \pm 1.0)$ & 0.020 \\
\hline Range & $0-9$ & $0-4$ & \\
\hline
\end{tabular}




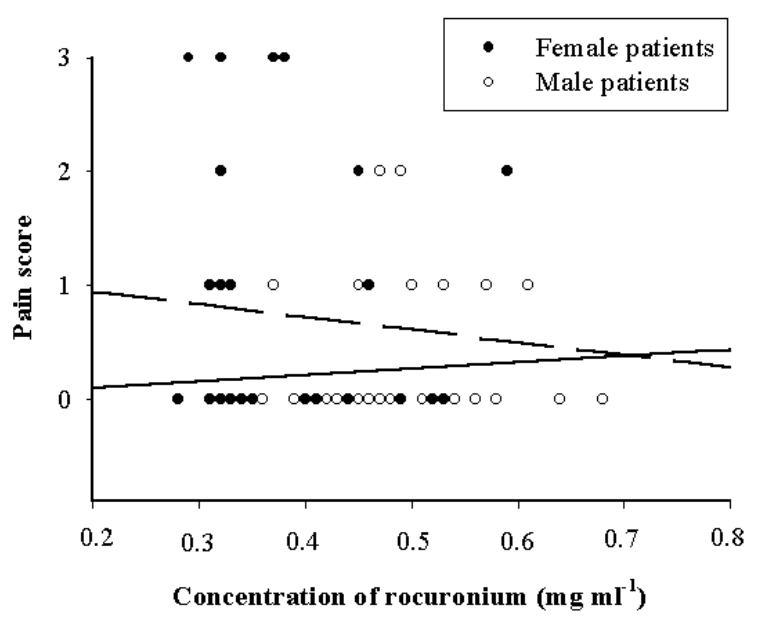

Figure 2. Correlation analysis of the applied concentrations of rocuronium and pain score; $-=$ Male group $(\mathrm{r}=0.08, \mathrm{P}=0.62)$; $--=$ Female group $(r=-0.09, P=0.56)$

\section{Discussion}

The major findings of the present study were: Women experienced more pain on injection of a precurarization dose of rocuronium than men. This is an additional evidence for sex differences in pain perception.

Rocuronium-associated side effects include pain on injection and the occurrence of sudden flexion and withdrawal movements of the wrist or arm where rocuronium is administered [6-10,13,14]. When rocuronium was injected in subparalysing doses, 50-100\% of patients reported a severe, burning pain [6, 810]. The underlying mechanism, by which rocuronium induces pain, remains still unclear. A local release of mediators $[8,15]$ or a direct activation of Cnociceptors [16] as a cause have been suggested. In the present study rocuronium was diluted with saline to an injection volume of $5.0 \mathrm{ml}$. Thus, the concentration in the solution was lower than in other studies investigating rocuronium-associated pain and therefore it might have been a weaker activator. The correlation analysis of the concentration of rocuronium and pain intensity revealed no significant relationship (Fig 2). However, the applied concentration (0.2-0.8 $\left.\mathrm{mg} \mathrm{ml}^{-1}\right)$ of the solution in the present study was lower compared to the commercial concentration of $10.0 \mathrm{mg} \mathrm{m}^{-1}$ (Fig 2). This is a limitation of 
the study, because we did not examine the higher concentration, and the range used was small.

The aim of the present study was to determine a possible gender-related difference in pain perception caused by injection of a precurarization dose of rocuronium. In fact, our data clearly demonstrate that the rocuroniumassociated pain was sex-related, with women being significantly more sensitive than men $(P<0.05)$ (Table 2$)$. The present study was designed as a placebocontrolled trial to show that the observed gender difference in pain perception was related to rocuronium; the sex-related differences did not occur among the placebo groups. Generally, women have a lower pain threshold and have a higher overall prevalence of pain than men [11]. In a previous study we demonstrated that female patients had significantly more frequent rocuroniumassociated withdrawal movements than compared with men [14]. However, these patients received an intubating dose of rocuronium $\left(0.6 \mathrm{mg} \mathrm{kg}^{-1}\right.$, i.e. $2 \mathrm{xED} 95)$ after induction of anaesthesia and therefore the injection pain could not be assessed clearly [14]. It was speculated that the spontaneous movements associated with rocuronium might be the direct consequence of pain on injection [8]. The results of the present study support this hypothesis because the differences in the incidences between female and male patients in both studies are very similar [14]. The possible mechanisms leading to higher pain scores in women as shown in the current study are not fully understood [17]. Females had lower cold pressor pain thresholds and pain tolerance levels, as well as reported greater sensory pain than males [2]. The authors suggested that females reported more negative pain experiencies than males [2]. An influence of sex hormones on the neurochemical mediation of analgesia is discussed in the literature [1]. Moreover, female patients are more sensitive than males to opioids, such as morphine [4].

Many studies have investigated different strategies to prevent the injection pain, e.g. a pretreatment with opioids like fentanyl, alfentanil, or tramadol as part of the induction technique may decrease the incidence of pain on injection $[6,13,15,18]$. When rocuronium is used as a precurarization agent, an analgesic pretreatment with opioids should be considered for female patients. In conclusion, women experienced more pain on injection of rocuronium than men, moreover this is an additional evidence for gender-related differences in pain perception. 


\section{References}

1. Giles BE, Walker JS. Gender differences in pain. Curr Opin Anaesthesiol 1999; 12: 591-5

2. Keogh E, Herdenfeld M. Gender, coping and the perception of pain. Pain 2002; 97: 195201

3. Ciccone GK, Holdcroft A. Drugs and sex differences: a review of drugs relating to anaesthesia. Br J Anaesth 1999; 82: 255-65

4. Pleym H, Spigset O, Kharasch ED, Dale O. Gender differences in drug effects: implications for anesthesiologists. Acta Anaesthesiol Scand 2003; 47: 241-59

5. Xue FS, Tong SY, Liao X, Liu JH, An G, Luo LK. Dose-response and time course of effect of rocuronium in male and female anesthetized patients. Anesth Analg 1997; 85: 667-71

6. Chiarella AB, Jolly DT, Huston CM, Clanachan AS. Comparison of four strategies to reduce pain associated with intravenous administration of rocuronium. Br J Anaesth 2003; 90: 377 9

7. Cheong KF, Wong WH. Pain on injection of rocuronium: influence of two doses of lidocaine pretreatment. Br J Anaesth 2000; 84: 106-7

8. Borgeat A, Kwiatkowski D. Spontaneous movements associated with rocuronium: is pain on injection the cause? Br J Anaesth 1997; 79: 382-3

9. Steegers MAH, Robertson EN. Pain on injection of rocuronium bromide. Anesth Analg 1996; 83: 203

10. Moorthy SS, Dierdorf SF. Pain on injection of rocuronium bromide. Anesth Analg 1995; 80: 1067

11. Cepeda MS, Carr DB. Women experience more pain and require more morphine than men to achieve a similar degree of analgesia. Anesth Analg 2003; 97: 1464-8

12. Zacharias M, Clarke SJ, Dundee JW, Johnston SB. Venous sequelae following etomidate. Br J Anaesth 1979; 51: 779-783

13. Memis D, Turan A, Karamanlioglu B, Süt N, Pamukcu Z. The prevention of pain from injection of rocuronium by ondansetron, lidocaine, tramadol, and fentanyl. Anesth Analg 2002; 94: 1517-20

14. Mencke T, Beerhalter U, Fuchs-Buder T. Spontaneous movements, local reactions and pain on injection of rocuronium. A comparison between female and male patients. Acta Anaesthesiol Scand 2001; 45: 1002-5

15. Borgeat A, Kwiatkowski D, Ruetsch YA. Spontaneous movements associated with rocuronium injection: the effects of prior administration of fentanyl. J Clin Anesth 1997; 9: 650-2

16. Blunk JA, Seifert F, Schmelz M, Reeh PW, Koppert W. Injection pain of rocuronium and vecuronium is evoked by direct activation of nociceptive nerve endings. Eur J Anaesthesiol 2003; 20: 245-53

17. Silomon M, Claus T, Huwer H, Biedler A, Larsen R, Molter G. Interpleural analgesia does not influence postthoracotomy pain. Anesth Analg 2000; 91: 44-50

18. Turan A, Memis D, Karamanlioglu B, Süt N, Pamukcu Z. The prevention of pain from injection of rocuronium by magnesium sulphate, lignocaine, sodium bicarbonate and alfentanil. Anaesth Intensive Care 2003; 31: 277-81 



\section{Chapter 6}

\section{Prevention of succinylcholine-induced fasciculation and myalgia}

A meta-analysis of randomized trials 


\begin{abstract}
Fifty-two randomized trials (5,318 patients) were included in this meta-analysis. In controls, the incidence of fasciculation was $95 \%$, and the incidence of myalgia at $24 \mathrm{~h}$ was $50 \%$. Nondepolarizing muscle relaxants, lidocaine, or magnesium prevented fasciculation (number needed to treat, 1.2-2.5). Best prevention of myalgia was with nonsteroidal antiinflammatory drugs (number needed to treat, 2.5 ) and with rocuronium or lidocaine (number needed to treat, 3 ). There was a dose-dependent risk of blurred vision, diplopia, voice disorders, and difficulty in breathing and swallowing (number needed to harm, <3.5) with muscle relaxants. There was evidence of less myalgia with $1.5 \mathrm{mg} \mathrm{kg}^{-1}$ succinylcholine (compared with $1 \mathrm{mg} \mathrm{kg}^{-1}$ ). Opioids had no impact. Succinylcholine-induced fasciculation may best be prevented with muscle relaxants, lidocaine, or magnesium. Myalgia may best be prevented with muscle relaxants, lidocaine, or nonsteroidal antiinflammatory drugs. The risk of potentially serious adverse events with muscle relaxants is not negligible. Data that allow for a risk-benefit assessment are lacking for other drugs.
\end{abstract}




\section{Introduction}

SUCCINYLCHOLINE is still the accepted standard for rapid sequence intubation [1,2]. It also seems to be a popular muscle relaxant for ambulatory anesthesia and short surgical procedures $[3,4]$. Perhaps no other drug used in anesthesia, however, is associated with a similarly high risk of complications [5]. Some complications are minor, but others are potentially life threatening. Fasciculation and myalgia are minor but frequent adverse effects of succinylcholine. Myalgia, which can be accompanied by muscle stiffness, can last for several days and can, at least in some patients, induce significant discomfort [6,7]. In 1990, a meta-analysis that included data from 45 randomized and nonrandomized trials concluded that atracurium, $d$-tubocurarine, gallamine, pancuronium, diazepam, and lidocaine all significantly decreased the frequency of myalgia by approximately $30 \%$ [8]. During the past $15 \mathrm{yr}$, many more trials that tested the efficacy of a large variety of pretreatments have been published. The aim of this quantitative systematic review was threefold: first, to update the previously published meta-analysis on the prevention of succinylcholine-related myalgia [8]; second, to include an analysis on the efficacy of pretreatments on succinylcholine-induced fasciculation; and finally, to quantify pretreatment-related adverse effects. This systematic review was performed following the Quality of Reporting of Meta-analyses (QUOROM) recommendations [9].

\section{Materials and Methods}

\section{Search Strategy}

A systematic search of the literature was performed without language restriction. We searched in MEDLINE, EMBASE, IndMED, and the Cochrane Controlled Trials Register using combinations of the free text terms succinylcholine, suxamethonium, postoperative AND pain, randomized, and myalgia. We did not use the term fasciculation because the primary aim was to study myalgia which is clinically more important. Electronic searches were conducted until February 2004 and were complemented by screening bibliographies of retrieved articles and reviews $[7,8]$. 


\section{Study Selection}

We considered published full reports of randomized controlled trials that tested the efficacy of pharmacologic regimens compared with placebo or no treatment for the prevention of succinylcholine-induced fasciculation or myalgia. Relevant trials had to report on dichotomous data on presence or absence of fasciculation or myalgia. We did not consider data from abstracts, letters, reviews, or animal research.

\section{Assessment of Validity}

Retrieved reports were screened for inclusion by two authors independently (J.U. S., M. R. T.), who excluded irrelevant reports at that stage. Each author then independently scored all eligible reports for methodologic validity using the five-point Oxford scale, which takes into account randomization, blinding, and description of withdrawals [10]. The minimum score of an included randomized study was 1 , and the maximum score was 5 . Detailed information from each trial was entered into standard collection sheets. This was done by one investigator (J.-U. S.) and independently checked by the others. Consensus on quality scores and extracted data were reached by discussion. We converted all variable doses to fixed doses using average body weights of the study populations as reported in the original trials.

\section{Data Synthesis}

Because undue weight would have been given to pretreatments that were tested in one or two trials only, we restricted quantitative analyses to those pretreatments that were tested in at least three trials. We used a fixed effect model because the data seemed to be clinically homogenous. We calculated relative benefits as relative risks with $95 \%$ confidence intervals for efficacy data. Adverse effects were expressed as Peto odds ratios with $95 \%$ confidence intervals because many trials had zero cells (i.e., they did not report on any event in one of the study groups). We calculated the number needed to treat (NNT) or to harm as an estimate of the clinical relevance of a treatment effect. The number needed to treat or to harm is the number of patients that must be treated with an experimental intervention to achieve a particular result (beneficial or harmful) in one of them which would not have been the case had they all received the control intervention (in this case, a placebo) [11]. Statistical analyses were per- 
formed using RevMan 4.2 (Cochrane Library, Updated Software, Oxford, United Kingdom) and Microsoft ${ }^{\bullet}$ Excel 98 for $\mathrm{Mac}^{\bullet}$ (Microsoft Corp., Redmond, WA).

\section{Results}

\section{Search Results}

We identified 161 potentially relevant trials but subsequently excluded 109 (fig. 1 ). We eventually analyzed data from 52 randomized trials that were published between 1971 and 2003 and that included 5,318 patients [3,12-62]. From the previously published meta-analysis [8] we accepted 17 studies but rejected 28, primarily because they were not randomized. There was one duplicate cluster [63] of which we considered the older report as the original [57] and excluded the duplicate.[64] One pediatric study was excluded,[65] because all other trials were in adults.

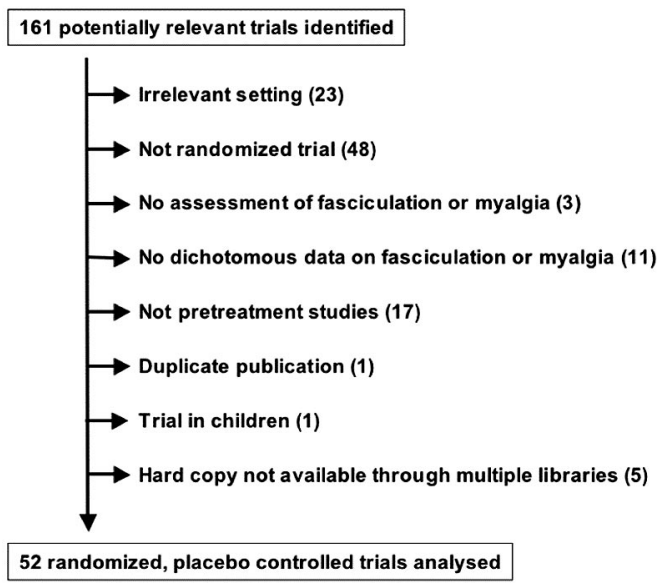

Figure 1. Flowchart of retrieved, excluded, and analyzed trials.

The median number of patients per study was 71 (range, 20-587). The median quality score was 2; 13 trials scored 1; 24 scored 2; 11 scored 3; and 4 scored 4 . Only 6 trials $(12 \%)$ reported an appropriate method of randomization, and only $8(15 \%)$ reported an adequate method of blinding.

Forty-six trials (88\%) studied fasciculation, 49 (94\%) studied myalgia, and 43 $(83 \%)$ studied both. Most trials scored the degree of fasciculation and myalgia 
on a four-point scale, ranging from, for example, none to mild, moderate, and severe. We extracted only data on complete absence of fasciculation and on complete absence of myalgia to avoid interpretation bias. The incidence of myalgia was most frequently reported at $24 \mathrm{~h}$ after surgery. Some studies reported on myalgia at $48 \mathrm{~h}$, and a few reported on myalgia at $72 \mathrm{~h}$.

\section{Underlying Risk}

We studied the relation between fasciculation and myalgia and tested the potential impact of the induction agent (propofol $v$ s. thiopentone), dose of succinylcholine, and effects of opioids at induction on the incidence of fasciculation and myalgia. For that purpose, we selected the 35 trials that reported on both fasciculation and myalgia at $24 \mathrm{~h}$ [3,13-16,21-23,25-27,29,30,32$36,38,39,41,44-46,48,50-54,56-59,61]$. In those, the average incidence of fasciculation in controls (i.e., the control event rate) was 94\% (range, 73-100\%) and of myalgia at $24 \mathrm{~h}$ was $51 \%$ (range, 10-83\%). Graphical display did not suggest any relation between the incidence of these two endpoints (fig. 2). The original data did not allow statistical testing for an association between severity of fasciculation and incidence of myalgia because severity of fasciculation was only inconsistently reported.

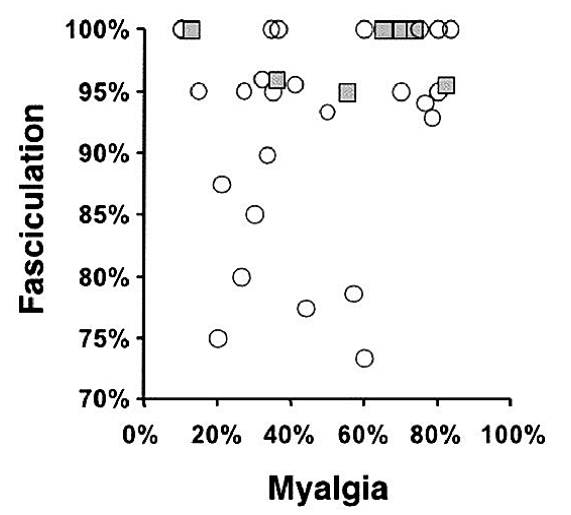

Figure 2. Incidence of fasciculation and of myalgia in control patients who received a placebo or no treatment (i.e., control event rate). Eachsymbolrepresents one trial. Data are shown for 35 trials that reported on both fasciculation and myalgia, and where the dose of succinylcholine was $1 \mathrm{mg} / \mathrm{kg}$ (gray squares) or $1.5 \mathrm{mg} / \mathrm{kg}$ (clear circles). Number of symbols does not add up because some symbols are overlapping.

In four trials, induction of anesthesia was with propofol $[26,33,41,61]$; in one, it was with propofol or thiopentone [30]; and in the other 47, it was with thiopentone. The average incidence of fasciculation was $95.2 \%$ with propofol and $95.0 \%$ with thiopentone. The difference was not statistically significant. The average incidence of myalgia at $24 \mathrm{~h}$ was $65.4 \%$ with propofol and $49.2 \%$ with 
thiopentone. This difference was statistically significant; for prevention of myalgia with thiopentone compared with propofol, the NNT was 6 (table 1).

Table 1. Impact of Induction Agent, Opioids, and Different Succinylcholine Doses on Myalgia and Fasciculation

\begin{tabular}{|c|c|c|c|c|c|c|}
\hline & $\begin{array}{l}\text { No. of Patients } \\
\text { with } \\
\text { Fasciculation/ } \\
\text { Total No. of } \\
\text { Patients (\%) }\end{array}$ & $\begin{array}{l}\text { Relative } \\
\text { Risk } \\
(95 \% \mathrm{CI})\end{array}$ & $\begin{array}{l}\text { No. Needed } \\
\text { to Treat } \\
(95 \% \mathrm{CI})\end{array}$ & $\begin{array}{l}\text { No. of Patients } \\
\text { with } \\
\text { Myalgia at } \\
24 \text { h/Total No. } \\
\text { of Patients (\%) }\end{array}$ & $\begin{array}{l}\text { Relative Risk } \\
(95 \% \text { CI) }\end{array}$ & $\begin{array}{l}\text { No. Needed } \\
\text { to Treat } \\
(95 \% \mathrm{CI})\end{array}$ \\
\hline Propofol & $\begin{array}{l}99 / 104 \\
(95.2)\end{array}$ & 1.00 & & $\begin{array}{l}68 / 104 \\
(65.4)\end{array}$ & 1.33 & 6 \\
\hline Thiopentone & $\begin{array}{l}725 / 763 \\
(95.0)\end{array}$ & $(0.96-1.05)$ & & $\begin{array}{l}391 / 795 \\
(49.2)\end{array}$ & $(1.14-1.55)$ & $(4-17)$ \\
\hline $\begin{array}{l}\text { Opiates at } \\
\text { induction }\end{array}$ & $\begin{array}{l}324 / 340 \\
(95.3)\end{array}$ & 1.01 & & $\begin{array}{l}182 / 340 \\
(53.5)\end{array}$ & 1.09 & \\
\hline $\begin{array}{l}\text { No opiates at in- } \\
\text { duction }\end{array}$ & $\begin{array}{l}521 / 551 \\
(94.6)\end{array}$ & $(0.98-1.04)$ & & $\begin{array}{l}271 / 551 \\
(49.2)\end{array}$ & $(0.96-1.24)$ & \\
\hline $1 \mathrm{mg} \mathrm{kg}^{-1} \mathrm{SCh}$ & $\begin{array}{l}227 / 231 \\
(98.3)\end{array}$ & 1.07 & 16 & $\begin{array}{l}145 / 231 \\
(62.8)\end{array}$ & 1.41 & 6 \\
\hline $1.5 \mathrm{mg} \mathrm{kg}^{-1} \mathrm{SCh}$ & $\begin{array}{l}521 / 551 \\
(92.0)\end{array}$ & $(1.04-1.10)$ & $(11-28)$ & $\begin{array}{l}268 / 601 \\
(44.6)\end{array}$ & $(1.23-1.61)$ & $(4-9)$ \\
\hline
\end{tabular}

Subgroup analyses were performed with data from control patients who received succinylcholine without any pretreatment. Data from trials that reported on both fasciculation and myalgia at 24 $\mathrm{h}$ are considered. Numbers needed to treat are shown for statistically significant results.

CI confidence interval; SCh succinylcholine.

Fentanyl [3,16,21,26,33,41,44,45,50,51,61], methadone [36], or meperidine [29] was given at induction in 13 trials. In the others, no opioids were used for induction. The average incidence of fasciculation was $95.3 \%$ with opioids and $94.6 \%$ without. The average incidence of myalgia at $24 \mathrm{~h}$ was $53.5 \%$ with opioids and $49.2 \%$ without. None of these differences were statistically significant (table 1).

In 9 trials, the dose of succinylcholine was $1 \mathrm{mg} \mathrm{kg}^{-1}$ [16,21,23,$26,32,36,46,54,55]$, and in 25 trials, the dose was $1.5 \mathrm{mg} \mathrm{kg} \mathrm{kg}^{-1}$ $[3,14,15,22,25,27,29,30,33-35,38,39,41,44,45,48,51,53,55-59,61]$. The remaining trials used 1.3 or $2.0 \mathrm{mg} \mathrm{kg}^{-1}$ succinylcholine. The average incidence of fasciculation was $98.3 \%$ with $1 \mathrm{mg} \mathrm{kg}^{-1}$ succinylcholine and $92.0 \%$ with 
$1.5 \mathrm{mg} \mathrm{kg}^{-1}$. The average incidence of myalgia at $24 \mathrm{~h}$ was $62.8 \%$ with $1 \mathrm{mg} \mathrm{kg}^{-1}$ succinylcholine and $44.6 \%$ with $1.5 \mathrm{mg} \mathrm{kg}^{-1}$. Both differences were statistically significant; for prevention of fasciculation with $1.5 \mathrm{mg} \mathrm{kg}^{-1}$ succinylcholine compared with $1 \mathrm{mg} \mathrm{kg}^{-1}$, the NNT was 16 , and for prevention of myalgia, the NNT was 6 (table 1).

\section{Pretreatments}

A large variety of pretreatments were tested: nondepolarizing neuromuscular blockers (atracurium [16,21,30,37,40,41,46,49,50,53,57,61], cisatracurium $[3,33,44], d$-tubocurarine $[12,13,23,25,29,33,39,41-43,45,51,56,57]$, gallamine $[12,13,25,48,52]$, fazadinium [12,16] metocurine [13], mivacurium $[18,41,60]$, pancuronium $[12-14,21,25,31,38,48,59,62]$, rocuronium $[26,33,35,41,54,61]$, vecuronium $[21,22,25,26,35,41,45])$, sodium channel blockers (lidocaine [24,32,43,52,53], phenytoin [29]), nonsteroidal antiinflammatory drugs (diclofenac [34], ketorolac [37], aspirin [42,46,56]) benzodiazepines (midazolam [27,45], diazepam [20,22,23,39,51]), vitamins (E [22,42], C[28]), magnesium sulfate [17,36,58], calcium chloride [42], dantrolene [19], dexamethasone [55], chlorpromazine [22,42] and succinylcholine [15,48,62].

\section{Prevention of Fasciculation}

The effect of 12 pretreatments on fasciculation was tested in at least three trials each (fig. 3). Nonsteroidal antiinflammatory drugs were not significantly different from placebo; all other pretreatments were. The NNT compared with placebo was approximately 10 with benzodiazepines and approximately 4 for cisatracurium and pancuronium. With magnesium, sodium channel blockers (four of five trials tested lidocaine), and the other nondepolarizing neuromuscular blockers, NNTs were between 1.2 and 2.5. 


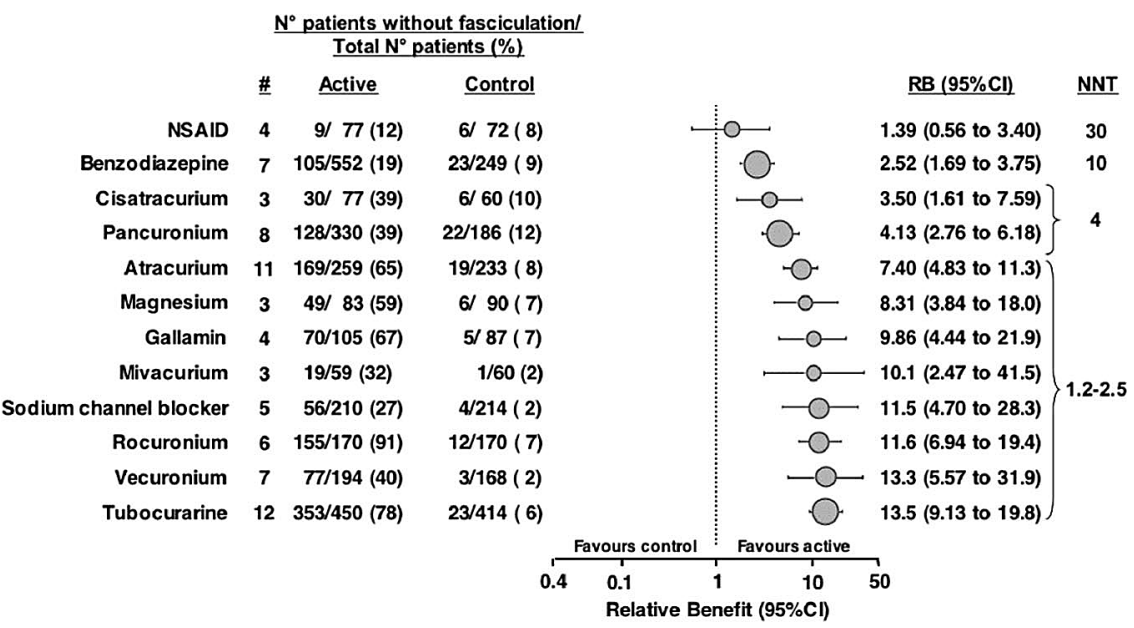

Figure 3. Prevention of succinylcholine-related fasciculation. For each intervention that was tested in at least three trials, a meta-analysis was performed $\#=$ number of analyzed trials).Symbol sizesare proportional to the number of analyzed patients. $\mathrm{CI}=$ confidence interval; NNT = number needed to treat; NSAID = nonsteroidal antiinflammatory drug (aspirin, diclofenac, ketorolac); benzodiazepine (diazepam, midazolam); sodium channel blocker (lidocaine, phenytoin); RB = relative benefit.

\section{Prevention of Myalgia at $24 \mathrm{~h}$}

The effect of nine pretreatments on myalgia at $24 \mathrm{~h}$ was tested in at least three trials each (fig. 4). Benzodiazepines had a weak but statistically significant effect on myalgia; the NNT was approximately 8 . With all nondepolarizing neuromuscular blockers, there was a statistically significant effect on myalgia; NNTs were between 6 (pancuronium) and 3 (gallamine, rocuronium). With sodium channel blockers (three of four trials tested lidocaine), the NNT was approximately 3. Best efficacy was with nonsteroidal antiinflammatory drugs (two trials tested aspirin, one tested diclofenac); the NNT was 2.5. 


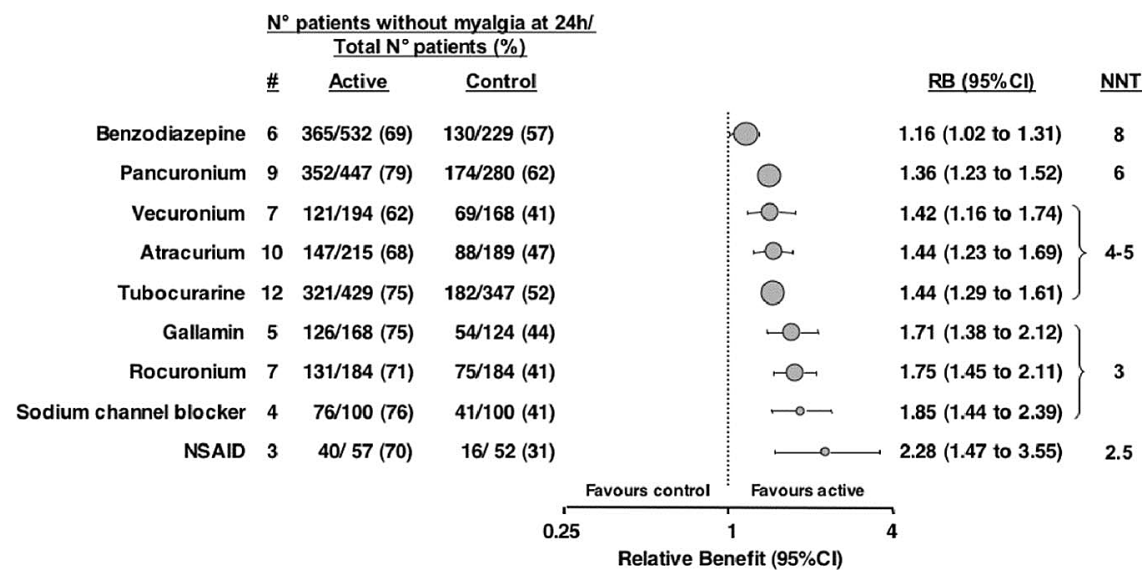

Figure 4. Prevention of succinylcholine-related myalgia at $24 \mathrm{~h}$. For each intervention that was tested in at least three trials, a meta-analysis was performed $(\#=$ number of analyzed trials).Symbol sizesare proportional to the number of analyzed patients. $\mathrm{CI}=$ confidence interval; NNT = number needed to treat; NSAID = nonsteroidal antiinflammatory drug (aspirin, diclofenac); benzodiazepine (diazepam, midazolam); sodium channel blocker (lidocaine, phenytoin); $\mathrm{RB}=$ relative benefit.

\section{Myalgia at 48 and $72 \mathrm{~h}$}

Myalgia at $48 \mathrm{~h}$ was reported in 16 trials $[12,14,15,22,25,29,32,35-$ $38,41,49,53,59,61]$. Of 374 controls, 189 (51\%) reported myalgia at $48 \mathrm{~h}$ (range, 5-87\%). Myalgia at $72 \mathrm{~h}$ was reported in 8 trials [16,22,29,30,$38,45,49,59]$. Of 185 controls, $51(28 \%)$ still had myalgia at $72 \mathrm{~h}$ (range, 0 $60 \%)$.

\section{Dose-Response with Nondepolarizing Neuromuscular Blockers}

With most nondepolarizing neuromuscular blockers, several doses corresponding to $10-30 \%$ of the respective ED95 were tested. To test for doseresponsiveness, we selected those trials that tested neuromuscular blockers and that reported on myalgia at $24 \mathrm{~h}$ [3,12-14,16,21,23,25,26,29,30,33,35,$38,39,41,44-46,48-54,56,57,59,61,62]$ and plotted doses versus relative benefits for prevention of myalgia. There was no clear evidence of dose-responsiveness for neuromuscular blocking agents (fig. 5). There were not enough data to allow for sensitivity analyses that addressed the time point of administration of neuromuscular blockers on efficacy. 

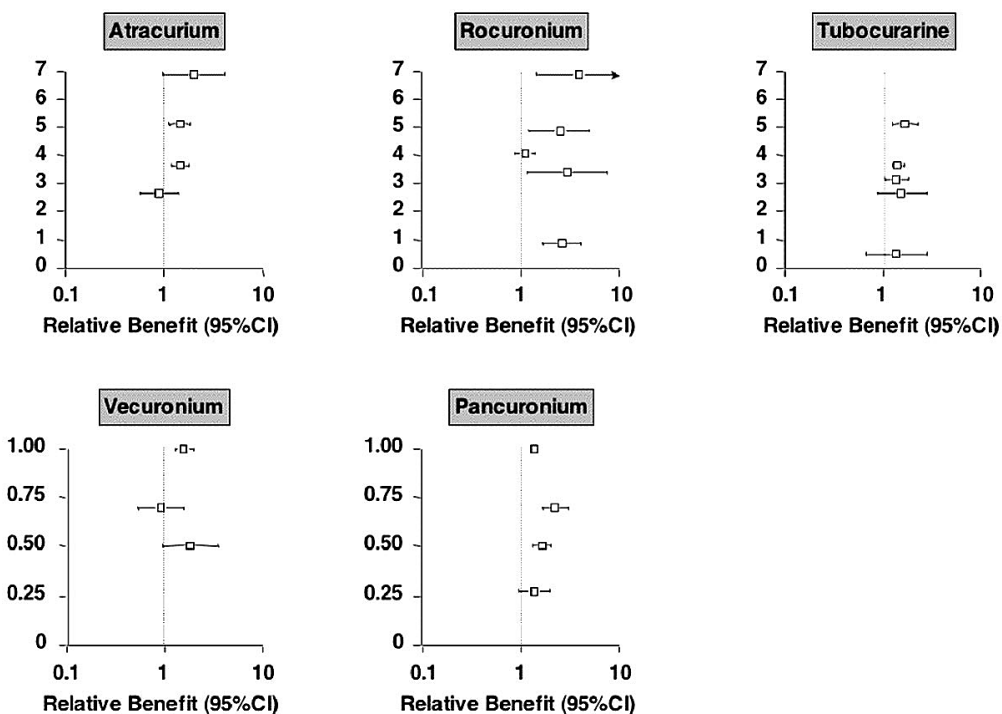

Figure 5. Relation between doses of nondepolarizing neuromuscular blocking agents (in milligrams, y-axes) and efficacy in preventing myalgia at $24 \mathrm{~h}$.Symbolsare relative benefits with $95 \%$ confidence intervals (CI). A relative benefit greater than 1 indicates less myalgia compared with control. For regimens that have been tested in more than one trial, meta-analyses were performed.

\section{Adverse Effects}

Nine trials reported on adverse effects [3,17,19,23,38,44,51,59,61]. Blurred vision, diplopia, heavy eyelids, muscle weakness, difficulty in swallowing, and voice disorder were significantly more often reported in patients who received a nondepolarizing muscle relaxant (table 2). With pancuronium, doseresponsiveness could be tested with data from two trials [38,59]. For that purpose, we arbitrarily divided pancuronium regimens into low $(0.21-0.28 \mathrm{mg})$, medium $(0.42-0.49 \mathrm{mg})$, and high dose $(0.63-0.7 \mathrm{mg})$, corresponding to approximately 4,7 , and $10 \mu \mathrm{gg}^{-1}$, respectively, for a patient with $70 \mathrm{~kg}$ body weight. There was consistent evidence of dose-responsiveness for blurred vision, diplopia, heavy eyelids, and muscle weakness. Number-needed-to-harm values were 3.5 or lower (table 2) with the high-dose regimen. There were not enough valid data to allow for similar sensitivity analyses for other adverse effects and for other neuromuscular blocking agents. Adverse effects with other drugs were pain on injection and dizziness with diazepam [23,51], weakness and dizziness with dantrolene [19], and heat sensation with magnesium [17]. 
Table 2. Analysis of Adverse Effects after Pretreatment with Neuromuscular Blockers Blocking Agents

\begin{tabular}{|c|c|c|c|c|c|}
\hline \multirow[b]{2}{*}{ Adverse Effect } & \multicolumn{5}{|c|}{$\begin{array}{l}\text { No. with Adverse Effect/ } \\
\text { Total No. (\%) }\end{array}$} \\
\hline & $\begin{array}{l}\text { Experimental } \\
\text { Intervention }\end{array}$ & $\begin{array}{l}\text { Control } \\
\text { Intervention }\end{array}$ & $\begin{array}{l}\text { Odds Ratio } \\
(95 \% \mathrm{CI})\end{array}$ & $\begin{array}{l}\text { Number } \\
\text { Needed } \\
\text { to Harm }\end{array}$ & References \\
\hline \multicolumn{6}{|l|}{ Blurred vision } \\
\hline $\begin{array}{l}\text { Any neuromuscular } \\
\text { blocking agent }\end{array}$ & $\begin{array}{l}72 / 208 \\
(34.6)\end{array}$ & $\begin{array}{l}3 / 74 \\
(4.1)\end{array}$ & $5.76(3.0-11.1)$ & 3 & $38,59,61$ \\
\hline Pancuronium, low dose* & $\begin{array}{l}11 / 60 \\
(18.3)\end{array}$ & $\begin{array}{l}3 / 60 \\
(5)\end{array}$ & $3.91(1.25-12.3)$ & 7.5 & 38,59 \\
\hline $\begin{array}{l}\text { Pancuronium, medium } \\
\text { dose }\end{array}$ & $\begin{array}{l}23 / 60 \\
(38.3)\end{array}$ & $\begin{array}{l}3 / 60 \\
(5)\end{array}$ & $7.27(3.04-17.4)$ & 3 & 38,59 \\
\hline Pancuronium, high dose & $\begin{array}{l}38 / 60 \\
(63.3)\end{array}$ & $\begin{array}{l}3 / 60 \\
(5)\end{array}$ & $17.6(7.97-39.0)$ & 2 & 38,59 \\
\hline \multicolumn{6}{|l|}{ Diplopia } \\
\hline $\begin{array}{l}\text { Any neuromuscular } \\
\text { blocking agent }\end{array}$ & $\begin{array}{l}65 / 260 \\
(25.0)\end{array}$ & $\begin{array}{l}5 / 120 \\
(4.2)\end{array}$ & $4.99(2.80-8.88)$ & 5 & $3,38,44,59$ \\
\hline Pancuronium, low dose & $\begin{array}{l}4 / 60 \\
(6.7)\end{array}$ & $\begin{array}{l}1 / 60 \\
(1.7)\end{array}$ & $3.62(0.59-22.3)$ & 20 & 38,59 \\
\hline $\begin{array}{l}\text { Pancuronium, medium } \\
\text { dose }\end{array}$ & $\begin{array}{l}16 / 60 \\
(26.7)\end{array}$ & $\begin{array}{l}1 / 60 \\
(1.7)\end{array}$ & $8.00(2.85-22.5)$ & 4 & 38,59 \\
\hline Pancuronium, high dose & $\begin{array}{l}18 / 60 \\
(30.0)\end{array}$ & $\begin{array}{l}1 / 60 \\
(1.7)\end{array}$ & $9.90(3.58-27.4)$ & 3.5 & 38,59 \\
\hline \multicolumn{6}{|l|}{ Heavy eyelids } \\
\hline $\begin{array}{l}\text { Any neuromuscular } \\
\text { blocking agent }\end{array}$ & $\begin{array}{l}155 / 260 \\
(59.6)\end{array}$ & $\begin{array}{l}14 / 120 \\
(11.7)\end{array}$ & $8.44(5.38-13.2)$ & 2 & $3,38,44,59$ \\
\hline Pancuronium, low dose & $\begin{array}{l}15 / 60 \\
(25.0)\end{array}$ & $\begin{array}{l}1 / 60 \\
(1.7)\end{array}$ & $7.89(2.72-22.9)$ & 4 & 38,59 \\
\hline $\begin{array}{l}\text { Pancuronium, medium } \\
\text { dose }\end{array}$ & $\begin{array}{l}33 / 60 \\
(55.0)\end{array}$ & $\begin{array}{l}1 / 60 \\
(1.7)\end{array}$ & $14.0(6.32-31.1)$ & 2 & 38,59 \\
\hline Pancuronium, high dose & $\begin{array}{l}49 / 60 \\
(81.7)\end{array}$ & $\begin{array}{l}1 / 60 \\
(1.7)\end{array}$ & $25.8(12.6-53.1)$ & 1.3 & 38,59 \\
\hline \multicolumn{6}{|l|}{ Weakness } \\
\hline $\begin{array}{l}\text { Any neuromuscular } \\
\text { blocking agent }\end{array}$ & $\begin{array}{l}89 / 220 \\
(40.5)\end{array}$ & $\begin{array}{l}14 / 100 \\
(14)\end{array}$ & $5.67(3.31-9.72)$ & 4 & $3,38,59$ \\
\hline Pancuronium, low dose & $\begin{array}{l}7 / 60 \\
(11.7)\end{array}$ & $\begin{array}{l}5 / 60 \\
(8.3)\end{array}$ & $1.45(0.44-4.75)$ & 30 & 38,59 \\
\hline $\begin{array}{l}\text { Pancuronium, medium } \\
\text { dose }\end{array}$ & $\begin{array}{l}16 / 60 \\
(26.7)\end{array}$ & $\begin{array}{l}5 / 60 \\
(8.3)\end{array}$ & $3.50(1.37-8.94)$ & 5.5 & 38,59 \\
\hline
\end{tabular}




\begin{tabular}{|c|c|c|c|c|c|}
\hline \multirow{3}{*}{ Adverse Effect } & \multicolumn{5}{|c|}{$\begin{array}{l}\text { No. with Adverse Effect/ } \\
\text { Total No. (\%) }\end{array}$} \\
\hline & Experimental & Control & Odds Ratio & Number & References \\
\hline & Intervention & Intervention & $(95 \% \mathrm{CI})$ & $\begin{array}{l}\text { Needed } \\
\text { to Harm }\end{array}$ & \\
\hline \multirow[t]{2}{*}{ Pancuronium, high dose } & $30 / 60$ & $5 / 60$ & $7.31(3.34-16.0)$ & 2 & 38,59 \\
\hline & $(50.0)$ & (8.3) & & & \\
\hline \multicolumn{6}{|l|}{ Difficulty in breathing } \\
\hline Any neuromuscular & $154 / 308$ & $20 / 308$ & $2.23(0.91-5.48)$ & 26 & $3,38,41,44$ \\
\hline blocking agent & $(6.5)$ & $(2.6)$ & & & 59,61 \\
\hline \multicolumn{6}{|l|}{ Difficulty in swallowing } \\
\hline Any neuromuscular & $16 / 100$ & $2 / 80$ & 4.45 (1.65 to & 7 & $3,41,44$ \\
\hline blocking agent & $(16.0)$ & $(2.5)$ & 12.0) & & \\
\hline \multicolumn{6}{|l|}{ Voice disorder } \\
\hline Any neuromuscular & $13 / 80$ & $0 / 60$ & 6.71 (2.08 to & 6 & 3,44 \\
\hline blocking agent & $(16.3)$ & $(0)$ & 21.6) & & \\
\hline
\end{tabular}

* Variable doses were converted to fixed doses using average body weights of the study populations as reported in the original trials. Low dose $0.21-0.28 \mathrm{mg}\left(3-4 \mu \mathrm{g} \mathrm{kg}^{-1}\right.$, respectively, for 70 $\mathrm{kg}$ body weight); medium dose $0.42-0.49 \mathrm{mg}\left(6-7 \mu \mathrm{g} \mathrm{kg}{ }^{-1}\right.$, respectively); high dose $0.63-0.70$ $\mathrm{mg}\left(9-10 \mu \mathrm{g} \mathrm{kg}^{-1}\right.$, respectively). Dose ranges were arbitrarily chosen.

CI confidence interval.

\section{Discussion}

Five main results emerge from this meta-analysis: Two confirm existing knowledge, and three challenge widespread opinion or provide new insights. First, the incidence of succinylcholine-induced myalgia is high, and symptoms sometimes last for several days. Second, small doses of nondepolarizing muscle relaxants (i.e., approximately $10-30 \%$ of the ED95) prevent fasciculation and myalgia to some extent; however, the risk of potentially serious adverse effects is not negligible. Third, higher doses of succinylcholine decrease the risk of myalgia compared with lower doses, opioids for induction do not seem to have any impact, and, as to the choice of the induction agent, it cannot be excluded that there is less myalgia when thiopentone is used compared with propofol. Fourth, there is no clear relation between succinylcholine-related fasciculation and myalgia. Finally, pretreatment with sodium channel blockers (i.e., lidocaine) or nonsteroidal antiinflammatory drugs (diclofenac and aspirin) may prevent myalgia. 
Our meta-analysis has limitations. Most are related to weaknesses in the original trials. The average methodologic quality of the trials was low. For example, a minority only reported an adequate method of blinding, leaving room for observer bias. We do not know whether these trials were correctly performed but poorly reported. Also, the size of most trials was limited. This may partly explain the large variability in event rates, with some trials reporting less than $20 \%$ of controls having myalgia at $24 \mathrm{~h}$ and others reporting more than $80 \%$. Follow-up was $24 \mathrm{~h}$ in most trials. This may not be long enough to provide an adequate view on the usefulness of pretreatment. Finally, many trials did not report on drug-related adverse reactions. However, lack of reporting of adverse reactions does not mean that none have occurred. For example, we would expect some cardiac adverse effects in susceptible patients with lidocaine. Also, the use of nonsteroidal antiinflammatory drugs such as aspirin may interfere with platelet function. In particular surgical settings, regular perioperative treatment with these analgesics may not be warranted [66]. Finally, potentially serious adverse effects such as difficulty in swallowing were reported with nondepolarizing neuromuscular blocking agents. Relevant data, however, came from only three studies, with a total of 100 patients who received pretreatment $[3,41,44]$. We were unable to provide reliable information on optimal regimens for each drug. Pretreatment intervals and tested doses were too diverse.

On average, one half of the patients who received succinylcholine without pretreatment had myalgia at $24 \mathrm{~h}$ and even at $48 \mathrm{~h}$. After 3 days, approximately one third of patients still experienced muscle pain. It has been known for a long time that myalgia can last for up to 1 week $[6,14]$. The trials did not allow conclusions about the severity of muscle ache. However, as long as succinylcholine is used in daily clinical practice [67], there is a need for an effective treatment against this bothersome side effect, and this may explain the large number of published trials dealing with this subject.

Contrary to widespread belief, we were unable to find a clear relation between the incidence of fasciculation and myalgia. Clearly, the ability of nondepolarizing muscle relaxants to prevent both seems to link them tightly. However, benzodiazepines had a favorable effect only on fasciculation and almost no effect on myalgia, and nonsteroidal antiinflammatory drugs did not prevent fasciculation but were effective against myalgia. These data suggest that fasciculation and myalgia may have different origins. Fasciculation is thought to be related to a prejunctional agonistic action of succinylcholine on nicotinic receptors that results in rapid firing [68]. Nondepolarizing muscle relaxants effec- 
tively prevent fasciculation, presumably by blocking presynaptic nicotinic receptors. The etiology of succinylcholine-induced myalgia, however, remains obscure. The fact that very different drugs such as diclofenac, lidocaine, or pancuronium all attenuate myalgia to some extent provides indirect evidence that the origin of succinylcholine-induced myalgia must be, as previously suggested, multifactorial $[7,69]$. The beneficial effect of sodium channel blockers such as lidocaine may be explained through their cell membrane-stabilizing properties. The efficacy of nonsteroidal antiinflammatory drugs suggests that there is an inflammatory genesis and that prostaglandins may be involved [46,70]. This assumption, however, is contentious [55].

Patients who received a higher dose of succinylcholine were less likely to have myalgia compared with those who received a lower dose. A biologic basis for that differential effect may be that higher doses of succinylcholine reduce forces on muscle spindles and therefore produce more synchronous muscle contractions and subsequently less myalgia [7]. However, after administration of succinylcholine, biochemical markers of muscle damage, such as myoglobin or creatine kinase, did not correlate with the incidence of myalgia [71,72]. Recently published data suggested that succinylcholine doses as low as $0.6 \mathrm{mg} \mathrm{kg}^{-1}$ still provided satisfactory intubation conditions with a shorter recovery and apnea period $[73,74]$. Clinicians will have to make the choice as to whether it is worthwhile to use a small dose of succinylcholine to shorten recovery and apnea period at the price of increasing the risk of postoperative myalgia. It has been suggested that a high induction dose of propofol decreases the risk of succinylcholine-induced myalgia [75]. We were unable to confirm this; however, results of the relevant subgroup analysis should be interpreted carefully because only a small number of trials that used propofol for induction could be included. Finally, whether an opioid was used for induction had no impact on myalgia.

Surprisingly, sodium channel blockers (most trials tested lidocaine) and nonsteroidal antiinflammatory drugs including aspirin were among the most efficacious drug classes to prevent myalgia. However, relatively small number of patients were tested, and, accordingly, 95\% confidence intervals around the relative benefit point estimates were wide, reflecting some uncertainty in the degree of efficacy. Not unexpectedly, pretreatment with a small dose of a nondepolarizing muscle relaxant, perhaps the most popular technique in this setting, decreased the incidence of myalgia. Almost all manufactured muscle relaxants were tested in at least one study, and there was no obvious difference between specific drugs. All nondepolarizing muscle relaxants had NNTs for the 
prevention of fasciculation and myalgia within a similar range, and $95 \%$ confidence intervals were overlapping. The degree of efficacy seems to be very similar for all nondepolarizing muscle relaxants. However, three issues must be discussed in this context. First, with this technique, the risk of potentially serious adverse effects is not negligible. Some may be minor, e.g., heavy eyelids, blurred vision, or diplopia, at worst causing some discomfort. Others are potentially serious, e.g., difficulty in breathing or swallowing. For pancuronium, the most frequently tested nondepolarizing muscle relaxant in these studies, a consistent and clinically relevant dose-response for adverse effects became apparent. Approximately 30 of 100 patients present symptoms of muscle weakness with 10 $\mu \mathrm{g} \mathrm{kg}{ }^{-1}$. Approximately 15 of 100 patients are symptomatic at $7 \mu \mathrm{g} \mathrm{kg}^{-1}$. The same degree of risk and a similar dose-response may apply to all other nondepolarizing muscle relaxants. This assumption is supported by a dose-response analysis for rocuronium that used a pharmacodynamic and pharmacokinetic model [76]. Second, and contrary to the data on adverse effects, there was no clear evidence of dose-responsiveness for efficacy with any of the nondepolarizing muscle relaxants. Therefore, if pretreatment with one of these drugs is chosen as a strategy to reduce succinylcholine-induced myalgia, the smallest dose of each agent that has shown efficacy in these randomized trials should be given. These doses are unlikely to be above $10 \%$ of the respective ED95. Finally, a standard dose of succinylcholine is likely to have a weaker paralyzing effect after pretreatment with a nondepolarizing muscle relaxant. Therefore, an increased dose of succinylcholine may be needed to achieve optimal intubation conditions [77].

Our meta-analysis provides rationale for future research. First, knowing that pretreatment with nondepolarizing neuromuscular blocking agents prevents myalgia to some extent but produces a finite risk of potentially serious adverse effects begs the question as to whether this method should still be recommended, and whether further research is actually warranted with this technique. It may be worthwhile to try to optimize the effect of dose and timing of administration of nondepolarizing muscle relaxants. Alternative drugs such as lidocaine or nonsteroidal antiinflammatory drugs seem promising. Among those, nonsteroidal antiinflammatory drugs are perhaps the most logical choice, considering their symptomatic analgesic efficacy in a variety of acute pain syndromes such as strains and sprains that strongly resemble succinylcholineinduced myalgia. However, the increased risk of surgical bleeding must be kept in mind. Second, it may be useful to test combinations of drugs with different 
mechanisms to enhance efficacy. The origin of myalgia is likely to be multifactorial, and it may be naive to believe that one single drug can completely prevent it. The most effective prevention may be with a drug combination. Third, it may be a sensible option to treat muscle pain in patients who complain about it, rather than to try to prevent it in all patients. The myalgia is of minor harm only; not all patients, even if untreated, are affected; and none of the tested pretreatments are universally effective. There is no rationale why treatment of myalgia should be less effective than prevention. None of the retrieved trials examined the treatment of established myalgia symptoms with, for example, a single dose of a nonsteroidal antiinflammatory drug. Finally, the importance of pretreatment in the prevention of more serious succinylcholine-induced adverse effects, such as hyperkalemia or an increase in intraocular or intracranial pressure, remains unclear. There is some evidence that with low-dose mivacurium, succinylcholine-induced increase in intraocular pressure may be prevented [18]. However, there is no clear evidence that succinylcholine increases intracranial pressure in patients with brain injuries [78], and only limited data are available for patients with brain tumors [79]. If muscle fasciculation was a causative factor of these effects, the prevention of succinylcholine-induced fasciculation may be an important goal.

In conclusion, nondepolarizing muscle relaxants, lidocaine, or magnesium may be used for the prevention of succinylcholine-induced fasciculation. Myalgia may best be prevented with nondepolarizing muscle relaxants, lidocaine, or nonsteroidal antiinflammatory drugs. Nondepolarizing muscle relaxants should be used cautiously because the risk of potentially serious adverse effects is not negligible. There is a lack of relevant data to allow for a rational risk-benefit analysis for other pretreatments. 


\section{References}

1. Hofmockel R, Geldner G, Diefenbach C, Fuchs-Buder T, Ulm K, Blobner M: Die Anwendung von Muskel relaxanzien zur Blitzintubation in Deutschland. Anaesthesist 2003; 52:516-21

2. Morris J, Cook TM: Rapid sequence induction: A national survey of practice. Anaesthesia 2001; 56:1090-7

3. Mencke T, Schreiber JU, Becker C, Bolte M, Fuchs Buder T: Pretreatment before succinylcholine for outpatient anesthesia? Anesth Analg 2002; 94:573-6

4. Tang J, Joshi GP, White PF: Comparison of rocuronium and mivacurium to succinylcholine during outpatient laparoscopic surgery. Anesth Analg 1996; 82:994-8

5. Bevan DR, Donati F: Suxamethonium in clinical praxis, Neuromuscular Transmission. Edited by BooijLHDJ. London, BMJ Publishing Group, 1996, p 84

6. Churchill-Davidson HC: Suxamethonium (succinylcholine) chloride and muscle pain. Br J Anesth 1952; 1:74-5

7. Wong SF, Chung F: Succinylcholine-associated postoperative myalgia. Anaesthesia 2000; 55:144-52

8. Pace NL: Prevention of succinylcholine myalgias: A meta-analysis. Anesth Analg 1990; 70:477-83

9. Moher D, Cook DJ, Eastwood S, Olkin I, Rennie D, Stroup DF: Improving the quality of reports of meta-analyses of randomised controlled trials: The QUOROM statement. Quality of Reporting of Meta-analyses. Lancet 1999; 354:1896-900

10. Jadad AR, Moore RA, Carroll D, Jenkinson C, Reynolds DJ, Gavaghan DJ, McQuay HJ: Assessing the quality of reports of randomized clinical trials: Is blinding necessary? Control Clin Trials 1996; 17:1-12

11. Tramèr MR, Walder B: Number needed to treat (or harm). World J Surg 2005; 5:576-81

12. Bennetts FE, Khalil KI: Reduction of post-suxamethonium pain by pretreatment with four non-depolarizing agents. Br J Anesth 1981; 53:531-6

13. Blitt CD, Carlson GL, Rolling GD, Hameroff SR, Otto CW: A comparative evaluation of pretreatment with nondepolarizing neuromuscular blockers prior to the administration of succinylcholine. Anesthesiology 1981; 55:687-9

14. Brodsky JB, Brock-Utne JG, Samuels SI: Pancuronium pretreatment and postsuccinylcholine myalgias. Anesthesiology 1979; 51:259-61

15. Brodsky JB, Brock-Utne JG: Does self-taming with succinylcholine prevent postoperative myalgia? Anesthesiology 1979; 50:265-7

16. Budd A, Scott RF, Blogg CE, Goat VA: Adverse effects of suxamethonium: Failure of prevention by atracurium or fazadinium. Anaesthesia 1985; 40:642-6

17. Chestnutt WN, Dundee JW: Failure of magnesium sulphate to prevent suxamethonium induced muscle pains. Anaesthesia 1985; 40:488-90

18. Chiu CL, Lang CC, Wong PK, Delilkan AE, Wang CY: The effect of mivacurium pretreatment on intra-ocular pressure changes induced by suxamethonium. Anaesthesia 1998; 53:501-5 
19. Collier CB: Dantrolene and suxamethonium: The effect of pre-operative dantrolene on the action of suxamethonium. Anaesthesia 1979; 34:152-8

20. Davies AO: Oral diazepam premedication reduces the incidence of post-succinylcholine muscle pains. Can Anaesth Soc J 1983; 30:603-6

21. Ebeling BJ, Keienburg T, Hausmann D, Apfelstaedt C: Das Wirkungsprofil von Succinylcholin nach Präkurarisierung mit Atracurium, Vecuronium oder Pancuronium. Anasthesiol Intensivmed Notfallmed Schmerzth 1996; 31:304-8

22. Erk G, Gogus N, Gul F, Kanbak O, Unal O: Süksinilkoline Bağlı Fasikülasyon ve Postoperatif Miyaljinin ÖOnlenmesi. Turk Anesteziyol Reanim 1995; 23:452-6

23. Fahmy N, Malek N, Lappas D: Diazepam prevents some adverse effects of succinylcholine. Clin Pharmacol Ther 1979; 26:395-8

24. Fassoulaki A, Kaniaris P: Use of lignocaine throat spray to reduce suxamethonium muscle pains. Br J Anesth 1981; 53:1087-9

25. Ferres C, Mirakhur R, Craig H, Browne E, Clarke R: Pretreatment with vecuronium as a prophylactic against post-suxamethonium muscle pain: Comparison with other nondepolarizing neuromuscular blocking drugs. Br J Anaesth 1983; 55:735-41

26. Findlay GP, Spittal MJ: Rocuronium pretreatment reduces suxamethonium-induced myalgia: Comparison with vecuronium. Br J Anaesth 1996; 76:526-9

27. Fisher QA, Fisher E, Matjasko MJ: Midazolam pretreatment does not ameliorate myoglobinemia or the clinical side effects of succinylcholine. J Clin Anesth 1993; 5:414-8

28. Gupte S, Savant N: Post suxamethonium pains and vitamin C. Anaesthesia 1971; 26:436-40

29. Hatta V, Saxena A, Kaul HL: Phenytoin reduces suxamethonium-induced myalgia. Anaesthesia 1992; 47:664-7

30. Hochhalter CM: Evaluation of succinylcholine-induced fasciculations and myalgias with or without atracurium pretreatment. AANA J 1996; 64:336-40

31. Houghton IT, Aun CS, Gin T, Lau JT, Oh TE: Suxamethonium myalgia: An ethnic comparison with and without pancuronium pretreatment. Anaesthesia 1993; 48:377-81

32. Jain P, Katiyar K, Gairola R, Purang N: Lignocaine in the prevention of suxamethonium side effects. Ind J Anaesth 1985; 33:36-42

33. Joshi GP, Hailey A, Cross S, Thompson Bell G, Whitten CC: Effects of pretreatment with cisatracurium, rocuronium, and d-tubocurarine on succinylcholine-induced fasciculations and myalgia: A comparison with placebo. J Clin Anesth 1999; 11:641-5

34. Kahraman S, Ercan S, Aypar UEK: Effect of preoperative i.m. administration of diclofenac on suxamethonium-induced myalgia. Br J Anaesth 1993; 71:238-41

35. Kim JH, Cho H, Lee HW, Lim HJ, Chang SH, Yoon SM: Comparison of rocuronium and vecuronium pretreatment for prevention of fasciculations, myalgia and biochemical changes following succinylcholine administration. Acta Anaesthesiol Sin 1999; 37:173-8

36. Laveneziana D, Riva A, Zorzetto C: Magnesio solfato e dolori da succinilcolina. Minerva Anestesiol 1983; 49:713-5

37. Leeson Payne C, Nicoll JMV, Hobbs GJ: Use of ketorolac in the prevention of suxamethonium myalgia. Br J Anaesth 1994; 73:788-90

38. Manani G, DelVecchio A, Civran E, Suma V, Cirillo F, Giron G: La précurarisation par pancuronium chez le sujet de sexe masculin. Évaluation de certains effets cliniques. Ann Fr Anesth Reanim 1979; 20:31-6 
39. Manchikanti L: Diazepam does not prevent succinylcholine-induced fasciculations and myalgia: A comparative evaluation of the effect of diazepam and d-tubocurarine pretreatments. Acta Anaesthesiol Scand 1984; 28:523-8

40. Manchikanti L, Grow J, Collivier J, Canella M, Hadley C: Atracurium pretreatment for succinylcholine-induced fasciculations and postoperative myalgia. Anesth Analg 1985; 64:1010-4

41. Martin R, Carrier J, Pirlet M, Claprood Y, Tetrault JP: Rocuronium is the best nondepolarizing relaxant to prevent succinylcholine fasciculations and myalgia. Can J Anaesth 1998; 45:521-5

42. McLoughlin C, Elliot P, McCarthy G, Mirakhur RK: Muscle pains and biochemical changes following suxamethonium administration after six pretreatment regimens. Anaesthesia 1992; 47:202-6

43. Melnick B, Chalasani J, Uy NT, Phitayakorn P, Mallett SV, Rudy TE: Decreasing postsuccinylcholine myalgia in outpatients. Can J Anaesth 1987; 34:238-41

44. Mencke T, Becker C, Schreiber J, Bolte M, Fuchs Buder T: Präkurarisierung von Succinylcholin mit Cisatracurium: Der Einfluss des Präkurarisierungsintervalls. Anaesthesist 2002; 51:721-5

45. Mingus ML, Herlich A, Eisenkraft JB: Attenuation of suxamethonium myalgias: Effect of midazolam and vecuronium. Anaesthesia 1990; 45:834-7

46. Naguib M, Farag H, Magbagbeola JA: Effect of pretreatment with lysine acetyl salicylate on suxamethonium-induced myalgia. Br J Anaesth 1987; 59:606-10

47. Naguib M, Farag H, Magbagbeola JA: Failure of lidocaine to modify suxamethonium induced biochemical changes. Middle East J Anesthesiol 1988; 9:375-82

48. O Sullivan EP, Williams NE, Calvey TN: Differential effects of neuromuscular blocking agents on suxamethonium-induced fasciculations and myalgia. Br J Anaesth 1988; 60:367-71

49. Oxorn DC, Whatley GS, Knox JW, Hooper J: The importance of activity and pretreatment in the prevention of suxamethonium myalgias. Br J Anaesth 1992; 69:200-1

50. Pagani I, Ramaioli F, Albertari F, Mora R, Dionigni R: Impiego dell'atracurium nell prevenzione delle fascicolazioni e delle mialgie da succinilcolina in atleti sottoposti a chirurgica ortopedica. Minerva Anestesiol 1990; 56:1413-7

51. Perry J, Wetchler BV: Effects of diazepam pretreatment for succinylcholine on fasciculation or postoperative myalgia in out-patient surgery. AANA J 1984; 52:48-50

52. Ramakrishna V, Jaggan K, Wagh S: Comparative study of lignocaine and gallamine for prophylaxis against postsuxamethonium myalgia. Ind J Anaesth 1985; 33:26-30

53. Raman SK, San WM: Fasciculations, myalgia and biochemical changes following succinylcholine with atracurium and lidocaine pretreatment. Can J Anaesth 1997; 44:498-502

54. Ray S, Kundu S, Rudra A, Mazumder P: Attenuation of post suxamethonium myalgia with rocuronium pretreatment. Ind J Anaesth 1999; 43:34-7

55. Schreiber JU, Mencke T, Biedler A, Furst O, Kleinschmidt S, Buchinger H, Fuchs-Buder T: Postoperative myalgia after succinylcholine: No evidence for an inflammatory origin. Anesth Analg 2003; 96:1640-4

56. Sharma A, Mehrota A, Saraswat M: Effect of pretreatment of prostaglandin synthesis inhibitor on suxamethonium myalgia. J Anaesth 1994; 10:175-8 
57. Sosis M, Broad T, Lanjani GE, Marr AT: Comparison of atracurium and d-tubocurarine for prevention of succinylcholine myalgia. Anesth Analg 1987; 66:657-9

58. Stacey MR, Barclay K, Asia T, Vaughan RS: Effects of magnesium sulphate on suxamethonium-induced complications during rapid-sequence induction of anaesthesia. Anaesthesia 1995; 50:933-6

59. Suma V, Manani G, Angel A, Meroni M, Bruchi M, Giron GP: Pancuronium bromide precurarisation: An evaluation of clinical aspects in patients of female sex. Acta Anaesthesiol Belg 1979; 30:127-37

60. Tekin M, Kirdemir P, Okutur E, Horosanli E, Goegues N: Mivaküryum ve Sisatraküryum prekürizasyonunun Süksinilkolinin indüklediği göziçi basinç artişina ve hemodinamiye etkisi. Gulhane Med J 2001; 43:321-7

61. Tsui BCH, Reid S, Gupta S, Kearney R, Mayson T, Finucane B: A rapid precurarization technique using rocuronium. Can J Anaesth 1998; 45:397-401

62. Wald-Oboussier G, Lohmann C, Viell B, Doehn M: Self-taming: Eine Alternative zur Prophylaxe des durch Succinylcholin induzierten Schmerzes. Anaesthesist 1987; 36:426-30

63. von Elm E, Poglia G, Walder B, Tramèr MR: Different patterns of duplicate publication: An analysis of articles used in systematic reviews. JAMA 2004; 291:974-80

64. Marr A, Sosis M: Effectiveness of atracurium in preventing succinylcholine myalgia. AANA J 1989; 57:128-30

65. Theroux MC, Rose JB, Iyengar S, Katz MS: Succinylcholine pretreatment using gallamine or mivacurium during rapid sequence induction in children: A randomized, controlled study. J Clin Anesth 2001; 13:287-92

66. Møiniche S, Rømsing J, Dahl JB, Tramèr MR: Nonsteroidal antiinflammatory drugs and the risk of operative site bleeding after tonsillectomy: A quantitative systematic review. Anesth Analg 2003; 96:68-77

67. Miller R: Will succinylcholine ever disappear? Anesth Analg 2004; 98:1674-5

68. Hartman GS, Fiamengo SA, Riker Jr WF: Succinylcholine: Mechanism of fasciculations and their prevention by d-tubocurarine or diphenylhydantoin. Anesthesiology 1986; 65:405-13

69. Mayrhofer O: Die Wirksamkeit von d-tubocurarin zur Verhütung der Muskelschmerzen nach Succinylcholin. Anaesthesist 1959; 8:313-5

70. McLoughlin C, Nesbitt G, Howe J: Suxamethonium induced myalgia and the effect of preoperative administration of oral aspirin: A comparison with a standard treatment and an untreated group. Anaesthesia 1988; 43:565-7

71. Laurence AS: Myalgia and biochemical changes following intermittent suxamethonium administration: Effects of alcuronium, lignocaine, midazolam and suxamethonium pretreatments on serum myoglobin, creatinine kinase and myalgia. Anaesthesia 1987; 42:503-10

72. McLoughlin C, Leslie K, Caldwell JE: Influence of dose on suxamethonium-induced muscle damage. Br J Anesth 1994; 73:194-8

73. El Orbany MI, Joseph NJ, Salem MR, Klowden AJ: The neuromuscular effects and tracheal intubation conditions after small doses of succinylcholine. Anesth Analg 2004; 98:1680-5

74. Naguib M, Samarkandi A, Riad W, Alharby SW: Optimal dose of succinylcholine revisited. Anesthesiology 2003; 99:1045-9

75. Kararmaz A, Kaya S, Turhanoglu S, Ozyilmaz MA: Effects of high-dose propofol on succinylcholine-induced fasciculations and myalgia. Acta Anaesthesiol Scand 2003; 47:180-4 
76. Kopman AF, Khan NA, Neuman GG: Precurarization and priming: A theoretical analysis of safety and timing. Anesth Analg 2001; 93:1253-63

77. Eisenkraft JB, Mingus ML, Herlich A, Book WJ, Kopman AF: A defasciculating dose of dtubocurarine causes resistance to succinylcholine. Can J Anaesth 1990; 37:538-42

78. Clancy M, Halford S, Walls R, Murphy M: In patients with head injuries who undergo rapid sequence intubation using succinylcholine, does pretreatment with a competitive neuromuscular blocking agent improve outcome? A literature review. Emerg Med J 2001; 18:373-5

79. Stirt JA, Grosslight KR, Bedford RF, Vollmer D: Defasciculation with metocurine prevents succinylcholine-induced increases in intracranial pressure. Anesthesiology 1987; 67:50-3 


\section{Chapter 7}

\section{Does preoperatively administered parecoxib prevent succinylcholine- associated myalgia?}

A randomized, placebo-controlled trial 


\begin{abstract}
Background and objective:: Data from several studies implicate that pretreatment with nonselective cyclooxygenase inhibitors such as aspirin or diclofenac may decrease the incidence of postoperative succinycholine-related myalgia. We tested the influence of a preoperatively administered selective cyclooxygenase 2 inhibitor, parecoxib, on postoperative myalgia.

Methods:: After Ethics Committee approval, 68 patients were randomized into two groups $(n=34$ each). Group 1 received parecoxib $40 \mathrm{mg}$ intravenously $3 \mathrm{~min}$ before induction of anaesthesia, and Group 2 received saline (in a double-blinded manner). Incidence and severity of myalgia was evaluated systematically with a standardized questionnaire 24,48 and $72 \mathrm{~h}$ after anaesthesia. We also the assessed the number of patients who felt limited in their activity due to myalgia.

Results:: Seven patients in the parecoxib-treated group complained of myalgia compared with 11 in the control group (not significant). No significant difference in the severity of myalgia or in the limitation of patients activity was found between the groups.

Conclusion:: Intravenous parecoxib $40 \mathrm{mg}$, when administered before induction of anaesthesia, did not reduce incidence and severity of postoperative myalgia and did not improve activity in those who suffered from myalgia.
\end{abstract}




\section{Introduction}

Due to its unique pharmacological properties, succinylcholine still keeps its place in anaesthetic practice [1]. A frequent adverse effect of succinylcholine is myalgia that can last for several days in varying intensity. Myalgia may cause discomfort and can delay normal activity. This has led to the implication that succinylcholine may not be a suitable drug for ambulatory anaesthesia [2]. Results of a recent meta-analysis showed that parenteral pretreatment with nonselective cyclooxygenase inhibitors such as aspirin or diclofenac may reduce the incidence of succinylcholine-related myalgia $24 \mathrm{~h}$ after anaesthesia [3]. In contrast, preoperative administration of intravenous (i.v.) ketorolac or oral aspirin did not lead to a decreased rate of myalgia $48 \mathrm{~h}$ after surgery $[4,5]$.

Adverse effects may limit the use of non-selective cyclooxygenase inhibitors for the prevention of postoperative myalgia. Due to their pharmacological mechanism, agents as diclofenac may interfere with haemostasis and may cause an increase in intraoperative blood loss compared with selective cyclooxygenase 2 inhibitors [6]. For use in the ambulatory setting, an agent for parenteral administration with a rapid analgesic onset would be favourable.

The aim of this randomized, placebo-controlled trial was to test the effect of pretreatment with parecoxib, a parenteral, selective cyclooxygenase 2 inhibitors, on incidence and severity of succinylcholine-associated myalgia over $72 \mathrm{~h}$ after anaesthesia. In addition, impairment of patients' activity was evaluated.

\section{Material and Methods}

After Ethics Committee (Chamber of physicians of Saarland) approval and informed consent, 68 adult patients (ASA I-II) scheduled for minor surgery were planned for inclusion. Types of surgery were hernia repair, implant removal after osteosynthesis of the lower ankle and inguinal lymph node dissection. Exclusion criteria were chronic intake of non-steroidal anti-inflammatory drugs, obesity (body mass index $(\mathrm{BMI})>30 \mathrm{~kg} \mathrm{~m}^{-2}$ ), neuromuscular disease, acute or chronic inflammatory diseases and contraindications for parecoxib.

Incidence and severity of myalgia was evaluated with a standardized questionnaire [7]. During the premedication visit, patients were informed about the questionnaire and the methodology of the numeric analogue scale $(0=$ no pain to $10=$ worst pain). On the day before surgery, patients were allocated according to a computer generated randomization list to a pretreatment group (group 
COX) or to a control group (group SAL). Midazolam $7.5 \mathrm{mg}$ orally was used for premedication $1 \mathrm{~h}$ preoperatively. After placing an i.v. cannula, group COX received $40 \mathrm{mg}$ parecoxib in $2 \mathrm{~mL}$ saline i.v. (Dynastat ${ }^{\circ}$; Pfizer, Karlsruhe, Germany); group SAL (control group) received $2 \mathrm{~mL}$ saline. For administration of the study drug, unlabelled syringes were used. These were prepared preoperatively by an assistant and according to the randomization scheme. The performing anaesthetist was blinded to the group assignment. Three minutes after administration of the study drug, induction of anaesthesia started with $1 \mu \mathrm{g} \mathrm{kg}^{-1}$ fentanyl i.v. Five minutes later, propofol $2 \mathrm{mg} \mathrm{kg}^{-1}$ i.v. was administered followed by succinylcholine $1 \mathrm{mg} \mathrm{kg}^{-1}$ after loss of consciousness. Sixty seconds later the patient's trachea was intubated. Anaesthesia was maintained with remifentanil $0.25 \mu \mathrm{g} \mathrm{kg}^{-1} \mathrm{~min}^{-1}$ and desflurane 0.5 minimal alveolar concentration (MAC). All patients received piritramide $3 \mathrm{mg}$ i.v., a synthetic opioid for postoperative pain therapy, 20 min before the expected end of surgery. Postoperative pain therapy was standardized with oral diclofenac $50 \mathrm{mg}$ twice a day and, if additional medication was needed, piritramide $0.05 \mathrm{mg} \mathrm{kg}^{-1}$ i.v.

All patients were visited at 24, 48 and $72 \mathrm{~h}$ after surgery by an investigator who was not aware of the group assignment. According to a standardized questionnaire, incidence, severity, and location of myalgia, and impairment of activity were assessed. To simplify data analysis, postoperative myalgia was graded as none, mild (numeric analogue scale 1-3), moderate (4-6) and severe (7-10). Muscle groups were divided into three regions (head/neck/shoulder, trunk and limbs).

Data are presented as means $( \pm \mathrm{SD})$ or absolute values. $\chi 2$-test, Fisher'sexact test, and $U$-test were used as appropriate. A $P<0.05$ was considered significant. The number-needed-to-treat (NNT) was calculated [8]. The NNT indicated how many patients have to receive pretreatment with parecoxib to prevent postoperative myalgia in one of them who would have had myalgia had they all received saline. We regarded an NNT $<5$ as clinically relevant. For statistical calculations SigmaStat ${ }^{\circ} 2.0$ for Windows ${ }^{\bullet}$ (Jandel Corporation, San Rafael, CA, USA) and Microsoft Excel $^{\oplus} \mathrm{X}$ for Macintosh ${ }^{\bullet}$ (Microsoft Corporation, Redmont, WA, USA) were used. Calculation of sample size was based on previous studies $[9,10]$. When assuming a myalgia incidence of $60 \%$ in the control group, 34 patients per group were needed to detect a 55\% reduction in myalgia with pretreatment $(\alpha=0.05, \beta=0.2)$. 


\section{Results}

Due to protocol violation (unexpected major surgery) one patient of the COX group was excluded from data analysis; consequently, data from 67 patients were analysed. Patient characteristics data, duration of anaesthesia and consumption of additional analgesic medication were comparable between the two groups (Table 1). In the COX group, seven patients reported myalgia compared with 11 patients in the SAL group; $P=0.2$. The number of episodes of myalgia in the COX group did not differ significantly from the SAL group (13 vs. 21 episodes, $P=0.175$ ) (Table 2 ). In the SAL group, one patient requested additional analgesics due to myalgia. In the COX group, no such requests were reported. The number of patients who felt limited in their activity due to myalgia, and the severity of myalgia was not significantly different between the two groups; $P=0.11$ (Table 3). The NNT to prevent myalgia in one patient compared with saline was 9 (95\% confidence interval, 3 to -10$)$. No adverse drug reactions that could possibly be related to parecoxib were observed.

Table 1. Patient characteristics data

\begin{tabular}{lll}
\hline & COX $(n=33)$ & SAL $(n=34)$ \\
\hline Age $(\mathrm{yr})$ & $36.9( \pm 13)$ & $44.6( \pm 15.4)$ \\
Gender $(\mathrm{M} / \mathrm{F})$ & $23 / 10$ & $26 / 8$ \\
Height $(\mathrm{cm})$ & $174.3( \pm 7.2)$ & $172.3( \pm 8.4)$ \\
Weight $(\mathrm{kg})$ & $73.5( \pm 13.3)$ & $75.9( \pm 13.0)$ \\
Duration of anaesthesia $(\mathrm{min})$ & $114.7( \pm 48.5)$ & $114.3( \pm 55.3)$ \\
Additional piritramide dose $(\mathrm{mg})$ & $7.5( \pm 7.5)$ & $9.3( \pm 7.8)$ \\
\hline
\end{tabular}

Data are numbers or mean $( \pm S D)$. There were no significant differences.

Table 2. Incidence of postoperative myalgia

\begin{tabular}{lcc}
\hline & COX $(n=33)$ & SAL $(n=34)$ \\
\hline $24 \mathrm{~h}$ & 7 & 9 \\
$48 \mathrm{~h}$ & 4 & 10 \\
$72 \mathrm{~h}$ & 2 & 2 \\
Overall & \\
Patients with myalgia $^{*}$ & $7(21 \%)$ & $11(32 \%)$ \\
Number of episodes $^{\dagger}$ & 13 & 21 \\
\hline
\end{tabular}

* Number of patients who had at least one episode of myalgia during follow-up.

${ }^{\dagger}$ Number of episodes with myalgia during follow-up.

There were no significant differences. 
Table 3. Severity and location of myalgia, and impairment of activity

\begin{tabular}{|c|c|c|}
\hline & $\begin{array}{l}\text { COX-patients with } \\
\text { myalgia }(n=7)\end{array}$ & $\begin{array}{l}\text { SAL-patients with } \\
\text { myalgia }(\mathrm{n}=11)\end{array}$ \\
\hline \multicolumn{3}{|l|}{ Severity of myalgia* } \\
\hline Mild & 3 & 5 \\
\hline Moderate & 2 & 4 \\
\hline Severe & 2 & 2 \\
\hline Impairment of activity $^{\dagger}$ & 0 & 4 \\
\hline \multicolumn{3}{|l|}{ Localization of myalgia } \\
\hline Neck/shoulder & 6 & 7 \\
\hline Trunk & 5 & 7 \\
\hline Limbs & 0 & 4 \\
\hline
\end{tabular}

*Highest ranking during follow-up reported by patients with myalgia.

${ }^{\dagger}$ Number of patients who reported a limitation of activity due to myalgia.

'Multiple notifications were allowed.

There were no significant differences.

\section{Discussion}

The present study examined for the first time whether parecoxib might reduce succinylcholine-related myalgia. The main finding was that preoperatively administered parecoxib failed to reduce incidence and intensity of myalgia over 72 $h$ after anaesthesia.

Several studies have shown a significantly decreased incidence of myalgia following preoperative administration of a parenteral non-selective cyclooxygenase inhibitor such as aspirin or diclofenac [9,11]. In contrast, a preoperatively administered dose of intravenous ketorolac failed to reduce myalgia over $48 \mathrm{~h}$ after anaesthesia [4]. The authors of this study explained their result through the short duration of action of ketorolac. Another reason might have been the limited dose of ketorolac i.v. $(10 \mathrm{mg})$ that was used in this study. Thus, the rationale to use parecoxib in our study was that this agent has a longer duration of action but a comparable onset of analgesic activity compared with ketorolac $[12,13]$. We used a bolus dose of parecoxib $40 \mathrm{mg}$. This corresponds to the highest single bolus dose that is recommended by the manufacturer, and we assumed that this dose had comparable analgesic properties as 30 $\mathrm{mg}$ of ketorolac. Moreover, parecoxib does not impair platelet function [14], and it was at least as efficient or even superior to ketorolac in different pain models $[15,16]$. It was also analgesic following preoperative administration [17]. 
It has been reported that the incidence of succinylcholine-related myalgia varies between $1.5 \%$ and $89 \%$ [18]. A variety of other factors may influence the incidence and severity of myalgia (e.g. type and location of surgery, ambulation, intubation trauma). To minimize any confounding factors on succinylcholineinduced myalgia, we limited the type of surgery to minor interventions. Postoperative evaluation of succinylcholine-associated myalgia was done with an established questionnaire that allows distinction between succinylcholine-associated myalgia and other forms of postoperative myalgia [7]. Also postoperative pain therapy was standardized.

The incidence of myalgia in the control group was lower compared with our recent study on patients undergoing minor eyes, nose, throat surgery [10]. This difference may be due to the different surgical settings. Other factors as the method of evaluation of postoperative myalgia and postoperative pain therapy were comparable between the two trials.

It could be hypothesized that the use of diclofenac for postoperative pain therapy interfered with the incidence of postoperative myalgia. So far, no data are available on the effect of non-steroidal anti-inflammatory drugs on established succinylcholine-associated myalgia. Moreover, it is unclear whether cyclooxygenase inhibitors have advantages compared to other regimens (e.g. opioids) regarding a decreased rate of postoperative myalgia. To avoid any doserelated effect of diclofenac on mylagia, a standard dose was used in all patients. Due to the design, our study should be sensitive enough to detect a prophylactic effect of parecoxib if there was one.

Postoperative myalgia has been described as a complex mechanism with different steps [18]. Furthermore it has been postulated that succinylcholinerelated tissue damage and myalgia are separate entities [5]. In the study by Laurence, no relationship between the usage of succinylcholine, changes in biochemical markers as creatine kinase, and the incidence of myalgia was found [19]. Recent data showed that there is no evidence for a significant inflammatory reaction contributing to myalgia [10]. This led to the assumption that the primary effect of cyclooxygenase inhibitors on myalgia is not directly related to damage of muscular tissue and subsequent inflammatory reaction but to the influence on the effect of prostaglandines in nociception. Kahraman and colleagues observed a decrease of prostaglandin E2-like activity in patients pretreated with the cyclooxygenase inhibitor diclofenac before succinylcholine compared with a control group [11]. Additionally, there is some evidence for a pre-emptive analgesic effect of non-selective cyclooxygenase inhibitors as ke- 
torolac and selective cyclooxygenase 2 inhibitors $[20,21]$. In this context, a preventive administration of an intravenous long-acting cyclooxygenase 2 inhibitor to avoid myalgia might be rationale. Our data show that the administration of parecoxib $40 \mathrm{mg}$ i.v. immediately before induction of anaesthesia does not lead to a clinically relevant reduction of myalgia at any time during the follow-up. This result is in contrast to the findings of a recent meta-analysis that found a clinically relevant effect of preoperatively administered non-selective cyclooxygenase inhibitors on postoperative myalgia $24 \mathrm{~h}$ after anaesthesia [3]. Moreover, neither the severity of myalgia nor the limitation of patients' activity related to myalgia was significantly influenced by the pretreatment. Also the consumption of piritramide as an additional analgesic was comparable in both groups.

We cannot exclude that earlier administration of parecoxib would improve its efficacy; however, in an ambulatory setting, a longer pretreatment interval might be impracticable.

Recent reports about severe adverse effects with parecoxib in different surgical settings suggested that this agent could possibly be harmful in patients with an increased perioperative risk $[22,23]$. This begs the question as to whether the use of parecoxib is generally justified to avoid a comparatively minor problem as postoperative myalgia. However, in our study no parecoxib-related adverse effects were observed.

In conclusion, the results of this trial show that preoperatively administered parecoxib does not significantly reduce succinylcholine-related myalgia over $72 \mathrm{~h}$. The use of parecoxib for the prevention of postoperative myalgia does not seem to be justified.

\section{Acknowledgments}

The authors thank Sarah Klein, BS (University of the Saarland, Homburg, Germany), Natascha Schlaich, MD (Department of Anaesthesiology and Critical Care Medicine, University Hospital of the Saarland, Homburg, Germany) and Oliver Fürst, MD (Department of Anaesthesiology and Critical Care Medicine, University Hospital of the Saarland, Homburg, Germany) for their assistance in data acquisition. Support for this study was given solely from institutional resources. 


\section{References}

1. Miller R. Will succinylcholine ever disappear? Anesth Analg 2004; 98: 1674-1675.

2. Trepanier CA, Brousseau C, Lacerte L. Myalgia in outpatient surgery: comparison of atracurium and succinylcholine. Can J Anaesth 1988; 35: 255-258.

3. Schreiber JU, Lysakowski C, Fuchs-Buder T, Tramèr MR. Prevention of succinylcholineinduced fasciculation and myalgia: a meta-analysis of randomized trials. Anesthesiology 2005; 103: 877-884.

4. Leeson-Payne CG, Nicoll JM, Hobbs GJ. Use of keterolac in the prevention of suxamethonium myalgia. Br J Anaesth 1994; 73: 788-790.

5. McLoughlin C, Elliott P, McCarthy G, Mirakhur RK. Muscle pains and biochemical changes following suxamethonium administration after six pretreatment regimens. Anaesthesia 1992; 47: 202-206.

6. Hegi TR, Bombeli T, Seifert B et al. Effect of rofecoxib on platelet aggregation and blood loss in gynaecological and breast surgery compared with diclofenac. Br J Anaesth 2004; 92: 523-531.

7. Mikat-Stevens M, Sukhani R, Pappas AL, Fluder E, Kleinman B, Stevens RA. Is succinylcholine after pretreatment with d-tubocurarine and lidocaine contraindicated for outpatient anesthesia? Anesth Analg 2000; 91: 312-316.

8. Laupacis A, Sackett DL, Roberts RS. An assessment of clinically useful measures of the consequences of treatment. New Engl J Med 1988; 318: 1728-1733.

9. Naguib M, Farag H, Magbagbeola JAO. Effect of pretreatment with lysine acetyl salicylate on suxamethonium-induced myalgia. Br J Anaesth 1987; 59: 606-610.

10. Schreiber JU, Mencke T, Biedler A et al. Postoperative myalgia after succinylcholine: no evidence for an inflammatory origin. Anesth Analg 2003; 96: 1640-1644.

11. Kahraman S, Ercan S, Aypar U, Erdem K. Effect of preoperative i.m. administration of diclofenac on suxamethonium-induced myalgia. Br J Anaesth 1993; 71: 238-241.

12. Rømsing J, Møiniche S. A systematic review of COX-2 inhibitors compared with traditional NSAIDs, or different COX-2 inhibitors for post-operative pain. Acta Anaesthesiol Scand 2004; 48: 525-546.

13. Barton SF, Langeland FF, Snabes MC et al. Efficacy and safety of intravenous parecoxib sodium in relieving acute postoperative pain following gynecologic laparotomy surgery. Anesthesiology 2002; 97: 306-314.

14. Noveck RJ, Laurent A, Kuss $M$ et al. Parecoxib sodium does not impair platelet function in healthy elderly and non-elderly individuals. Two randomised, controlled trials. Clin Drug Invest 2001; 21: 465-476.

15. Mehlisch DR, Desjardins PJ, Daniels S, Hubbard RC. Single doses of parecoxib sodium intravenously are as effective as ketorolac in reducing pain after oral surgery. J Oral Maxillofac Surg 2003; 61: 1030-1037.

16. Rasmussen GL, Steckner K, Hogue C, Torri S, Hubbard RC. Intravenous parecoxib sodium for acute pain after orthopedic knee surgery. Am J Orthop 2002; 31: 336-343. 
17. Desjardins PJ, Grossman EH, Kuss ME et al. The injectable cyclooxygenase-2-specific inhibitor parecoxib sodium has analgesic efficacy when administered preoperatively. Anesth Analg 2001; 93: 721-727.

18. Wong SF, Chung F. Succinylcholine-associated postoperative myalgia. Anaesthesia 2000; 55: $144-152$.

19. Laurence AS. Myalgia and biochemical changes following intermittent suxamethonium administration. Effects of alcuronium, lignocaine, midazolam and suxamethonium pretreatments on serum myoglobin, creatine kinase and myalgia. Anaesthesia 1987; 42: 503-510.

20. Norman PH, Daley MD, Lindsey RW. Preemptive analgesic effects of ketorolac in ankle fracture surgery. Anesthesiology 2001; 94: 599-603.

21. Reuben SS, Bhopatkar S, Maciolek H, Joshi W, Sklar J. The preemptive analgesic effect of rofecoxib after ambulatory arthroscopic knee surgery. Anesth Analg 2002; 94: 55-59.

22. Nussmeier NA, Whelton AA, Brown MT et al. Complications of the COX-2 inhibitors parecoxib and valdecoxib after cardiac surgery. New Engl J Med 2005; 352: 1081-1091.

23. Looney Y, O'Shea A, O'Dwyer R. Severe bronchospasm after parenteral parecoxib: cyclooxygenase-2 inhibitors: not the answer yet. Anesthesiology 2005; 102: 473-475. 


\section{Appendix: Postoperative questionnaire for myalgia study}

Patient ID:

Date of surgery:

Type of surgery:

Follow-up: $\quad 24 \mathrm{~h} \quad 48 \mathrm{~h} \quad 72 \mathrm{~h}$

1. Do you have any stiffness or soreness in your body besides headache and pain at the surgical side? yes no

2. Have you been up? yes no

3. Is there pain and stiffness in the muscles? yes no

4. In which sites do you have the muscle pain/stiffness? Jaw Throat Neck Shoulders Arm Chest Abdomen Back__ Buttocks Thighs Calves Generalized Buttocks Thighs

Calves Generalized

5. When did you first noticed the pain?

6. Rate the muscle stiffness/pain on score ( 0 being no pain and 10 worst pain ever) only on the sites to be painful by the patient. Jaw Throat Neck Shoulders Arm Chest Abdomen Back Buttocks Thighs Calves Generalized

7. What makes the muscle stiffness/pain worst? Movement Rest

8. Describe the muscle pain/stiffness in your (patient's) own words.

9. Do you think the muscle pain is restricting your activity? yes no

10. Is the muscle pain preventing you from getting out of bed? yes no

11. Have you ordered any extra pain medication because of the muscle pain? yes no

12. Are you taking your prescribed pain medication to help your surgical pain or your muscle pain 

Chapter 8

Discussion 
Many advances in anaesthesia techniques have been made over the last 50 years. However, during acute situations, anaesthesiologists still trust a drug with a lot of adverse effects. Efforts were made to find a successor for succinylcholine with comparable properties. Rocuronium, introduced in the 1990, seemed to be the first non-depolarizing agent with an onset profile that was comparable to succinylcholine. However, the dose of rocuronium for a succinylcholine-like onset is huge (3-4* ED95), which results in a duration of action that is 10 to 15 times longer than the duration of action of succinylcholine.

In 2000 the non-depolarizing rapacuronium was introduced in the USA, and only for the US market. The pharmacological properties of this agent were promising and with a rapid onset and offset almost mimicking succinylcholine. Unfortunately, several fatalities were associated with the use of rapacuronium and, therefore, it was withdrawn from the market shortly after its introduction.

The last agent that has been dedicated to be a potent successor for succinylcholine, until now, was the benzylisochinoline gantacurium (GW280430A, AV430). But the agent is still undergoing clinical testing and it is not predictable if it will ever enter the market and become a place in clinical practice [1].

In 2008 sugammadex, a specific binding agent for steroidal neuromuscular blockers such as rocuronium and vecuronium was introduced in clinical practice. Due to its mechanism of action this cyclodextrin provides a rapid reversal even of a deep neuromuscular block within minutes. Therefore, it has been suggested that succinylcholine should be withdrawn from clinical practice and might be replaced by a combination of rocuronium with sugammadex, which now offers a rapid onset combined with a rapid offset due to the antagonist [2]. However, when focusing on intubation conditions during a rapid sequence induction, succinylcholine still offers intubation conditions which are superior in comparison to rocuronium. This has been implied by a recent systematic review in the field of anaesthesia [3] and was also stated in the field of emergency medicine [4]. Consequently, one can expect that succinylcholine still will claim its place in clinical anaesthesia. Probably, the rapid sequence induction will be a small niche for the agent, but a very important one. Another clinical field where succinylcholine is commonly in use until today is the field of electroconvulsive therapy [5]. Furthermore, succinylcholine, as a very inexpensive agent in comparison to rocuronium/sugammadex, will play a role, when the budget is tight for example in underdeveloped areas, but also in our crisis ridden situation.

Two main aspects emerge from today's situation. 
Firstly, there is still a necessity for clinical research on succinylcholine, its effects, and its side effects.

Secondly, the need for a non-depolarizing successor of succinylcholine with a beneficial side-effects profile is still existent.

The present thesis focuses on the problem of postoperative myalgia. As stated before, the aetiology of this problem seems to be multifactoral and it might be an illusion to find an universal strategy in preventing this adverse effect. However, some new insights can be taken from this work with respect to the emphasized research questions. In the future, this may improve the clinical use of succinylcholine.

Several factors such as gender, age, type of surgery, and ambulation have been associated with an increased incidence and severity of succinylcholineassociated myalgia [6].

However, an underlying baseline risk for postoperative myalgia specifically for outpatients for several neuromuscular blockers has been already described [7-9]. Thus, the first trial of the present thesis estimates the baseline risk of myalgia for outpatients at the institution the research took place (University Hospital of the Saarland, Homburg, Germany). The study could confirm the findings that episodes of myalgia were also present in patients who did not receive succinylcholine but received rocuronium (chapter 3). Therefore, the implication that, because of postoperative myalgia, succinylcholine might not be an appropriate drug for ambulatory anaesthesia seems to be questionable [10]. Furthermore, it remains speculative whether the use of rocuronium/sugammadex for outpatients may decrease the incidence of postoperative myalgia in this specific group of patients.

Postoperative myalgia has some clinical similarities with muscle pain following unaccustomed muscular stress, i.e. delayed onset muscular soreness (DOMS). Soreness normally occurs 24 hours after muscular stress, the characteristics of pain are comparable, and also the exact aetiology of DOMS is also still unknown. A number of theories have been proposed to be associated with the origin of DOMS. These included lactate acidosis, muscle spasm, connective tissue and cell damage, enzyme efflux, and inflammation [11]. Some of these aetiologies were also investigated in patients receiving succinylcholine. But neither electrolytes nor enzymes as a marker for cell damage could be successfully linked with the intensity of postoperative myalgia following succinylcholine. Data from sports medicine implied that an inflammatory process might take part in the aetiology of DOMS due to an increase of pro-inflammatory cyto- 
kines following exercise and, therefore, also in postoperative myalgia [12]. The findings in sports medicine were confirmed in various settings of exercise by several authors. Due to the fact that interleukin- 6 is produced in the skeletal muscle this cytokine has been termed as an "inflammation-responsive" myokine [13]. Consequently, it should be highly specific for trauma and inflammation in the muscular tissue. However, a significant increase of inflammatory parameters such as interleukin- 6 could not be observed in patients with succinylcholineassociated myalgia. Furthermore, an anti-inflammatory agent with a strong potency (i.e. dexamethasone) did not influence the incidence or intensity of succinylcholine-associated myalgia (chapter 4). Thus, in contrast to the well known soreness phenomenon following unaccustomed exercise it might be concluded that inflammation does not play a key role in the pathogenesis of succinylcholine-associated myalgia. However, anti-inflammatory agents such as diclofenac were found effective in reducing postoperative myalgia when administered before succinylcholine [14]. Basically, these clinical findings were confirmed in a meta-analysis (Chapter 6) and might be best explained by inhibiting the production of pain mediating prostanoids. The cited meta-analysis also showed that data on the prophylactic use of non-steroidal anti-inflammatory agents and aspirin in the prevention of myalgia are currently limited.

Due to the lack of data about non-steroidal anti-inflammatory drugs in the prevention of postoperative myalgia a trial was initiated where the effect of a selective cyclooxygenase- 2 inhibitor was tested. Cyclooxygenase- 2 inhibitors are offering some advantages regarding postoperative bleeding complications when compared with non-selective cyclooxygenase inhibitors such as diclofenac [15]. It this trial parecoxib failed to be efficient in the prevention of myalgia following succinylcholine (chapter 7). A calculated number-needed-to-treat of 9 reflects this issue. Regarding a lack of efficacy and in the light of several reports about adverse cardiac events following the use of parecoxib does not seem to be justified in the prophylaxis of a comparable minor problem such as myalgia. The results of the trial also emphasize the question if a concept of preemptive analgesia does promise success for postoperative soreness. However, it remains unclear if a postoperative treatment of myalgia with a cyclooxygenase inhibitor (selective or non-selective) will be successful.

Another aspect of this thesis regards the side effects of different pretreatments. As stated in the meta-analysis (chapter 6) pretreatment with different agents may lead to adverse effects associated with these agents. The available data allowed a risk-analysis for adverse effects following a pretreatment with 
non-depolarizing neuromuscular blocking agents. These adverse effects included weakness, shortness of breath, diplopia, and difficulties in swallowing. Beside these there are side effects which are more specific for the single agents. Rocuronium has been described as the most efficient non-depolarising blocking agent in the prophylaxis of succinylcholine-associated myalgia (chapter 6). However, rocuronium itself may cause pain during injection even in subparalyzing doses. Thus, the effect of a dose of $0.1^{*}$ ED95 rocuronium was tested in a randomized controlled trial in 120 patients (Chapter 5). In this trial $32 \%$ of the patients felt injection pain following rocuronium. Women were significantly more affected than men ( 45 vs. $20 \%$ ). It was already suggested that gender may have an influence onto pain tolerances and sensation of pain [16]. But this gender-related effect might also depend on the type of pain initiation [17]. It seems that not even the perception of myalgia shows gender-related differences, but also those following rocuronium. During the last years several strategies have been published to avoid injection pain after rocuronium which included lidocaine, opioids, sodium bicarbonate, and esmolol [18,19]. It might be a recommendation to consider one of these strategies before the use of rocuronium, even before using a pretreatment dose.

In conclusion, four main results are emerging from the present thesis. Firstly, myalgia does not appear exclusively after the use of succinylcholine but also following non-depolarizing neuromuscular blockers. Secondly, it does not seem that an inflammatory component takes a significant part in the pathogenesis of succinylcholine-associated myalgia. Thus, the usefulness of antiinflammatory agents in the prevention of succinylcholine-associated myalgia might be limited. Thirdly, non-depolarizing neuromuscular blocking agents and sodium channel inhibitors are effective in the prevention of succinylcholine-associated myalgia, according to an evidence-based approach. This might be also the case for non-steroidal anti-inflammatory drugs. However, data are limited for this class of agents. And fourthly, gender-related differences of pain perception are not restricted to postoperative myalgia but may occur also after pretreatment with rocuronium.

Finally, the exact aetiology and pathogenesis of succinylcholine-associated myalgia still remains unknown. However, this clinical problem continues to be important for clinicians and patients as recent publications have shown [20,21]. Thus, there is still a need for future research on the field of the prevention and, maybe more important, the therapy of succinylcholine-associated myalgia. 


\section{References}

1. Naguib M, Brull SJ. Update on neuromuscular pharmacology. Curr Opin Anaesthesiol 2009; 22:483-90.

2. Lee C. Goodbye suxamethonium!. Anaesthesia 2009; 64 Suppl 1:73-81.

3. Perry JJ, Lee JS, Sillberg VA, Wells GA. Rocuronium versus succinylcholine for rapid sequence induction intubation. Cochrane Database Syst Rev 2008(2):CD002788.

4. Mallon WK, Keim SM, Shoenberger JM, Walls RM. Rocuronium vs. Succinylcholine in the emergency department: A critical appraisal. J Emerg Med 2009; 37:183-8.

5. Matsumoto N, Tomioka A, Sato T, Kawasaki M, Kadoi Y, Saito S. Relationship between cardiac output and onset of succinylcholine chloride action in electroconvulsive therapy patients. J ECT 2009, Feb 25.

6. Wong SF, Chung F. Succinylcholine-Associated postoperative myalgia. Anaesthesia 2000; 55:144-52.

7. Zahl K, Apfelbaum JL. Muscle pain occurs after outpatient laparoscopy despite the substitution of vecuronium for succinylcholine. Anesthesiology 1989; 70:408-11.

8. Smith I, Ding Y, White PF. Muscle pain after outpatient laparoscopy--influence of propofol versus thiopental and enflurane. Anesth Analg 1993; 76:1181-4.

9. Mikat-Stevens M, Sukhani R, Pappas AL, Fluder E, Kleinman B, Stevens RA. Is succinylcholine after pretreatment with d-tubocurarine and lidocaine contraindicated for outpatient anesthesia? Anesth Analg 2000; 91:312-6.

10. Trépanier CA, Brousseau C, Lacerte L. Myalgia in outpatient surgery: Comparison of atracurium and succinylcholine. Can J Anaesth 1988; 35:255-8.

11. Cheung K, Hume P, Maxwell L. Delayed onset muscle soreness : Treatment strategies and performance factors. Sports Med 2003; 33:145-64.

12. MacIntyre DL, Sorichter S, Mair J, Berg A, McKenzie DC. Markers of inflammation and myofibrillar proteins following eccentric exercise in humans. Eur J Appl Physiol 2001; 84(3):180-6.

13. Peake J, Nosaka K, Suzuki K. Characterization of inflammatory responses to eccentric exercise in humans. Exerc Immunol Rev 2005;11:64-85.

14. Kahraman S, Ercan S, Aypar U, Erdem K. Effect of preoperative i.m. administration of diclofenac on suxamethonium-induced myalgia. Br J Anaesth 1993; 71:238-41.

15. Hegi TR, Bombeli T, Seifert B, Baumann PC, Haller U, Zalunardo MP, et al. Effect of rofecoxib on platelet aggregation and blood loss in gynaecological and breast surgery compared with diclofenac. Br J Anaesth 2004; 92:523-31.

16. Keogh E, Herdenfeldt M. Gender, coping and the perception of pain. Pain 2002; 97:195201.

17. Neziri AY, Andersen OK, Petersen-Felix S, Radanov B, Dickenson AH, Scaramozzino P, et al. The nociceptive withdrawal reflex: Normative values of thresholds and reflex receptive fields. Eur J Pain 2009, Jun 6.

18. Yavascaoglu B, Kaya FN, Ozcan B. Esmolol pretreatment reduces the frequency and severity of pain on injection of rocuronium. J Clin Anesth 2007, Sep;19(6):413-7. 
19. Chiarella AB, Jolly DT, Huston CM, Clanachan AS. Comparison of four strategies to reduce the pain associated with intravenous administration of rocuronium. $\mathrm{Br} \mathrm{J}$ Anaesth 2003; 90:377-9.

20. Allen TK, Habib AS, Dear GL, White W, Lubarsky DA, Gan TJ. How much are patients willing to pay to avoid postoperative muscle pain associated with succinylcholine? J Clin Anesth 2007; 19:601-8.

21. Brodsky JB, Lemmens HJ. Succinylcholine and morbid obesity: The debate continues. Obes Surg 2009, Oct 8. 

Chapter 9

Summary 
The depolarizing neuromuscular blocking agent succinylcholine was introduced in 1952 into clinical practice. Despite its high rate of possible adverse effects the agent has become very popular in clinical anaesthesia due to its unique pharmacological properties such as rapid onset and offset. Like every drug, succinylcholine has side effects. Some of the known side effects of the agent might be life threatening such as malignant hyperthermia or bradycardia. Others are relatively minor but may cause discomfort to the patient such as postoperative myalgia (POM) which is associated with the use of succinylcholine and may last for several days.

Many efforts were undertaken in the prevention of POM since the introduction of succinylcholine and several techniques were tested regarding their efficacy. Most of these were pharmacological pretreatments with different agents such as non-depolarizing neuromuscular blockers. However, none of the tested techniques seems to completely reliable in the prevention of POM. One of the difficulties in finding an optimal prevention might be that there is still a lack of knowledge about the aetiology of POM.

Therefore, one of the aims of this thesis was to find some new insights in the aetiology of POM investigating the hypothesis of an inflammatory reaction that possibly contributes myalgia. Further, the efficacy and side effects of different pretreatment regimens were analysed and the effect of cyclooxygenase- 2 inhibitors on POM was tested.

Chapter 1 introduces the problem of postoperative myalgia following succinylcholine. It briefly describes the history of succinylcholine in clinical anaesthesia. Further, several hypotheses over the aetiology of succinylcholineassociated myalgia and different strategies in its prevention are reflected.

Chapter 2 gives a general overview about the physiology and pharmacology of the neuromuscular junction. All neuromuscular blocking agents that are currently in use are discussed with their pharmacological properties and possible side effects. In a second part the various techniques of neuromuscular monitoring are described in detail. The chapter offers information about devices, stimulation patterns, and recent recommendations about the use of neuromuscular monitoring.

The basic incidence of POM in outpatients at the institution where all of the clinical trials in this thesis took place (University Hospital of the Saarland, Homburg, Germany) was estimated in a study that is presented in chapter 3. 120 patients were tested with three different regimens for neuromuscular blockade in a randomized controlled trial. The three regimens of neuromuscular block for 
intubation included either the non-depolarizing agent rocuronium or the depolarizing agent succinylcholine. The third group of patients received succinylcholine after a precurarization dose of rocuronium $\left(0.1^{*}\right.$ ED95). All other anaesthetic conditions were standardized. Myalgia was assessed in all patients over 24 hours. There was no significant difference in the incidence of myalgia between the three groups. Moreover, the precurarization regimen led to an increased count of side effects such as heavy eyelids, diplopia, and difficulty in swallowing. Thus, routine precurarization in outpatients might be questionable.

In chapter 4 the hypothesis if an underlying inflammation may contribute to succinylcholine-associated myalgia was tested. Therefore, 64 patients scheduled for ENT-surgery were included in a randomized controlled trial. The patients were randomized into two groups; group one received an anaesthetic pretreatment with dexamethasone $8 \mathrm{mg}$ and group two a pretreatment with saline in a double blinded manner. The saline group underwent an additional subgroup randomization. Interleukin- 6 which is a pro-inflammatory cytokine was estimated in the ten patients of this subgroup at different times of the perioperative period. Anaesthetic regimen included succinylcholine and was standardized in all patients. The incidence of POM was estimated in all patients over 72 hours postoperatively. Dexamethasone-pretreatment did not influence the incidence of POM significantly. In the subgroup no correlation between POM and an increase of plasma interleukin- 6 concentrations was found. This led to the conclusion that there in no evidence for an inflammatory origin of succinylcholineassociated myalgia.

Chapter 5 describes a trial that investigates a side effect of rocuronium. Even in a small precurarization dose of $0.1 *$ ED95 rocuronium may cause injection pain. The hypothesis was tested whether gender may influence the pain perception on a subparalyzing dose of rocuronium. 120 patients (60 women and 60 men) were included in the study. 80 ( 40 women and $40 \mathrm{men}$ ) of them received a subparalyzing dose of rocuronium following a randomization scheme. All others received saline for control. The main endpoints were pain on injection, thrombophlebitis, and other signs of local irritation. Women reported significantly more pain on injection even of a subparalyzing dose of rocuronium which might be taken as additional evidence in a gender-related difference in pain perception.

Since the introduction of succinylcholine a great variety of pretreatment strategies were tested on the efficacy. Chapter $\mathbf{6}$ contains a meta-analysis that was done in accordance to current standards in evidence based medicine (QUORUM statement). The efficacy of different pretreatments in the prevention of 
succinylcholine-associated myalgia and fasciculations was calculated based on the results of 52 randomized controlled trials with 5318 patients. Non-depolarizing neuromuscular blockers, lidocaine, and magnesium were efficient in preventing fasciculations with a calculated number-needed-to-treat of 1.2-2.5. Myalgia after 24 hours postoperatively was best prevented by non-steroidal anti-inflammatory drugs (NSAID), lidocaine, and rocuronium with a number-needed-to-treat of 2.5-3. There was a dose-dependent risk of side effects such as blurred vision, diplopia, heavy eyelids, and difficulty in swallowing if neuromuscular blocking agents were used for pretreatment. Furthermore, there was evidence that myalgia was less if a dose of $1.5 \mathrm{mg} \mathrm{kg}^{-1}$ succinylcholine was used (instead of $1 \mathrm{mg} \mathrm{kg}^{-1}$ ). Thus, myalgia may best be prevented with muscle relaxants, lidocaine, or nonsteroidal antiinflammatory drugs. The risk of potentially serious adverse events with muscle relaxants is not negligible. Data that allow for a risk-benefit assessment were lacking for other drugs.

Due to the fact that NSAID were found efficient in the previous metaanalysis a follow-up trial was established to test the effect of a selective cyclooxygenase 2-inhibitor on POM. The results of this randomized controlled trial that included 67 patients are described in chapter 7. Non-selective NSAID may increase the risk of blood loss in the perioperative period; a side effect that should not be observed following a selective cyclooxygenase 2-inhibitor. Parecoxib was chosen as the testing drug. In contrast to the results of the previous meta-analysis parecoxib was not clinically efficient in the prevention of POM with a calculated number-needed-to-treat of 9 . Further, no significant decrease in the impairment of activity due to POM was found in patients who were pretreated with parecoxib. Moreover, the use of cyclooxygenase 2 -inhibitors in the prevention of a comparably minor problem such as POM remains questionable in the light of possible cardiovascular side effects which were associated with this class of agents.

Chapter 8 is the final one which highlights the main results of this thesis. The impact of recent developments in clinical anaesthesia such as the introduction of new agents and its relevance on the future use of succinylcholine are discussed. However, a successor of succinylcholine with a comparable pharmacological profile has not bee found yet. Moreover, the exact pathogenesis remains unclear and is not fully understood. Therefore, no optimal pretreatment or treatments of succinylcholine-associated myalgia are available. This emphasizes the necessity for future research on succinylcholine-associated myalgia. 


\section{Samenvatting}

De depolariserende spierverslapper succinylcholine werd geïntroduceerd in 1952 in de klinische praktijk. Ondanks de hoge waarschijnlijkheid van mogelijke negatieve effecten van deze substantie is hij zeer populair geworden in de klinische anesthesie, vanwege zijn unieke farmacologische eigenschappen zoals snelle onset en offset. Succinylcholine heeft bijwerkingen zoals elk ander geneesmiddel. Enkele van de bekende bijwerkingen van de agent zijn mogelijk levensbedreigend zoals bijvoorbeeld maligne hyperthermie of bradycardie. Andere geassocieerde bijwerkingen zijn relatief ongevaarlijk, maar leiden tot ongemak voor de patiënt, zoals postoperatieve spierpijn (POM). POM kan een week duren.

Sinds de invoering van succinylcholine werden een groot aantal onderzoeken verricht over de preventie van POM en verschillende technieken werden getest met betrekking tot hun effectiviteit. De meeste van deze waren farmacologische voorbehandelingen met verschillende middelen, zoals nietdepolariserende spierverslappers. Echter, geen van de beproefde technieken lijkt volledig betrouwbaar in de preventie van POM. Een van de moeilijkheden bij het vinden van een optimale preventie zou kunnen zijn dat er nog steeds een gebrek aan kennis is over de etiologie van POM.

Een van de doelstellingen van dit proefschrift was een aantal nieuwe inzichten in de etiologie van POM te vinden, met name het onderzoek naar de hypothese van een ontstekingsreactie die mogelijk bijdraagt aan de spierpijn. Verder werden de werkzaamheid en bijwerkingen van verschillende preventieve behandelingsschema's geanalyseerd en het effect van cyclooxygenase-2-remmers op POM werd getest. 
Hoofdstuk 1 introduceert het probleem van postoperatieve spierpijn na succinylcholine. Het beschrijft de geschiedenis van succinylcholine in de klinische anesthesie. Verder werden er een aantal hypothesen over de etiologie van succinylcholine-geassocieerde spierpijn en verschillende strategieën in de preventie van POM behandeld.

Hoofdstuk 2 geeft een algemeen overzicht over de fysiologie en farmacologie van de neuromusculaire junctie. Alle spierverslappers die momenteel klinisch in gebruik zijn worden besproken met hun farmacologische eigenschappen en mogelijke bijwerkingen. In een tweede deel werden verschillende technieken van de neuromusculaire bewaking gedetailleerd beschreven. Het hoofdstuk biedt informatie over apparaten, stimulatie technieken, en de recente aanbevelingen over het gebruik van de neuromusculaire bewaking.

De incidentie van POM bij poliklinische patiënten in de instelling waar alle klinische studies in dit proefschrift hebben plaatsgevonden (Universitair Ziekenhuis Saarland, Homburg, Duitsland) werd bepaald door een studie die wordt gepresenteerd in hoofdstuk 3. 120 patiënten werden getest met drie verschillende regimes voor spierverslapping in een gerandomiseerde en gecontroleerde trial. De drie regimes van de neuromusculaire blokkade voor intubatie bevatte de niet-depolariserende agent rocuronium of de depolariserende agent succinylcholine. De derde groep patiënten kreeg succinycholine na een precurarisatie dosis rocuronium $(0,1 *$ ED95). Alle andere voorwaarden waren gestandaardiseerd. Myalgie werd onderzocht bij alle patiënten gedurende 24 uur. Er was geen significant verschil in de incidentie van spierpijn tussen de drie groepen. Bovendien leidde de precurarisatie regime tot een verhoogd incidentie van bijwerkingen zoals zware oogleden, diplopie, en moeite met slikken. Concluderend lijkt routine precurarisatie bij poliklinische patiënten twijfelachtig.

In hoofdstuk 4 werd de hypothese getest of een onderliggende ontsteking kan bijdragen tot succinylcholine-geassocieerde spierpijn. Daarom werden 64 elective KNO-patiënten opgenomen in een gerandomiseerde gecontroleerde trial. De patiënten werden gerandomiseerd in twee groepen. Een groep kreeg een preoperatief voorbehandeling met dexamethason $8 \mathrm{mg}$ en groep twee een voorbehandeling met zout (controle) op een dubbel blinde manier. De controle groep onderging een extra subgroep randomisatie. De pro-inflammatoire cytokine interleukine- 6 werd bepaald in de tien patiënten van deze subgroep op verschillende tijdstippen van de postoperative periode. Het anesthesie regime was gestandaardiseerd bij alle patiënten. De postoperatieve incidentie van de POM werd geëvalueerd voor 72 uur. Dexamethason-voorbehandeling had geen 
significante invloed op de incidentie van POM. In de subgroep werd er geen correlatie tussen POM en een toename van de plasma concentraties van interleukine- 6 gevonden. Dit leidde tot de conclusie dat er geen aanwijzingen voor een ontstekingsreactie als oorsprong van succinylcholine-geassocieerde spierpijn zijn.

Hoofdstuk 5 beschrijft een studie die een neveneffect van rocuronium onderzoekt. Zelfs in een klein dosis voor precurarisatie van 0,1 * ED95 kan rocuronium injectie pijn veroorzaken. De hypothese werd getest of het geslacht van invloed kunnen zijn op der pijn perceptie na een subparalyseerende dosis rocuronium. 120 patiënten (60 vrouwen en 60 mannen) werden opgenomen in de studie. Gerandomiseerd kregen 80 (40 vrouwen en 40 mannen) van hen een subparalyseerend dosis rocuronium. Als controle kregen de anderen een zoutoplossing. De voornaamste eindpunten waren pijn bij injectie, tromboflebitis, en andere tekenen van lokale irritatie. Vrouwen meldde significant meer pijn bij injectie zelfs van een subparalyseerend dosis rocuronium. Dit resultaat zou als aanvullend bewijs voor geslachtsgerelateerde verschil in pijn perceptie kunnen worden gezien.

Sinds de invoering van succinylcholine werd er een grote verscheidenheid van preventie strategieën getest op de werkzaamheid om succinylcholinegeassocieerde spierpijn te voorkomen. Hoofdstuk $\mathbf{6}$ bevat een meta-analyse die werd gedaan in overeenstemming met de huidige normen in de evidence based medicine (QUORUM verklaring). De werkzaamheid van de verschillende voorbehandelingen in de preventie van succinylcholine-geassocieerde spierpijn en fasciculaties werd berekend op basis van de resultaten van 52 gerandomiseerde gecontroleerde studies met in totaal 5318 patiënten. Niet-depolariserende neuromusculaire blokkers, lidocaïne, en magnesium zijn efficiënt in het voorkomen van fasciculaties met een berekende number-needed-to-treat van 1.22.5. Spierpijn na 24 uur postoperatief werd het beste voorkomen door nietsteroïdale anti-inflammatoire geneesmiddelen (NSAID), lidocaïne, en rocuronium met een number-needed-to-treat van 2.5-3. Er was een dosis-afhankelijke risico op bijwerkingen zoals wazig zien, diplopie, zware oogleden, en moeite met slikken als neuromusculair blokkerende stoffen werden gebruikt voor de voorbehandeling. Bovendien waren er aanwijzingen dat spierpijn minder was als een dosis van $1,5 \mathrm{mg} \mathrm{kg}^{-1}$ succinylcholine werd gebruikt (in plaats van $1 \mathrm{mg} \mathrm{kg}^{-1}$ ). Zo kan spierpijn met spierverslappers, lidocaïne, of niet-steroïde antiinflammatoire drugs best worden voorkomen. Het risico van potentieel ernstige ongewenste voorvallen met spierverslappers is niet te onderschatten. De gege- 
vens die het mogelijk maken om een risico-benefit analyse te maken ontbraken voor andere voorbehandelingen.

Vanwege het feit dat NSAID efficiënt werden gevonden in de vorige metaanalyse, werd een follow-up studie opgezet om het effect van een selectieve cyclooxygenase 2-remmer op POM te onderzoeken. De resultaten van deze gerandomiseerde gecontroleerde studie met 67 geanalyseerde patiënten worden beschreven in hoofdstuk 7. Niet-selectieve NSAID's kunnen het risico van bloedverlies verhogen tijdens de perioperative periode, een bijwerking die na toediening van een selectieve cyclooxygenase 2-remmer niet zou gebeuren. Voor dit onderzoek werd parecoxib gekozen. In tegenstelling tot de resultaten van de vorige meta-analyse was parecoxib klinisch niet efficiënt in de preventie van POM met een berekende number-needed-to-treat van 9. Verder werd geen significante afname van een activiteitsbeperking als gevolg van POM gevonden bij patiënten die een voorbehandeling met parecoxib ontvingen. Bovendien blijft het gebruik van cyclooxygenase-2-remmers in de preventie van een relatief klein probleem, zoals POM bedenkelijk in het licht van mogelijke cardiovasculaire bijwerkingen die werden geassocieerd met deze klasse van agenten.

In de afsluitend Hoofdstuk $\mathbf{8}$ worden de belangrijkste resultaten van dit proefschrift samengevat. De impact van de recente ontwikkelingen in de klinische anesthesie, zoals de invoering van nieuwe medicijnen en de relevantie daarvan voor het toekomstige gebruik van succinylcholine worden besproken. Er is echter nog geen opvolger van succinylcholine met een vergelijkbaar farmacologisch profiel gevonden. Bovendien blijft de exacte pathogenese nog niet volledig begrepen. Daarom is er geen optimale voorbehandeling of behandeling van succinylcholine-geassocieerde spierpijn beschikbaar. Dit benadrukt de noodzaak voor toekomstig onderzoek op succinylcholine-geassocieerde spierpijn. 


\section{Curriculum vitae}

Jan-Uwe Schreiber was born on December 30, 1969 in Gütersloh, Germany. In 1989 he graduated from secondary school and worked as an Emergency Medical Technician for three years. In 1993 he started his medical studies at the Albert-Ludwigs-Universität Freiburg, Germany where he also earned his medical degree in May 2000. In the same year his doctoral thesis (Dr. med.) on "Escape rhythms in patients following His-bundle ablation and third-degree AV nodal block" was finished at the University of Freiburg and rated "cum laude". He began his training in anaesthesiology in September 2000 at the Department of Anaesthesia and Critical Care Medicine at the University Hospital of the Saarland, Homburg, Germany (Prof. Dr. R. Larsen). After receiving board certification as an anaesthesiologist he became staff member of the department in 2005 and later Oberarzt. From 2007 to 2008 he completed his fellowship in intensive care medicine and got his board certification ("Zusatzbezeichnung Intensivmedizin"). In august 2008 he joined the staff of the Department of Anaesthesia and Pain Management at azM/Maastricht UMC.

His main scientific interests are the clinical pharmacology of neuromuscular blocking agents and evidence-based approaches in clinical anaesthesia. He is adhoc reviewer for several peer-reviewed journals such as Anesthesia \& Analgesia, Acta Anaesthesiologica Scandinavica, and Journal of Clinical Anesthesia and active member of several national and international anaesthesia societies. Clinically, his main interests are cardiovascular anaesthesia and intraoperative transesophageal echocardiography. 


\section{List of Publications}

\section{Original papers}

Schreiber JU, Mencke T, Pradarutti S, Jeblick S, Fuchs-Buder T. Does preoperatively administered parecoxib prevent succinylcholine-associated myalgia? A randomized, placebo-controlled trial. European Journal of Anaesthesiology 23 (2006): 332-7.

Knoll H, Ziegeler S, Schreiber JU, Buchinger H, Bialas P, Semyonov K, Graeter $\mathrm{T}$, Mencke T. Airway injuries after one-lung ventilation: a comparison between double-lumen tube and endobronchial blocker: a randomized, prospective, controlled trial. Anesthesiology 105 (2006), 471-7.

Mencke T, Knoll H, Schreiber JU, Echternach M, Klein S, NoeldgeSchomburg G, Silomon M. Rocuronium is not associated with more vocal cord injuries than succinylcholine after Rapid-Sequence Induction: A randomized, prospective, controlled trial. Anesthesia \& Analgesia 102 (2006), 943-9.

Mencke T, Schreiber JU, Knoll H, Werth M, Grundmann U, Rensing H. Einfluss des Geschlechts auf die Intubationsbedingungen nach Rocuronium. Anaesthesist 54 (2005), 884-8. 
Kreuer S, Schreiber JU, Bruhn J, Wilhelm W. Impact of patient age on propofol consumption during propofol-remifentanil anaesthesia. European Journal of Anaesthesiology 22 (2005), 123-8.

Schreiber JU, Lysakowski C, Fuchs-Buder T, Tramèr MR. Prevention of Succinylcholine-induced Fasciculation and Myalgia : A meta-analysis of randomized trials. Anesthesiology 103 (2005), 877-84

Fuchs-Buder T, Strowitzki M, Rentsch K, Schreiber JU, Philipp-Ostermann S, Kleinschmidt $S$. Concentration of rocuronium in cerebrospinal fluid of patients undergoing cerebral aneurysm clipping - In: British Journal of Anaesthesia, 92 (2004), 419-21.

Mencke T, Schreiber JU, Knoll H, Stracke C, Kleinschmidt S, Rensing H, Silomon M.Women report more pain on injection of a precurarization dose of rocuronium. Acta Anaesthesiologica Scandinavica, 28 (2004), 1245-8.

Schreiber JU, Mencke T, Biedler A, Fürst O, Kleinschmidt S, Buchinger S, Fuchs-Buder T. Post-operative myalgia after succinylcholine: No evidence for an inflammatory origin. Anesthesia \& Analgesia 96 (2003), 1640-4.

Mencke T, Becker C, Schreiber J, Bolte M, Fuchs-Buder T. Präkurarisierung von Succinylcholin mit Cisatracurium: Der Einfluß des Präkurarisierungsintervalls. Anästhesist 51 (2002), 721-5.

Mencke T, Schreiber JU, Becker C, Bolte M, Fuchs-Buder T. Pretreatment before succinylcholine for outpatient anesthesia? Anesthesia \& Analgesia 94 (2002), 573-6.

\section{Reviews (peer-reviewed)}

Fuchs-Buder T, Schreiber JU, Meistelman C. Monitoring neuromuscular block: an update. Anaesthesia 64 (2009) Suppl.1, 82-9.

Schreiber JU, Fuchs-Buder T. Neuromuskuläre Blockade: Substanzen, Überwachung, Antagonisierung. Anaesthesist 55 (2006), 1225-36. 
Grundmann U, Schreiber JU. Selektive Zyklooxygenase-2-Inhibitoren zur postoperativen Schmerztherapie - Wirksamkeit und Nebenwirkungsprofil. Anaesthesist 53 (2004), 1211-18.

Jung J, Schreiber JU. Aktuelle Therapie der Herzinsuffizienz. Anaesthesist 52 (2003), 612-18.

\section{Letters}

Schreiber JU, Fuchs-Buder T. Succinylcholine: the dilemma with the evidence. Obesity Surgery 20 (2010), 134.

Mencke T, Becker C, Schreiber JU, Fuchs-Buder T. A longer pre-treatment interval does not improve cisatracurium as a precurarizing agent. Canadian Journal of Anaesthesia 49 (2002), 640-1.

\section{Abstracts}

Euroanaesthesia 2008, Copenhagen, Denmark

Knoll H, Oehrlein R, Pradarutti S, Morinello E, Schreiber J. The postoperative effect of local applicated $S(+)$-ketamine after inguinal hernia surgery: a doubleblinded, randomized, controlled trial. European Journal of Anaesthesiology 25 (2008) Supp. 44, 14AP3-1.

\section{Euroanaesthesia 2006, Madrid, Spain}

Schreiber JU, Mucha E, Fuchs-Buder T. Calibrated vs. uncalibrated acceleromyography to assess neuromuscular recovery: a Bland-Altman-Analysis. European Journal of Anaesthesiology 23 (2006) Supp. 37, A-163.

Schreiber JU, Mucha E, Fuchs-Buder T. Assessment of incidence of residual paralysis after a single intubating dose of atracurium using a calibrated acceleromyograph. European Journal of Anaesthesiology 23 (2006) Suppl. 37, A532. 
Knoll H, Schreiber JU, Ziegeler S, Buchinger H, Semyonov K, Bialas P, Larsen $\mathrm{R}$, Mencke T. Laryngeal morbidity after single lung ventilation: a comparison of two different techniques. European Journal of Anaesthesiology 23 (2006), Suppl. 37, A-1015.

\section{Euroanaesthesia 2005, Vienna, Austria}

Mencke T, Schreiber JU, Knoll H, Noeldge-Schomburg G. Gender differences in the intubating conditions of rocuronium. European Journal of Anaesthesiology 22 (2005) Suppl. 34, A-451.

Schreiber JU, Lysakowski C, Fuchs-Buder T, Tramér, MR. Prevention of succinylcholine-related fasciculations and myalgia: a systematic review of randomized trials. European of Journal Anaesthesiology 22 (2005) , Suppl. 34, A-23.

\section{Euroanaesthesia 2004, Lisbon, Portugal}

Mencke T, Knoll H, Johann U, Schreiber JU, Echternach M, Afan N, Rensing $\mathrm{H}$, Plinkert PK, Larsen R. Does the best timing of tracheal intubation based on neuromuscular monitoring decrease laryngeal injury? European Journal of Anaesthesiology 21 (2004) Suppl. 32, A-100.

Mencke T, Schreiber JU, Stracke C, Kleinschmidt S, Rensing H, Knoll H, Larsen R. Gender differences in the pharmacodynamics of rocuronium: a randomized, prospective, placebo-controlled trial. European Journal of Anaesthesiology 21 (2004) Suppl. 32, A-570.

Mencke T, Werth M, Knoll H, Schreiber JU, Stracke C, Echternach M, Klein S, Silomon M, Plinkert PK, Larsen R. Larnygeal morbidity and quality of tracheal intubation following rapid sequence induction: comparison of succinylcholine and rocuronium. European Journal of Anaesthesiology 21 (2004) Suppl. 32, A-574. 
Euroanaesthesia 2003 Glasgow, UK

Schreiber JU, Mencke T, Biedler A, Fuerst O, Kleinschmidt S, Buchinger H, Fuchs-Buder T. No evidence for an inflammatory origin of postoperative myalgia after use of succinylcholine. European Journal of Anaesthesiology 20 (2003), Suppl. 30, A-489.

7th International Neuromuscular Meeting 2001, Belfast, UK

Mencke T, Becker C, Schreiber JU, Bolte M, Fuchs-Buder T. Succinylcholine with or without rocuronium pretreatment for ambulatory anaesthesia - a randomized, prospective, controlled trial. European Journal of Anaesthesiology 18 (2001), Suppl. 23, 107.

\section{Other publications}

Schreiber JU. Postoperative laryngeale und bronchiale Morbidität nach EinLungen-Ventilation. Anaesthesist 56 (2007), 92-4.

Schreiber JU. Neuromuskuläre Restblockaden im Aufwachraum nach Gabe einer einmaligen Intubationsdosis eines mittellang wirksamen Muskelrelaxans. Anaesthesist 53 (2004), 1006-8. 


\section{Acknowledgments}

As I started my research efforts in clinical anaesthesia, I had no idea about the "how-to-do-it", the problems that may occur, or the patience you will need sometimes. But I also did not have any idea about the pleasure it will give you. Working in teams with other people who have the same interests, learning from these guys, and finding new insights can be a great experience. I would like to thank all the people, who have supported me on my way in completing this $\mathrm{PhD}$ thesis. Unfortunately, it is not possible, to mention everybody by name individually. However, I want to highlight some persons for their extraordinary role in this project.

First of all I would like to thank Thomas Fuchs-Buder, a friend and mentor. He was the one who has awaked my interest in the field of neuromuscular pharmacology. He gave ideas and input for projects and always supported my efforts during the last years. He is also one of the promotors of this thesis. Thank you!

I want to thank Thomas Mencke, friend and co-author of many of the publications in this thesis. Due to one of his clinical trials I came in touch with research in anaesthesia. Furthermore, Thomas was the one who has helped me during my first steps in writing scientific articles.

My promotors Maarten van Kleef and Marco Marcus at azM were the ones who supported the "final episode“ of this thesis with their knowledge and experience. I gratefully appreciate that. I also want to thank Hermina Gielen from the departmental office for her logistical support. 
I am also very grateful to the members of the assessment committee, namely Professor Dr. B. Kremer, Professor Dr. M. De Baets, Dr. C. Faber (all MUMC), and Professor Dr. G. Scheffer (UMC St. Radboud) for their work. I was very happy that Professor Dr. R. Larsen, my former chair at Saarland University Hospital also accepted the invitation to the assessment committee. Via this way I want to thank him for his trust in me.

Many thanks to Martin Tramér and Chris Lysakowski from the Division of Anaesthesia at Geneva University Hospitals. Especially Martin was the one who has introduced me into the field of evidence based approaches in clinical anaesthesia. I have learned a lot and it is due to him that I got a different view on many scientific publications.

Oliver Fürst was involved in the first study as a research student but supported some of the other studies with his enthusiasm and excellent knowledge about Personal Computers and computer networks. Thanks, Oli!

Many thanks to some former and current members of the Department of Anaesthesia and Critical Care at Saarland University Hospital. Natascha Schlaich, Stefan Kleinschmidt, Sascha Pradarutti, Heiko Buchinger, and Andreas Biedler supported the practical part in some of the clinical trials of this thesis. Further, I would like to mention Heike Knoll, Ulrich Grundmann, Sascha Kreuer, and Wolfram Wilhelm for their co-operation in projects not directly related to this thesis.

Finally, I want to express my respect and gratitude to all the patients who participated in one of the clinical trials of this thesis.

This chapter has been closed now. Thank you, Eva that you always have believed in me. 